US Army Corps

of Engineers .

Prepared for the U.S. Army Corps of Engineers, Portland District,

under a Government Order with the U.S. Department of Energy

Contract DE-AC05-76RL01830

\title{
Compliance Monitoring of Yearling Chinook Salmon and Juvenile Steelhead Survival and Passage at Bonneville Dam, Spring 2011
}

COMPLIANCE REPORT
JR Skalski
GR Ploskey
RL Townsend
TJ Carlson
AG Seaburg

June 2012

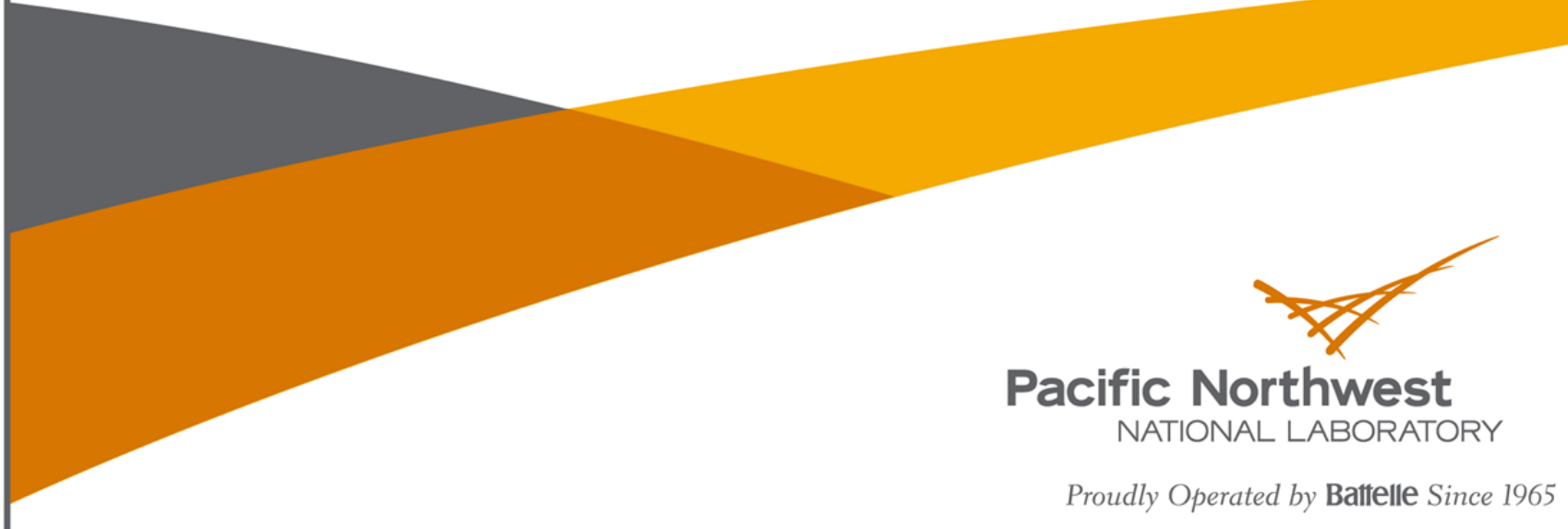




\title{
DISCLAIMER
}

This repor1 was prepared as an account of work sponsored by an agency of the United States Government. Neither the United States Government nor any agency thereof, nor Battelle Memorial Institute, nor any of their employees, makes any warranty, express or implied, or assumes any legal liability or responsibility for the accuracy, completeness, or usefulness of any information, apparatus, product, or process disclosed, or represents that its use would not infringe privately owned rights. Reference herein to any specific commercial product, process, or service by trade name, trademark, manufacturer, or otherwise does not necessarily constitute or imply its endorsement, recommendation, or favoring by the United States (iovernment or any agency thereof, or Battelle Memorial Institute. The views and opinions of authors expressed herein do not necessarily state or rellect those of the United States (jovernment or any agency thereor.

\author{
PACIFIC NORTIIWEST NATIONAL LABORATORY \\ operated by \\ BAltillat: \\ for the \\ UNITED STATES DEP $\Lambda$ RTMENT OF ENERGY \\ under Contract DE:-ACO5-76RI.01830
}

Printed in the Inited States of America

Available to DOE and DOE contractors from the

Office of Scientific and Technical Information,

P.O. Box 62, Oak Ridge. TN 37831-0062;

ph: $(865) 576-8401$

fax: $(865)$ 576-5728

email: reports $(\hat{a})$ adonis.osti.gov

\author{
Available to the public from the National Technical Information Service. \\ U.S. Department of Commerce, 5285 Port Royal Rd., Springfielı, VA 22161 \\ ph: $(800) 553-6847$ \\ fax: (703) 605-6900 \\ enail: orders@intis.fedworld.gov \\ online ordering: http://www.ntis.gov/ordering.htm
}




\section{Compliance Monitoring of Yearling Chinook Salmon and Juvenile Steelhead Survival and Passage at Bonneville Dam, Spring 2011}

\section{COMPLIANCE REPORT}

JR Skalski ${ }^{1}$

RL Townsend ${ }^{1}$

AG Seaburg ${ }^{1}$
GR Ploskey

TJ Carlson

June 2012

Prepared for

U.S. Army Corps of Engineers, Portland District

under a Government Order with the U.S. Department of Energy

Contract DE-AC05-76RL01830

Pacific Northwest National Laboratory

Richland, Washington 99352

\footnotetext{
${ }^{1}$ University of Washington, Seattle, Washington.
} 


\section{Preface}

This study was conducted by the Pacific Northwest National Laboratory (PNNL) and the University of Washington (UW) for the U.S. Army Corps of Engineers, Portland District (USACE). The PNNL and UW project managers are Drs. Thomas J. Carlson and John R. Skalski, respectively. The USACE technical lead is Mr. Brad Eppard. The study was designed to estimate dam passage survival at Bonneville Dam as stipulated by the 2008 Federal Columbia River Power System Biological Opinion, and provide additional performance measures at that site as stipulated in the Columbia Basin Fish Accords.

This summary report focuses on the spring run stocks, yearling Chinook salmon, and steelhead. A comprehensive technical report of the 2011 tagging studies at Bonneville Dam will be delivered in 2012.

This report was originally submitted in February 2012. It was revised in May 2012 based on review comments from the Studies Review Work Group of the USCAE's Anadromous Fish Evaluation Program.

Suggested citation for this report:

Skalski JR, RL Townsend, A Seaburg, GR Ploskey, and TJ Carlson. 2012. Compliance Monitoring of Yearling Chinook Salmon and Juvenile Steelhead Survival and Passage at Bonneville Dam, Spring 2011. PNNL-21175, Final Report, Pacific Northwest National Laboratory, Richland, Washington. 


\section{Executive Summary}

The purpose of this compliance study was to estimate dam passage survival of yearling Chinook salmon and steelhead smolts at Bonneville Dam during spring 2011. Under the 2008 Federal Columbia River Power System Biological Opinion (BiOp), dam passage survival should be greater than or equal to 0.96 and estimated with a standard error (SE) less than or equal to 0.015 . The study also estimated smolt passage survival from the forebay $2 \mathrm{~km}$ upstream of the dam to the tailrace $1 \mathrm{~km}$ below the dam, as well as the forebay residence time, tailrace egress, and spill passage efficiency, as required in the Columbia Basin Fish Accords.

A virtual/paired-release design was used to estimate dam passage survival at Bonneville Dam. The approach included releases of acoustic-tagged smolts above Bonneville Dam that contributed to the formation of a virtual release at the face of the dam. A survival estimate from this release was adjusted by a paired release below Bonneville Dam. A total of 7692 yearling Chinook salmon and 7766 steelhead smolts were tagged and released during the study. The Juvenile Salmon Acoustic Telemetry System (JSATS) tag model number ATS-156dB, weighing $0.438 \mathrm{~g}$ in air, was used in this investigation.

The high flows during spring 2011 disrupted planned $100 \mathrm{kcfs}$ spill operations at Bonneville Dam. Therefore, dam passage survival was estimated for the early part of the study (i.e., 30 April-13 May) when spill was about $100 \mathrm{kcfs}$ and for the entire season, which included much higher spill levels from 18-31 May 2011. The study results are summarized in the following tables.

Table ES.1. Estimates of dam passage survival ${ }^{(a)}$ at Bonneville Dam in 2011.

\begin{tabular}{lcc}
\hline \multicolumn{1}{c}{ Period of Performance } & Yearling Chinook Salmon & Steelhead \\
\hline Early season (30 April-13 May) & $0.9569(0.0042)^{(\mathrm{b})}$ & $0.9755(0.0180)$ \\
Season-wide (30 April-31 May) & $0.9597(0.0176)$ & $0.9647(0.0212)$ \\
\hline (a) Dam passage survival is defined as survival from the upstream face of the dam to a standardized reference point \\
in the tailrace.
\end{tabular}

Table ES.2. Fish Accords performance measures at Bonneville Dam in 2011.

\begin{tabular}{|c|c|c|}
\hline Performance Measures & Yearling Chinook Salmon & Steelhead \\
\hline \multicolumn{3}{|l|}{ Forebay-to-tailrace survival ${ }^{(\mathrm{a})}$} \\
\hline Early season (30 April-13 May) & $0.9579(0.0042)$ & $0.9752(0.0180)$ \\
\hline Season-wide (30 April-31 May) & $0.9528(0.0175)$ & $0.9589(0.0211)$ \\
\hline Forebay residence time (mean) & $5.34 \mathrm{~h}(0.46)$ & $7.00 \mathrm{~h}(0.43)$ \\
\hline Tailrace egress rate (mean) & $1.89 \mathrm{~h}(0.19)$ & $3.77 \mathrm{~h}(0.32)$ \\
\hline Spill passage efficiency ${ }^{(b)}$ & $0.5660(0.0067)$ & $0.5443(0.0066)$ \\
\hline Fish passage efficiency & $0.7070(0.0061)$ & $0.7401(0.0058)$ \\
\hline
\end{tabular}

(a) The forebay-to-tailrace survival estimate satisfies the "BRZ-to-BRZ" survival estimate called for in the Fish Accords.

(b) Spill passage efficiency presented here is the proportion of fish passing the dam at the spillway out of total project passage. However, by definition in the Fish Accords, spill passage efficiency includes passage through the spillway and the ice and trash sluiceway at Bonneville Dam, so this combined metric also is presented. 
Table ES.3. Survival study summary.

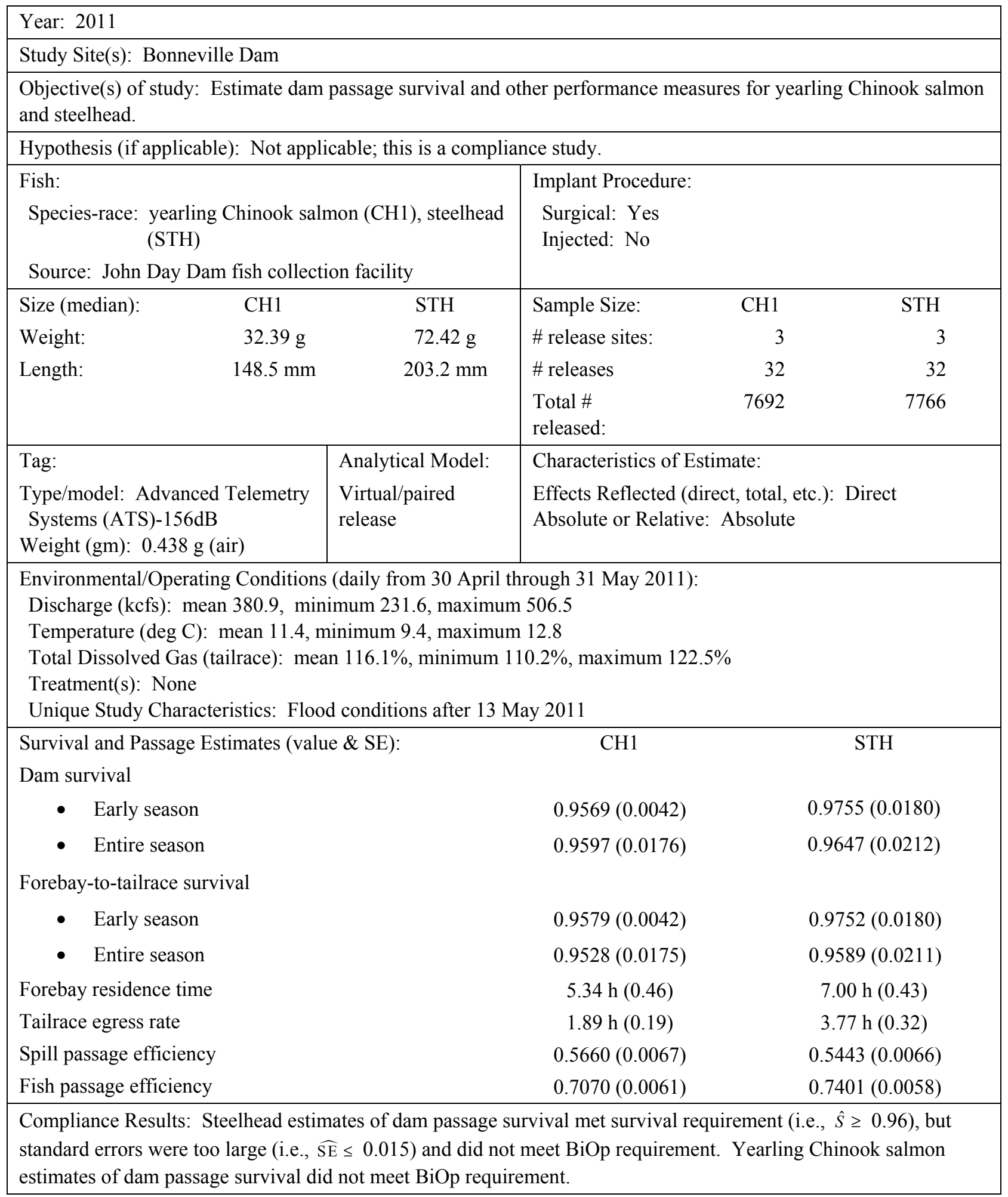




\section{Acknowledgments}

This study was the result of hard work by dedicated scientists from the Pacific Northwest National Laboratory (PNNL), Pacific States Marine Fisheries Commission (PSMFC), the U.S. Army Corps of Engineers, Portland District (USACE), and the University of Washington (UW). Their teamwork and attention to detail, schedule, and budget were essential for the study to succeed in providing high-quality, timely results to decision-makers.

- PNNL: C Arimescu, T Able, G Batten, C Brandt, A Bryson, K Carter, E Choi, D Deng, K Deters, G Dirkes, J Duncan, D Faber, E Fischer, A Flory, T Fu, D Geist, B Goodman, K Hall, M Halvorsen, K Ham, K Hand, M Hennen, JL Hughes, JS Hughes, G Johnson, F Kahn, R Karls, J Kim, B LaMarche, K Larson, K Lavender, J Martinez, B Miller, A Miracle, A Phillips, G Ploskey, G Roesijadi, I Royer, D Saunders, J Smith, G Squeochs, S Southard, N Tavin, A Thronas, S Titzler, N Trimble, D Trott, K Wagner, M Weiland, C Woodley, J Varvinec, and S Zimmerman.

- PSMFC: G Kolvachuk and D Ballenger along with the helpful staff at John Day and Bonneville Dam Juvenile Smolt Facilities. In addition, B Babcock, R Blanchard, S Carpenter, A Collins, L Cox, A Cushing, T Elder, D Etherington, M Gay, G George, A Halston, C Holzer, M Jenkins, K Knox, D Lock, R Martinson, D Marvin, T Monter, T Mitchell, M Neumann, L Oa's, T Royal, K Schaedel, $\mathrm{N}$ Tancreto, and R Wall.

- USACE: B Eppard, M Langeslay, and electricians, mechanics, riggers, operators, and biologists at John Day (M Zyndol and T Hurd), The Dalles (B Cordie), and Bonneville dams (J Rerecich, B Hausmann, and A Traylor).

- UW: J Skalski, R Townsend, A Seaburg, J Lady, and P Westhagen. 


\section{Acronyms and Abbreviations}

\begin{tabular}{|c|c|}
\hline${ }^{\circ} \mathrm{C}$ & degree(s) Celsius \\
\hline $3 \mathrm{D}$ & three-dimensional \\
\hline ATS & Advanced Telemetry Systems \\
\hline B1 & Bonneville Powerhouse 1 \\
\hline B2 & Bonneville Powerhouse 2 \\
\hline $\mathrm{B} 2 \mathrm{CC}$ & Bonneville Powerhouse 2 Corner Collector \\
\hline $\mathrm{BiOp}$ & Biological Opinion \\
\hline BRZ & boat-restricted zone \\
\hline FCRPS & Federal Columbia River Power System \\
\hline FPE & fish passage efficiency \\
\hline $\mathrm{g}$ & $\operatorname{gram}(\mathrm{s})$ \\
\hline h & hour(s) \\
\hline JSATS & Juvenile Salmon Acoustic Telemetry System \\
\hline kcfs & thousand cubic feet per second \\
\hline $\mathrm{km}$ & kilometer(s) \\
\hline $\mathrm{L}$ & liter(s) \\
\hline $\mathrm{m}$ & $\operatorname{meter}(\mathrm{s})$ \\
\hline $\mathrm{mg}$ & milligram(s) \\
\hline $\mathrm{mm}$ & millimeter(s) \\
\hline MOA & Memorandum of Agreement \\
\hline PIT & passive integrated transponder \\
\hline PNNL & Pacific Northwest National Laboratory \\
\hline PRI & pulse repetition interval \\
\hline rkm & river kilometer(s) \\
\hline RME & research, monitoring, and evaluation \\
\hline ROR & run-of-river \\
\hline RPA & Reasonable and Prudent Alternative \\
\hline $\mathrm{s}$ & second(s) \\
\hline SE & standard error \\
\hline SPE & spill passage efficiency \\
\hline USACE & U.S. Army Corps of Engineers \\
\hline UW & University of Washington \\
\hline
\end{tabular}




\section{Contents}

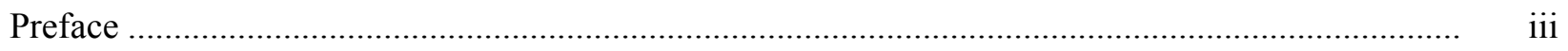

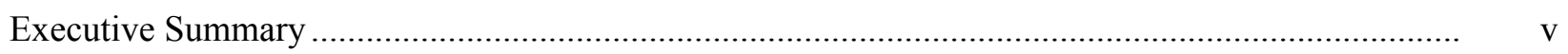

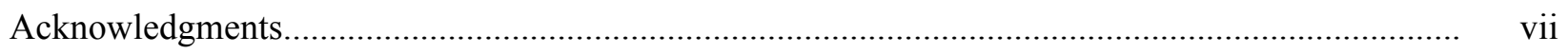

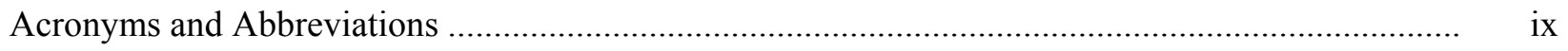

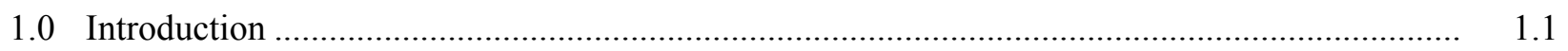

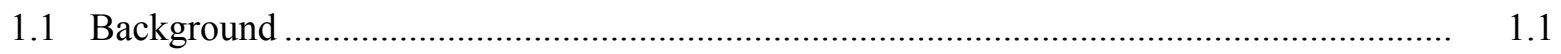

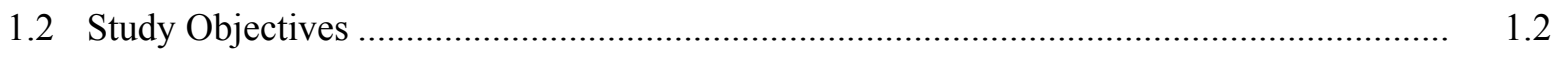

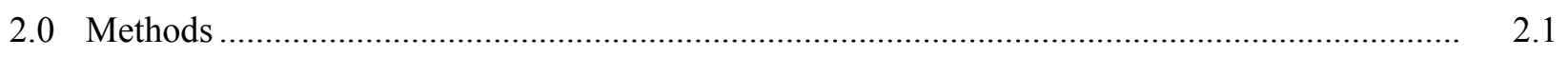

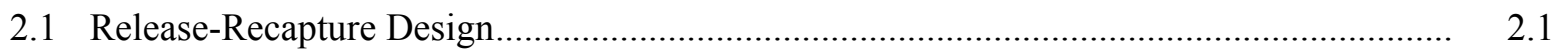

2.2 Handling, Tagging, and Release Procedures ................................................................. 2.3

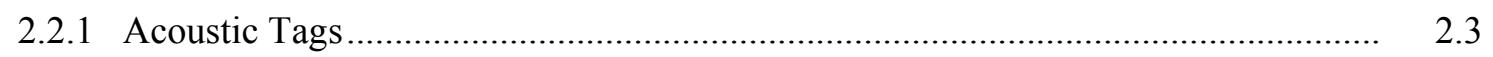

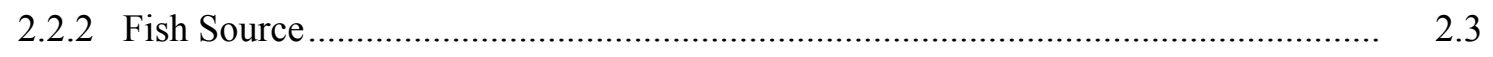

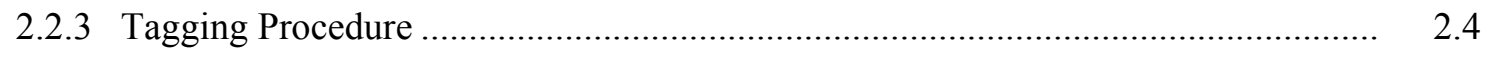

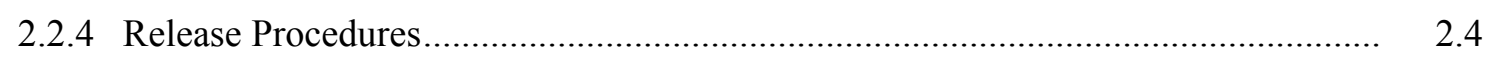

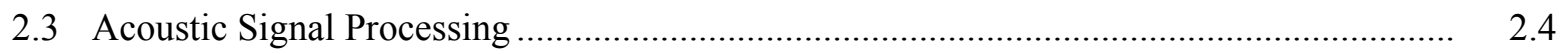

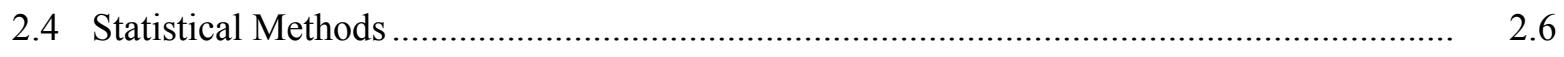

2.4.1 Estimation of Passage Survival ................................................................. 2.6

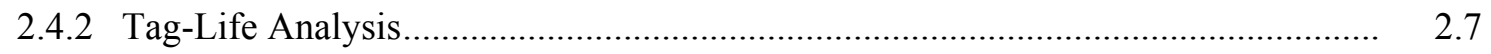

2.4.3 Tests of Assumptions .................................................................................... 2.7

2.4.4 Estimation of Forebay-to-Tailrace Survival ..................................................... 2.8

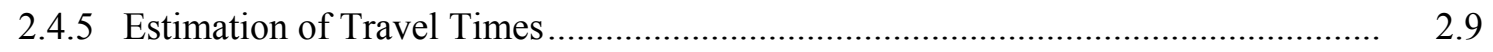

2.4.6 Estimation of Spill Passage Efficiency ............................................................... 2.9

2.4.7 Estimation of Spill + B2CC Passage Efficiency .................................................. 2.10

2.4.8 Estimation of Fish Passage Efficiency …......................................................... 2.10

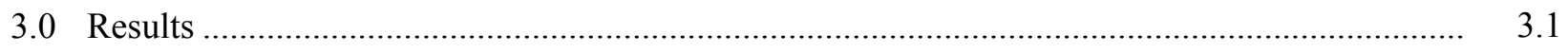

3.1 Fish Collection, Rejection, and Tagging ................................................................ 3.1

3.2 Discharge and Spill Conditions ............................................................................... 3.2

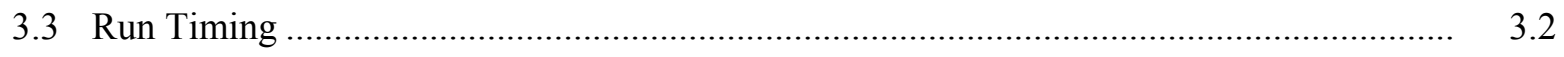

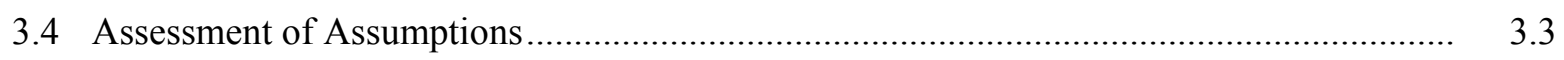

3.4.1 Examination of Tagger Effects...................................................................... 3.3

3.4.2 Examination of Tag-Lot Effects...................................................................... 3.3

3.4.3 Handling Mortality and Tag Shedding .............................................................. 3.3

3.4.4 Examination of Tailrace Release Location Effects on Survival............................. 3.3

3.4.5 Examination of Time In-River on Survivals of Different Release Groups .............. 3.4

3.4.6 Fish Size Distribution....................................................................................... 3.4

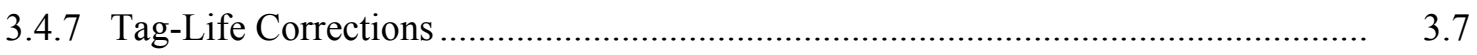




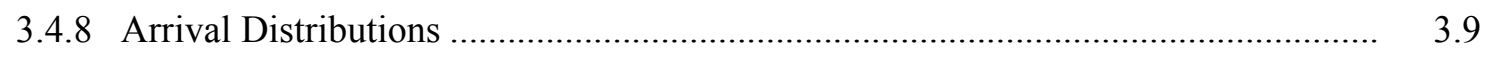

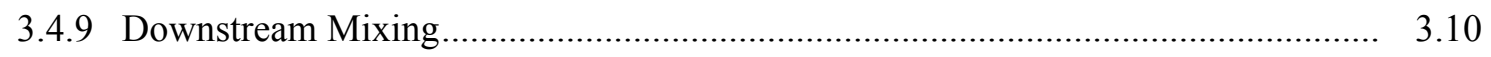

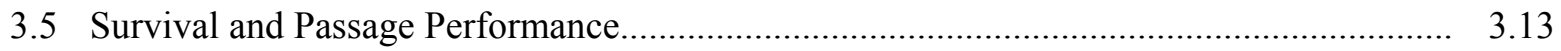

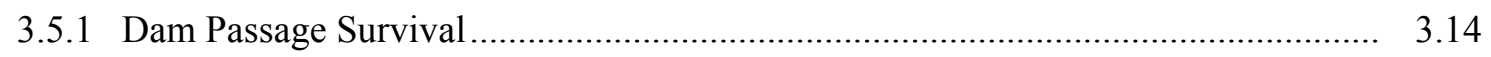

3.5.2 Forebay-to-Tailrace Passage Survival............................................................ 3.17

3.5.3 Forebay Residence Time .............................................................................. 3.17

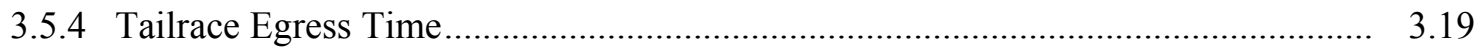

3.5.5 Spill Passage Efficiency ............................................................................. 3.20

3.5.6 Spill + B2CC Passage Efficiency .................................................................... 3.20

3.5.7 Fish Passage Efficiency......................................................................... 3.20

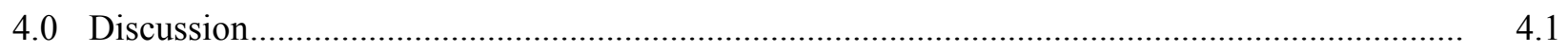

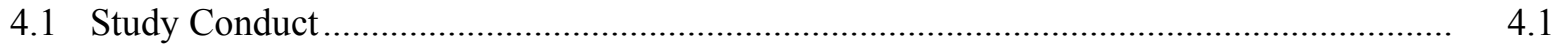

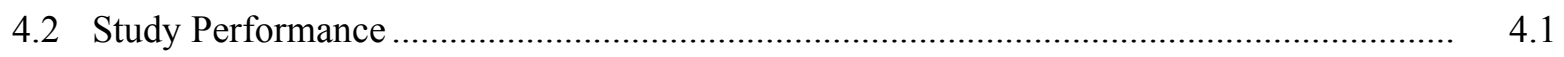

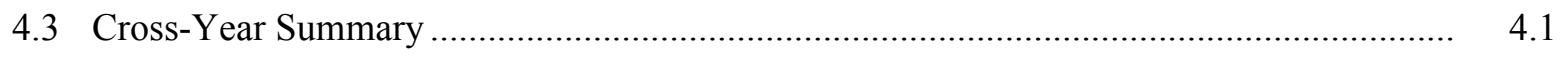

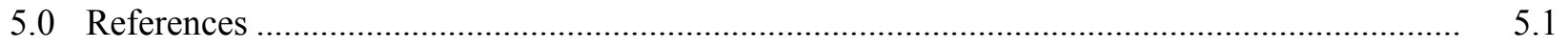

Appendix A - Tests of Assumptions .................................................................................. A.1

Appendix B - Capture Histories Used in Estimating Dam Passage Survival................................... B. B 


\section{Figures}

2.1 Schematic of the virtual/paired-release design used to estimate dam passage survival at Bonneville Dam .....

2.2 Front view schematic of hydrophone deployments at three turbines showing doubledetection arrays

3.1 Daily average total discharge and percent spill at Bonneville Dam during the 2011 JSATS study for yearling Chinook salmon and steelhead from 30 April to 31 May 2011

3.2 Plots of the cumulative percent of juvenile steelhead and yearling Chinook salmon that had passed Bonneville Dam in 2011

3.3 Distributions of tailrace detections of $V_{1}$ fish on autonomous nodes, numbers of fish released in the tailrace at five locations, and survival rates by tailrace release location

3.4 Relative frequency distributions for fish lengths of yearling Chinook salmon smolts used in Release $V_{1}$, Release $R_{2}$, Release $R_{3}$, and ROR fish sampled at John Day Dam by the Fish Passage Center.

3.5 Relative frequency distributions for fish lengths of steelhead smolts used in Release $V_{1}$, Release $R_{2}$, Release $R_{3}$, and ROR fish sampled at John Day Dam by the Fish Passage Center.

3.6 Range and median lengths of acoustic-tagged yearling Chinook salmon and steelhead used in the 2011 survival studies

3.7 Observed time of tag failure and fitted survivorship curves using the vitality model of $\mathrm{Li}$ and Anderson (2009) for tag lot 1, tag lot 2, and tag lots 3-5.

3.8 Comparison of fitted survivorship curves using the Vitality Model of Li and Anderson (2009) for JSATS tag lots 1, 2, and 3-5 used in the 2011 compliance studies

3.9 Plots of the fitted tag-life survivorship curves for tag lots 1,2,3-5 and the arrival-time distributions of yearling Chinook salmon smolts from CR390, CR346, CR325, CR307, CR275, CR233, and CR161 at the acoustic-detection array located at rkm 86

3.10 Plots of the fitted tag-life survivorship curves for tag lots $1,2,3-5$ and the arrival-time distributions of steelhead smolts for releases from CR390, CR346, CR325, CR307, CR275, CR233, and CR161 at the acoustic-detection array located at rkm 86

3.11 Frequency distribution plots of downstream arrival timing for yearling Chinook salmon releases $R_{2}$ and $R_{3}$ at detection arrays located at rkm 113 and rkm 86 ...

3.12 Frequency distribution plots of downstream arrival timing for steelhead releases $R_{2}$ and $R_{3}$ at detection arrays located at rkm 113 and rkm 86

3.13 Distribution of forebay residence times for yearling Chinook salmon and steelhead smolts at Bonneville Dam, 2011

3.14 Distribution of tailrace egress times for yearling Chinook salmon and steelhead smolts at Bonneville Dam, 2011 


\section{Tables}

ES.1 Estimates of dam passage survival at Bonneville Dam in 2011 .......................................... v

ES.2 Fish Accords performance measures at Bonneville Dam in 2011 ........................................ v

ES.3 Survival study summary................................................................................................ vi

2.1 Sample sizes of acoustic-tag releases used in the yearling Chinook salmon and steelhead

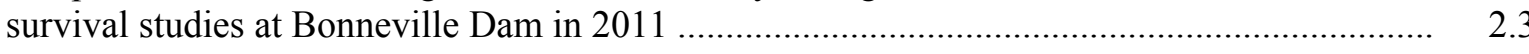

2.2 Relative release times for the acoustic-tagged fish to accommodate downstream mixing ......... 2.4

3.1 Total number of fish handled by PNNL during the spring of 2011 and counts of fish in several handling categories .....

3.2 Total number of fish handled by PNNL during the spring of 2011 and counts of fish with common maladies

3.3 Estimated probabilities of an acoustic tag being active at a downstream detection site for yearling Chinook salmon smolts and steelhead smolts by tag lot and release group.....

3.4 Survival, detection, and $\lambda$ parameters for final model used to estimate dam passage survival for yearling Chinook salmon smolts during the early part of spring...

3.5 Survival, detection, and $\lambda$ parameters for final model used to estimate dam passage survival for yearling Chinook salmon smolts for the entire study period.....

3.6 Survival, detection, and $\lambda$ parameters for final model used to estimate dam passage survival for steelhead smolts during the early part of spring

3.7 Survival, detection, and $\lambda$ parameters for final model used to estimate dam passage survival for steelhead smolts for the entire study period

3.8 Summary of the estimates of forebay-to-tailrace survival at Bonneville Dam in 2011 for yearling Chinook salmon and steelhead smolts for early season and the entire study

3.9 Estimated mean and median forebay residence times and mean and median tailrace egress times for yearling Chinook salmon and steelhead smolts at Bonneville Dam in 2011.

4.1 Summary of 2010 and 2011 estimates of dam passage survival using best available information from either a conservative single-release model or the virtual/pairedrelease model by fish stock 


\subsection{Introduction}

The compliance monitoring study reported here was conducted by researchers at Pacific Northwest National Laboratory (PNNL) and the University of Washington (UW) for the U.S. Army Corps of Engineers, Portland District (USACE) in spring 2011. The purpose of the study was to estimate dam passage survival at Bonneville Dam as stipulated by the 2008 Federal Columbia River Power System (FCRPS) Biological Opinion (BiOp), and provide additional performance measures at the dam as stipulated in the Columbia Basin Fish Accords for yearling Chinook salmon and steelhead (3 Treaty Tribes-Action Agencies 2008).

\subsection{Background}

The 2008 BiOp on operation of the FCRPS contains a Reasonable and Prudent Alternative (RPA) that includes actions calling for measurements of juvenile salmonid survival (RPAs 52.1 and 58.1). These RPAs are being addressed as part of the federal research, monitoring, and evaluation (RME) effort for the FCRPS BiOp. Most importantly, the FCRPS BiOp includes performance standards for juvenile salmonid survival in the FCRPS against which the Action Agencies (Bonneville Power Administration, Bureau of Reclamation, and USACE) must compare their performance estimates, as follows (after the RME Strategy 2 of the RPA):

Juvenile Dam Passage Performance Standards - The Action Agencies juvenile performance standards are an average across Snake River and lower Columbia River dams of $96 \%$ average dam passage survival for spring Chinook salmon and steelhead and 93\% average across all dams for Snake River subyearling Chinook. Dam passage survival is defined as survival from the upstream face of the dam to a standardized reference point in the tailrace.

The 2008 Columbia Basin Fish Accords Memorandum of Agreement [MOA] between the Three Treaty Tribes and FCRPS Action Agencies (3 Treaty Tribes-Action Agencies 2008), known informally as the Fish Accords, ${ }^{1}$ contains three additional requirements relevant to the 2010 survival studies (after the MOA Attachment A):

Dam Survival Performance Standard - Meet the 96\% dam passage survival standard for yearling Chinook salmon and steelhead and the 93\% standard for subyearling Chinook. Achievement of the standard is based on 2 years of empirical survival data....

Spill Passage Efficiency and Delay Metrics - Spill passage efficiency (SPE) and delay metrics under current spill conditions... are not expected to be degraded ("no backsliding") with installation of new fish passage facilities at the dams....

Future Research, Monitoring and Evaluation - The Action Agencies' dam survival studies for purposes of determining juvenile dam passage performance will also collect information about SPE, survival and delay between boat-restricted zones (BRZs), and other distribution and survival information. SPE and delay metrics will be considered in the performance check-ins or with Configuration and Operations Plan updates, but not as principal or priority metrics over dam

\footnotetext{
${ }^{1}$ Available at http://www.salmonrecovery.gov/Files/BiologicalOpinions/MOA_ROD.pdf.
} 
survival performance standards. Once a dam meets the survival performance standard, SPE and delay metrics may be monitored coincidentally with dam survival testing.

This report summarizes the results of the 2011 spring acoustic-telemetry study of yearling Chinook salmon and steelhead at Bonneville Dam to assess the Action Agencies' compliance with the performance criteria of the BiOp and Fish Accords.

\subsection{Study Objectives}

The purpose of spring 2011 compliance monitoring at Bonneville Dam was to estimate performance measures for yearling Chinook salmon and steelhead smolts as outlined in the FCRPS BiOp and Fish Accords. For each fish stock, the following metrics were estimated using the Juvenile Salmon Acoustic Telemetry System (JSATS) technology:

- Dam passage survival, defined as survival from the upstream face of the dam to a standardized reference point in the tailrace. Performance ${ }^{1}$ should be $\geq 96 \%$ survival for spring stocks (i.e., yearling Chinook salmon and steelhead). Survival should be estimated with a standard error (SE) $\leq 1.5 \%$.

- Forebay-to-tailrace survival, defined as survival from a forebay array $2 \mathrm{~km}$ upstream of the dam to a tailrace array $1 \mathrm{~km}$ downstream. The forebay-to-tailrace survival estimate satisfies the "BRZ-toBRZ" survival estimated called for in the Fish Accords.

- Forebay residence time is calculated by subtracting the time of first detection on the forebay entrance array (river kilometer [rkm] 236) from the time of last detection on the dam-face array (rkm 234). For the population of tagged smolts passing the forebay, we estimated the mean, standard error, and median forebay residence time.

- Tailrace egress time is calculated by subtracting the time of last detection on the dam-face array ( $\mathrm{rkm} 234$ ) from the time of last detection on the tailrace array (rkm 233). For the population of tagged smolts passing through the tailrace, we estimated the mean, standard error, and median egress time.

- SPE is defined as the fraction of fish going through the dam via the spillway.

- Spill + Bonneville Powerhouse 2 Corner Collector (B2CC) passage efficiency (SPE2) is defined as the fraction of fish passing through the dam via the spillway and B2CC, as defined by the 2008 Fish Accords.

- Fish passage efficiency (FPE), defined as the fraction of fish going through the dam via the spillway and the sluiceway. ${ }^{2}$

Results are reported for the two fish stocks by performance measure. This report is designed to provide a succinct and timely summary of $\mathrm{BiOp} /$ Fish Accords performance measures. A subsequent, comprehensive technical report scheduled for 2012 will provide more detailed data on survival and fish passage for yearling Chinook salmon and steelhead at Bonneville Dam in 2011.

\footnotetext{
${ }^{1}$ Performance as defined in the 2008 FCRPS BiOp, Section 6.0.

${ }^{2}$ This was called spill passage efficiency in the Fish Accords.
} 


\subsection{Methods}

Study methods involved fish release and recapture; the associated fish-handling, tagging, and release procedures; acoustic signal processing; and statistical and analytical approaches.

\subsection{Release-Recapture Design}

The release-recapture design used to estimate dam passage survival at Bonneville Dam consisted of a novel combination of a virtual release $\left(V_{1}\right)$ of fish at the face of the dam and a paired release below the dam (Figure 2.1) (Skalski et al. 2010a, 2010b). Tagged fish released at five sites upstream of Bonneville Dam were used to supply a source of fish known to have arrived alive at the face of the dam. Upstream release sites were near Roosevelt, Washington ( $\mathrm{rkm}$ 390), which is $41 \mathrm{~km}$ upstream of John Day Dam; the John Day Dam tailrace (rkm 346); Celilo, Oregon (rkm 325); The Dalles Dam tailrace (rkm 307); and Hood River, Oregon ( $r k m$ 275). By releasing the fish far enough upstream, they should have arrived at the dam in a spatial pattern typical of run-of-river (ROR) fish. This virtual-release group was then used to estimate survival through the dam and some distance beyond (i.e., rkm 161) (Figure 2.1). The location for the detection array at $\mathrm{rkm} 161$ was chosen so that there was little or no chance of detecting fish that died during dam passage and floated downriver with still active tags. To account and adjust for this extra reach mortality, we made paired releases below Bonneville Dam in the tailrace at $R_{2}$ and in the tailwater near Knapp, Washington at $R_{3}$ (Figure 2.1), to estimate survival in that river segment below the dam. Dam passage survival was then estimated as the quotient of the survival estimates for the virtual release to that of the paired release. The sizes of the releases of the acoustic-tagged fish used in the dam passage survival estimates are summarized in Table 2.1.

The same release-recapture design was also used to estimate forebay-to-tailrace survival, except that the virtual-release group was constructed of fish known to have arrived at the forebay array (rkm 236). The same below-dam paired release was used to adjust for the extra release mortality below the dam as was used to estimate dam passage survival. The double-detection arrays at the face of the dam (Figure 2.2) were analyzed as two independent arrays to allow estimation of detection probabilities by route of passage and assign routes of passage. These passage-route data were used to calculate SPE, spillway + B2CC passage efficiency, and FPE at Bonneville Dam. Detections on the forebay entrance array and dam-face array were used to estimate forebay residence time. The fish used in the virtual release at the face of the dam were also used to estimate tailrace egress time.

Three distinct manufacturing lots of tags were used during the spring 2011 JSATS study, (i.e., 1, 2, and 3-5). From each of these tag lots, approximately 50 tags (i.e., 50, 50, and 59, respectively) were randomly sampled to be used in tag-life assessments. The tags were activated, held in river water, and monitored continuously until they failed. The information from the tag-life study was used to adjust the perceived survival estimates from the Cormack-Jolly-Seber release-recapture model according to the methods of Townsend et al. (2006). 


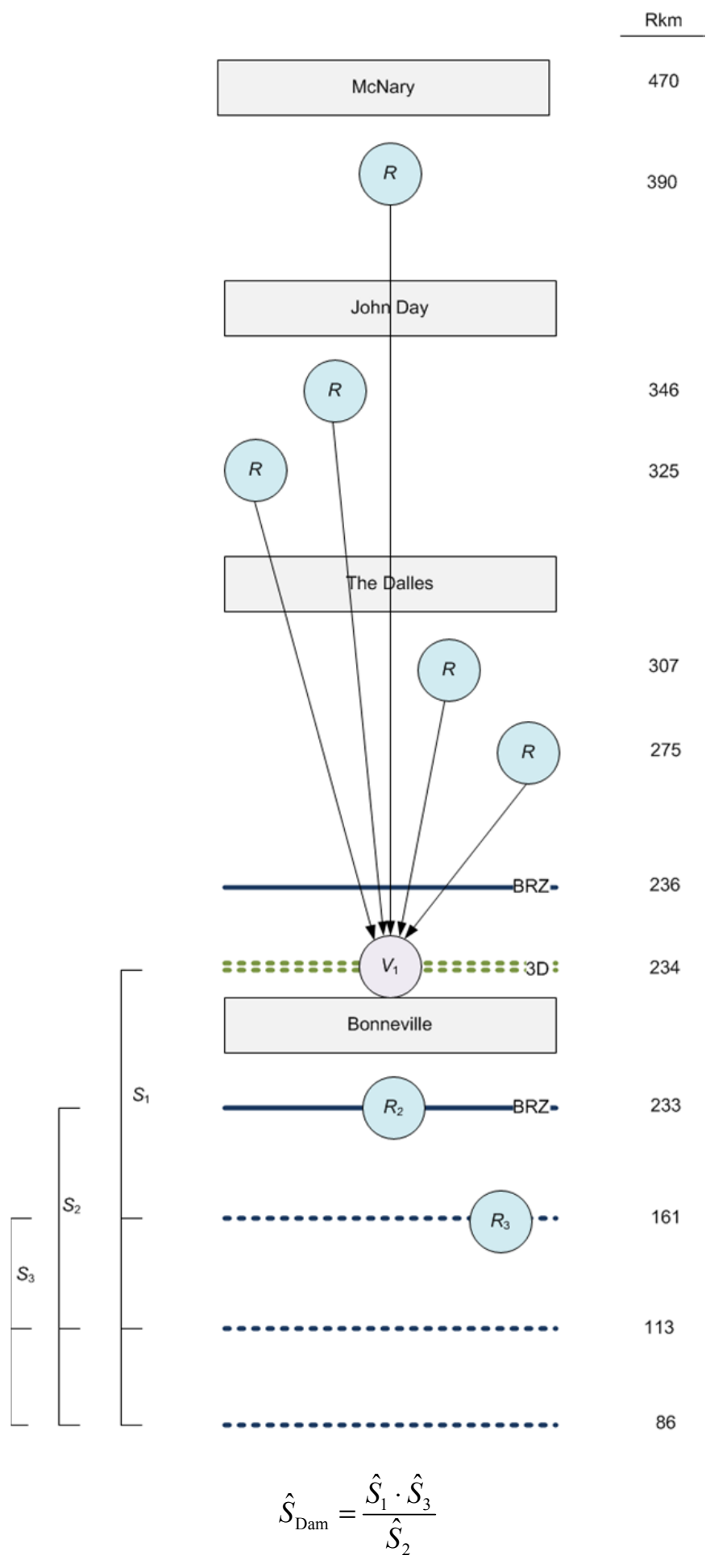

Figure 2.1. Schematic of the virtual/paired-release design used to estimate dam passage survival at Bonneville Dam. The virtual release $\left(V_{1}\right)$ was composed of fish that arrived at the dam face from the release locations at $\mathrm{rkm} 390,346,325,307$, and 275. The below-dam release pair was composed of releases $R_{2}$ and $R_{3}$ with detection arrays used in the survival analysis denoted by dashed lines. 
Table 2.1. Sample sizes of acoustic-tag releases used in the yearling Chinook salmon and steelhead survival studies at Bonneville Dam in 2011.

\begin{tabular}{lcc}
\hline \multicolumn{1}{c}{ Release Location } & Yearling Chinook Salmon & Steelhead \\
\hline Upriver Releases $\left(R_{1}\right)$ & 6100 & 6180 \\
Virtual Release $\left(V_{1}\right)$ & 5542 & 5663 \\
Bonneville Tailrace $\left(R_{2}\right)$ & 798 & 792 \\
Bonneville Reservoir $\left(R_{3}\right)$ & 794 & 794 \\
\hline
\end{tabular}

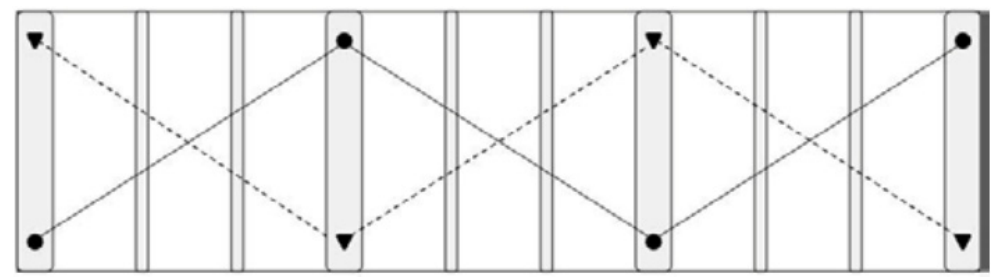

Figure 2.2. Front view schematic of hydrophone deployments at three turbines showing doubledetection arrays. Circles denote four hydrophones contributing to Array 1 and triangles show four hydrophones contributing to Array 2. The alternating shallow and deep hydrophone deployment pattern on successive piers was used at all turbines and spill bays at the dam.

\subsection{Handling, Tagging, and Release Procedures}

Fish obtained from the John Day Dam juvenile bypass system were surgically implanted with JSATS tags, and then transported to seven different release points, as described in the following sections.

\subsubsection{Acoustic Tags}

The acoustic tags used in the spring 2011 study were manufactured by Advanced Telemetry Systems (ATS). Each tag, model number ATS-156dB, measured approximately $12 \mathrm{~mm}$ in length, $5.2 \mathrm{~mm}$ in width, $3.7 \mathrm{~mm}$ in thickness, and weighed approximately $0.43 \mathrm{~g}$ in air. The tags had a nominal transmission rate of 1 pulse every $3 \mathrm{~s}$. Nominal tag life was expected to be about 25 days.

\subsubsection{Fish Source}

The yearling Chinook salmon and steelhead used in the study were all obtained from the John Day Dam juvenile bypass system. The Pacific States Marine Fisheries Commission diverted fish from the juvenile bypass system into an examination trough, as described by Martinson et al. (2006). Fish $\geq 95 \mathrm{~mm}$ in length without malformations or excessive descaling $(>20 \%)$ were selected for tagging. 


\subsubsection{Tagging Procedure}

The fish to be tagged were anesthetized in an 18.9-L "knockdown" bucket with fresh river water and tricaine methanesulfonate (MS-222; 80 to $100 \mathrm{mg} / \mathrm{L}$ ). Anesthesia buckets were refreshed repeatedly to maintain the temperature within $\pm 2^{\circ} \mathrm{C}$ of current river temperatures. Each fish was weighed and measured before tagging.

During surgery, each fish was placed ventral side up and a gravity-fed anesthesia supply line was placed into its mouth. The dilution of the "maintenance" anesthesia was $40 \mathrm{mg} / \mathrm{L}$. Using a surgical blade, a 6- to 8-mm incision was made in the body cavity between the pelvic girdle and pectoral fin. A passive integrated transponder (PIT) tag was inserted followed by an acoustic tag. Both tags were inserted toward the anterior end of the fish. The incision was closed using 5-0 Monocryl suture.

After closing the incision, the fish were placed in a dark 18.9-L transport bucket filled with aerated river water. Fish were held in these buckets for 18 to $24 \mathrm{~h}$ before being transported for release into the river. The loading rate was five fish per bucket.

\subsubsection{Release Procedures}

All fish were tagged at John Day Dam and transported by truck to release locations (Figure 2.1). Transportation routes for reference release pairs below study dams were standardized to provide equal transport times. In practice, transport times were similar for the five upstream release sites and longer $(2.5 \mathrm{~h})$ but identical for the two reference releases downstream of Bonneville Dam. Upon arriving at each release site (Table 2.1), fish buckets were transferred to a boat for transport to five release locations spanning the width of the river, and equal numbers of buckets of fish were released at each of the five locations.

Released fish arrived at Bonneville Dam over 30 consecutive days (from 30 April to 31 May 2011) during all hours of the day. This arrival pattern was facilitated by having five release sites located from 41 to $156 \mathrm{~km}$ upstream of the dam, and by alternating between daytime and nighttime releases at each site, over the course of the study. The timing of the releases at the release sites was staggered to help facilitate downstream mixing (Table 2.2).

Table 2.2. Relative release times for the acoustic-tagged fish to accommodate downstream mixing.

\begin{tabular}{cll}
\hline Release Location & \multicolumn{2}{c}{ Relative Release Times } \\
\hline$V_{1}(\mathrm{rkm} 234)$ & Continuous & Continuous \\
$R_{2}(\mathrm{rkm} 233)$ & Day 1: 0800 & Day 1: 2000 \\
$R_{3}(\mathrm{rkm} 161)$ & Day 2: 0500 & Day 2: 1700 \\
\hline
\end{tabular}

\subsection{Acoustic Signal Processing}

Transmissions of JSATS tag codes received on cabled and autonomous hydrophones were recorded in raw data files. These files were downloaded periodically and transported to PNNL's North Bonneville offices for processing. Receptions of tag codes within raw data files were processed to produce a data set 
of accepted tag-detection events. For cabled arrays, detections from all hydrophones at a dam were combined for processing. The following three filters were used:

- Multipath filter: For data from each individual cabled hydrophone, all tag-code receptions that occur within $0.156 \mathrm{~s}$ after an initial identical tag code reception were deleted under the assumption that closely lagging signals are multipath. Initial code receptions were retained. The delay of $0.156 \mathrm{~s}$ was the maximum acceptance window width for evaluating a pulse repetition interval (PRI) and was computed as 2(PRI_Window+12×PRI_Increment). Both PRI_Window and PRI_Increment were set at $0.006 \mathrm{~s}$, which was chosen to be slightly larger than the potential rounding error in estimating PRI to two decimal places.

- Multi-detection filter: Receptions were retained only if the same tag code was received at another hydrophone in the same array within $0.3 \mathrm{~s}$ because receptions on separate hydrophones within $0.3 \mathrm{~s}$ (about $450 \mathrm{~m}$ of range) were likely from a single tag transmission.

- PRI filter: Only those series of receptions of a tag code (or "messages") that were consistent with the pattern of transmissions from a properly functioning JSATS acoustic tag were retained. Filtering rules were evaluated for each tag code individually, and it was assumed that only a single tag would be transmitting that code at any given time. For the cabled system, the PRI filter operated on a message, which included all receptions of the same transmission on multiple hydrophones within $0.3 \mathrm{~s}$. Message time was defined as the earliest reception time across all hydrophones for that message. Detection required that at least six messages be received with an appropriate time interval between the leading edges of successive messages.

The receptions of JSATS tag codes within raw data files from autonomous nodes were also processed to produce a data set of accepted tag-detection events, or events for short. A single file was processed at a time, and no information about receptions at other nodes was used. The Multipath and PRI filters described above were used.

The output of this process was a data set of events that summarized accepted tag detections for all times and locations where hydrophones were operating. Each unique event record included a basic set of fields that indicated the unique identification number of the fish, the first and last detection time for the event, the location of detection, and how many messages were detected within the event. This list was combined with accepted tag detections from the autonomous arrays and PIT-tag detections for additional quality assurance/quality control analysis prior to survival analysis. Additional fields capture specialized information, where available. One such example was route of passage, which was assigned a value for those events that immediately precede passage at a dam based on spatial tracking of tagged fish movements to a location of last detection. Multiple receptions of messages within an event can be used to triangulate successive tag positions relative to hydrophone locations.

One of the most important quality control steps was to examine the chronology of detections of every tagged fish on all arrays above and below the dam-face array to identify any detection sequences that deviated from the expected upstream to downstream progression through arrays in the river. Except for possible detections on forebay entrance arrays after detection on a nearby dam-face array 1 to $3 \mathrm{~km}$ downstream, apparent upstream movements of tagged fish between arrays that were greater than $5 \mathrm{~km}$ apart or separated by one or more dams were very rare $(<0.015 \%)$ and probably represented false positive detections on the upstream array. False positive detections usually will have close to the minimum number of messages and were deleted from the event data set before survival analysis. 
Three-dimensional (3D) tracking of JSATS-tagged fish in the immediate forebay of Bonneville Dam was used to determine routes of passage to estimate SPE. Acoustic tracking is a common technique in bioacoustics based on time-of-arrival differences among different hydrophones. Usually, the process requires a three-hydrophone array for two-dimensional tracking and a four-hydrophone array for $3 \mathrm{D}$ tracking. For this study, only 3D tracking was performed. The methods were similar to those described by Weiland et al. (2010).

\subsection{Statistical Methods}

Statistical methods were used to test assumptions and estimate passage survival, tag life, forebay-totailrace survival, travel times, SPE, spill + B2CC passage efficiency, and FPE.

\subsubsection{Estimation of Passage Survival}

Maximum likelihood estimation was used to estimate dam passage survival at Bonneville Dam based on the virtual/paired-release design. The capture histories from all the replicate releases, both daytime and nighttime, were pooled to produce the estimate of dam passage survival. A joint likelihood model was constructed of a product multinomial with separate multinomial distributions describing the capture histories of the separate release groups (i.e., $V_{1}, R_{2}$, and $R_{3}$ ) and differentiated by tag lot. The major manufacturing lots (i.e., 1, 2, 3-5) had separately estimated tag-life corrections, but we assumed that all fish from a release location had common reach survival parameters.

The joint likelihood used to model the three release groups was initially fully parameterized. Each of the three releases was allowed to have unique survival and detection parameters. If precision was adequate (i.e., $\mathrm{SE} \leq 0.015$ ) with the fully parameterized model, no further modeling was performed. If initial precision was inadequate, then likelihood ratio tests were used to assess the homogeneity of parameters across release groups to identify the best parsimonious model to describe the capture history data. This approach was used to help preserve both precision and robustness of the survival results. All calculations were performed using Program ATLAS (http://www.cbr.washington.edu/paramest/atlas/).

Dam passage survival was estimated by the function

$$
\hat{S}_{\text {Dam }}=\frac{\hat{S}_{1}}{\left(\frac{\hat{S}_{2}}{\hat{S}_{3}}\right)}=\frac{\hat{S}_{1} \cdot \hat{S}_{3}}{\hat{S}_{2}}
$$

where $\hat{S}_{i}$ is the tag-life-corrected survival estimate for the $i$ th release group $(i=1, \ldots, 3)$. The variance of $\hat{S}_{\text {Dam }}$ was estimated in a two-step process that incorporated both the uncertainty in the tag-life corrections and the release-recapture processes.

In 2011, the compliance test at Bonneville Dam was disrupted by high flow conditions in late spring. Consequently, a post facto approach to examining dam passage survival during spring 2011 was necessary. Two alternative estimates of dam passage survival were computed as follows:

1. Survival during early period (30 April-13 May 2011)

2. Survival during entire season, including high flows (30 April-31 May 2011). 
In estimating dam passage survival during a particular segment of the study, all fish in releases $R_{2}$ and $R_{3}$ (see Figure 2.1) during the period were used in the analyses.

\subsubsection{Tag-Life Analysis}

For each of the three major manufacturing lots of JSATS tags (i.e., 1, 2, 3-5), 50-59 acoustic tags were systematically sampled over the course of the yearling Chinook salmon and steelhead smolt tagging process. The tags were continuously monitored from activation to failure in ambient river water. For each tag lot, the failure times were fit to the four-parameter vitality model of Li and Anderson (2009). The vitality model tends to fit acoustic-tag failure times well, because it allows for both early onset of random failure due to manufacturing as well as systematic battery failure later on.

The survivorship function for the vitality model can be rewritten as

$$
S(t)=1-\left(\Phi\left(\frac{1-r t}{\sqrt{u^{2}+s^{2} t}}\right)-e^{\left(\frac{2 u^{2} r^{2}}{s^{4}}+\frac{2 r}{s^{2}}\right)} \Phi\left(\frac{2 u^{2} r+r t+1}{\sqrt{u^{2}+s^{2} t}}\right)\right)^{e^{-k t}}
$$

where

$$
\begin{aligned}
\Phi & =\text { cumulative normal distribution } \\
r & =\text { average wear rate of components } \\
S & =\text { standard deviation in wear rate } \\
k & =\text { rate of accidental failure } \\
u & =\text { standard deviation in quality of original components. }
\end{aligned}
$$

The random failure component, in addition to battery discharge, gives the vitality model additional latitude to fit tag-life data not found in other failure-time distributions such as the Weibull or Gompertz. Parameter estimation was based on maximum likelihood estimation.

For the virtual-release group $\left(V_{1}\right)$ based on fish known to have arrived at the dam and with active tags, the conditional probability of tag activation, given the tag was active at the detection array at rkm 349, was used in the tag-life adjustment for that release group. The conditional probability of tag activation at time $t_{1}$, given it was active at time $t_{0}$, was computed by the quotient:

$$
P\left(t_{1} \mid t_{0}\right)=\frac{S\left(t_{1}\right)}{S\left(t_{0}\right)}
$$

\subsubsection{Tests of Assumptions}

Approaches to assumption testing are described below.

\subsubsection{Burnham et al. (1987) Tests}

Tests 2 and 3 (T2 and T3) of Burnham et al. (1987) have been used to assess whether upstream detection history has an effect on downstream survival. Such tests are most appropriate when fish are physically recaptured or segregated during capture as in the case with PIT-tagged fish going through the juvenile bypass system. However, acoustic-tag studies do not use physical recaptures to detect fish. 
Consequently, there is little or no relevance of these tests in acoustic-tag studies. Furthermore, the very high detection probabilities present in acoustic-tag studies frequently preclude calculation of these tests. For these reasons, these tests were not performed.

\subsubsection{Tests of Mixing}

Evaluation of the homogeneous arrival of release groups at downriver detection sites was based on graphs of arrival distributions. The graphs were used to identify any systematic and meaningful departures from mixing. Ideally, the arrival distributions should overlap one another with similarly timed modes.

\subsubsection{Tagger Effects}

Subtle differences in handling and tagging techniques can have an effect on the survival of acoustically tagged smolts used in the estimation of dam passage survival. For this reason, tagger effects were evaluated. The single release-recapture model was used to estimate reach survivals for fish tagged by different individuals. The analysis evaluated whether any consistent pattern of reduced reach survivals existed for fish tagged by any of the tagging staff.

For $k$ independent reach survival estimates, a test of equal survival was performed using the $F$-test

$$
F_{k-1, \infty}=\frac{s_{\hat{S}}^{2}}{\left(\frac{\sum_{i=1}^{k} \widehat{\operatorname{Var}}\left(\hat{S}_{i} \mid S_{i}\right)}{k}\right)}
$$

where

$$
s_{\hat{S}}^{2}=\frac{\sum_{i=1}^{k}\left(\hat{S}_{i}-\hat{\bar{S}}\right)^{2}}{k-1}
$$

and

$$
\hat{\bar{S}}=\frac{\sum_{i=1}^{k} \hat{S}_{i}}{k}
$$

The $F$-test was used in evaluating tagger effects as well as tag-lot effects.

\subsubsection{Estimation of Forebay-to-Tailrace Survival}

The same virtual/paired release methods used to estimate dam passage were also used to estimate forebay-to-tailrace survival. The only distinction was the virtual-release group $\left(V_{1}\right)$ was composed of fish known to have arrived alive at the forebay array ( $\mathrm{rkm} 236)$ of Bonneville Dam instead of at the dam face (Figure 2.1). 


\subsubsection{Estimation of Travel Times}

Travel times associated with forebay residence time and tailrace egress were estimated using arithmetic averages as specified in the Fish Accords, i.e.,

$$
\bar{t}=\frac{\sum_{i=1}^{n} t_{i}}{n}
$$

with the variance of $\bar{t}$ estimated by

$$
\widehat{\operatorname{Var}}(\bar{t})=\frac{\sum_{i=1}^{n}\left(t_{i}-\bar{t}\right)^{2}}{n(n-1)}
$$

and where $t_{i}$ was the travel time of the $i$ th fish $(i=1, \ldots, n)$. Median travel times were also computed and reported.

Tailrace egress time was calculated by subtracting the time of last detection of a fish on the dam-face array ( $\mathrm{rkm} 234)$ from its time of last detection on the tailrace array (rkm 233). Forebay residence time was calculated by subtracting the time of first detection of a fish on the forebay entrance array (rkm 236) from the time of last detection on the dam-face array ( $\mathrm{rkm} 234)$. For forebay residence time and tailrace egress time, we estimated the mean, standard error, and median travel times.

\subsubsection{Estimation of Spill Passage Efficiency}

SPE was estimated by the fraction

$$
\widehat{\mathrm{SPE}}=\frac{\hat{N}_{S P}}{\hat{N}_{S P}+\hat{N}_{B 1 S L}++\hat{N}_{B 1 T}+\hat{N}_{2 J B S}+\hat{N}_{B 2 C C}+\hat{N}_{B 1 T}},
$$

where $\hat{N}_{i}$ is the estimated abundance of acoustic-tagged fish through the $i$ th route ( $i=$ spillway [SP], Bonneville Powerhouse 1 sluiceway [B1SL], Powerhouse 1 turbines [B1T], Bonneville Power house 2 juvenile bypass system [B2JBS], Powerhouse 2 corner collector [B2CC], and Powerhouse 2 turbines $[\mathrm{B} 2 \mathrm{~T}])$. The double-detection array was used to estimate absolute abundance $(N)$ through a route using the single mark-recapture model (Seber 1982:60) independently at each route. Calculating the variance in stages, the variance of $\widehat{\mathrm{SPE}}$ was estimated as

$$
\begin{aligned}
\operatorname{Var}(\widehat{\mathrm{SPE}}) & =\frac{\mathrm{SPE}(1-\mathrm{SPE})}{\sum_{i=1}^{6} N_{i}}+\mathrm{SPE}^{2}(1-\mathrm{SPE})^{2} \\
& \cdot\left[\frac{\operatorname{Var}\left(\hat{N}_{S P}\right)}{N_{S P}^{2}}+\frac{\operatorname{Var}\left(\hat{N}_{B 1 S L}\right)+\operatorname{Var}\left(\hat{N}_{B 1 T}\right)+\operatorname{Var}\left(\hat{N}_{B 2 J B S}\right)+\operatorname{Var}\left(\hat{N}_{B 2 C C}\right)+\operatorname{Var}\left(\hat{N}_{B 2 T}\right)}{\left(N_{S L}+N_{B 1 T}+N_{B 2 J B S}+N_{B 2 C C}+N_{B 2 T}\right)^{2}}\right] .
\end{aligned}
$$




\subsubsection{Estimation of Spill + B2CC Passage Efficiency}

Spill + B2CC passage efficiency was estimated by the fraction

$$
\widehat{\mathrm{SPE}_{2}}=\frac{\hat{N}_{S P}+\hat{N}_{B 2 C C}}{\hat{N}_{S P}+\hat{N}_{B 1 S L}+\hat{N}_{B 1 T}+\hat{N}_{B 2 J B S}+\hat{N}_{B 2 C C}+\hat{N}_{B 2 T}} .
$$

The double-detection array was used to estimate absolute abundance $(N)$ through a route using the single mark-recapture model (Seber 1982:60) independently at each route. Calculating the variance in stages, the variance of $\widehat{\mathrm{SPE}}_{2}$ was estimated as

$$
\begin{aligned}
\operatorname{Var}\left(\mathrm{SPE}_{2}\right)= & \frac{\mathrm{SPE}_{2}\left(1-\mathrm{SPE}_{2}\right)}{\sum_{i=1}^{6} \hat{N}_{i}}+\operatorname{SPE}_{2}^{2}\left(1-\mathrm{SPE}_{2}\right)^{2} . \\
& \cdot\left[\frac{\operatorname{Var}\left(\hat{N}_{S P}\right)+\operatorname{Var}\left(\hat{N}_{B 2 C C}\right)}{\left(N_{S P}+N_{B 2 C C}\right)^{2}}+\frac{\operatorname{Var}\left(\hat{N}_{B 1 S L}\right)+\operatorname{Var}\left(\hat{N}_{B 1 T}\right)+\operatorname{Var}\left(\hat{N}_{B 2 J B S}\right)+\operatorname{Var}\left(\hat{N}_{B 2 T}\right)}{\left(N_{B 1 S L}+N_{B 2=1 T}+N_{B 2 J B S}+N_{B 2 T}\right)^{2}}\right] .
\end{aligned}
$$

\subsubsection{Estimation of Fish Passage Efficiency}

Fish passage efficiency was estimated by the fraction

$$
\widehat{\mathrm{FPE}}=\frac{\hat{N}_{S P}+\hat{N}_{B 2 C C}+\hat{N}_{B 1 S L}+\hat{N}_{B 2 J B S}}{\hat{N}_{S P}+\hat{N}_{B 1 S L}+\hat{N}_{B 1 T}+\hat{N}_{B 2 J B S}+\hat{N}_{B 2 C C}+\hat{N}_{B 2 T}} .
$$

Calculating the variance in stages, the variance of $\widehat{\mathrm{FPE}}$ was estimated as

$$
\begin{aligned}
\operatorname{Var}(\widehat{\mathrm{FPE}})= & \frac{\mathrm{FPE}(1-\mathrm{FPE})}{\sum_{i=1}^{6} N_{i}}+\mathrm{FPE}^{2}(1-\mathrm{FPE})^{2} \\
& \cdot\left[\frac{\operatorname{Var}\left(\hat{N}_{S P}\right)+\operatorname{Var}\left(\hat{N}_{B 2 C C}\right)+\operatorname{Var}\left(\hat{N}_{B 1 S L}\right)+\operatorname{Var}\left(\hat{N}_{B 2 J B S}\right)}{\left(N_{S P}+N_{B 2 C C}+N_{B 1 S L}+N_{B 2 J B S}\right)^{2}}+\frac{\operatorname{Var}\left(\hat{N}_{B 1 T}\right)+\operatorname{Var}\left(\hat{N}_{B 2 T}\right)}{\left(N_{B 1 T}+N_{B 2 T}\right)^{2}}\right] .
\end{aligned}
$$

In order to expedite this report, all passage efficiencies were calculated based on passage counts assuming all routes had equal probabilities of detection using a binomial sampling model. 


\subsection{Results}

The results cover four topics: 1) fish collection, rejection, and tagging; 2) discharge and spill conditions; 3) tests of assumptions; and 4) survival and passage estimates.

\subsection{Fish Collection, Rejection, and Tagging}

The total number of fish handled by PNNL in spring 2011 and the counts and percentages of fish by handling category are listed in Table 3.1. Over 20,000 yearling Chinook salmon and juvenile steelhead were handled during the study.

Table 3.1. Total number of fish handled by PNNL during the spring of 2011 and counts of fish in several handling categories. $\mathrm{CH1}=$ yearling Chinook salmon, and $\mathrm{STH}=$ juvenile steelhead.

\begin{tabular}{l|rrrrr}
\hline \multicolumn{1}{c}{ Handling Category } & CH1 & \%CH1 & STH & \%STH & Total \\
\hline Tagged at JDA & 7929 & 79 & 8003 & 77 & $\mathbf{1 5 9 3 2}$ \\
Extras (Released) & 584 & 6 & 479 & 5 & $\mathbf{1 0 6 3}$ \\
Drop/Jump (Released) & 16 & 0 & 12 & 0 & $\mathbf{2 8}$ \\
Previously Tagged (Released) & 449 & 4 & 326 & 3 & $\mathbf{7 7 5}$ \\
$<95$ or >300 mm FL (Released) & 1 & 0 & 9 & 0 & $\mathbf{1 0}$ \\
Pre-Tagging Mortalities (Released) & 14 & 0 & 3 & 0 & $\mathbf{1 7}$ \\
Non-Candidate based on Condition ${ }^{(\text {a) }}$ & 1070 & 11 & 1569 & 16 & $\mathbf{2 6 3 9}$ \\
\hline Total Handled & $\mathbf{1 0 0 6 3}$ & & $\mathbf{1 0 4 0 1}$ & & $\mathbf{2 0 4 6 4}$ \\
\hline
\end{tabular}

(a) In 2011, PIT scanning occurred after fish condition assessment, so the listed non-candidate count is inflated by some PIT-tag-bearing fish that should have been rejected solely for having been tagged previously. The order of processing will be changed for 2012 to better estimate numbers of non-candidate fish.

Staff rejecting fish from tagging recorded the reasons by tallying the maladies observed (Table 3.2). Conditions were based on the general recommendations of the Columbia Basin Rejection Criteria (Columbia Basin Surgical Protocol Steering Committee 2011). PNNL broadened some criteria to accept more fish, including fish that on any one side had less than 5\% fungus and open wounds, parasites that occurred on the head and flanks of the fish, operculum damage less than $75 \%$, red fins, any abrasions, and scarring. If more than $5 \%$ of the sample the day before had a particular malady/infection, the following day fish with that malady were accepted after approval by the fish condition study manager.

Table 3.2. Total number of fish handled by PNNL during the spring of 2011 and counts of fish with common maladies. $\mathrm{CH} 1=$ yearling Chinook salmon, and $\mathrm{STH}=$ juvenile steelhead.

\begin{tabular}{lrrrrr}
\hline & CH1 & \% CH1 & STH & \% STH & Total \\
\hline Moribund/Emaciated & 10 & 0 & 8 & 0 & $\mathbf{1 8}$ \\
Descaling $>20 \%$ & 437 & 5 & 659 & 7 & $\mathbf{1 0 9 6}$ \\
Diseases & 221 & 2 & 304 & 3 & $\mathbf{5 2 5}$ \\
Damage/Injury & 398 & 4 & 584 & 6 & $\mathbf{9 8 2}$ \\
Skeletal Deformity & 4 & 0 & 14 & 0 & $\mathbf{1 8}$ \\
Non-Candidate & 1070 & 11 & 1569 & 16 & $\mathbf{2 6 3 9}$ \\
\hline
\end{tabular}




\subsection{Discharge and Spill Conditions}

The average daily total discharge at Bonneville Dam during the first part of the JSATS survival study (30 April-13 May 2011) was $272.3 \mathrm{kcfs}$ with an average percent spill of $36.9 \%$ (Figure 3.1 ). Over the entire course of the study, average daily total discharge was $380.9 \mathrm{kcfs}$ with an average daily percent spill of $46.1 \%$ (Figure 3.1 ). By the end of the study, daily discharges exceeded $500 \mathrm{kcfs}$.

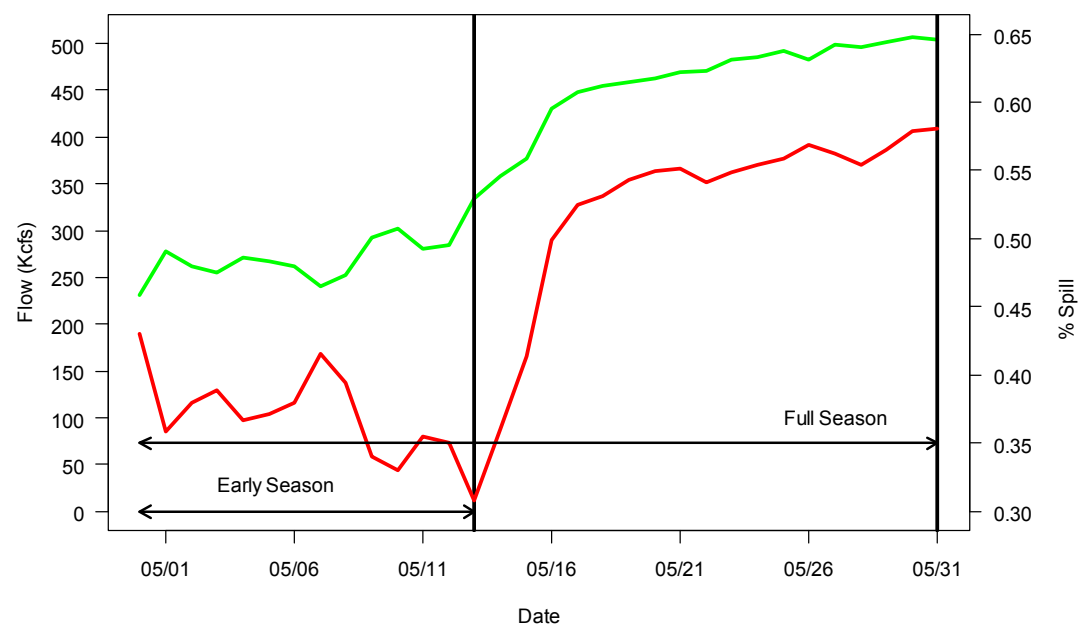

Figure 3.1. Daily average total discharge (kcfs) and percent spill at Bonneville Dam during the 2011 JSATS study for yearling Chinook salmon and steelhead from 30 April to 31 May 2011.

\subsection{Run Timing}

The cumulative percent of yearling Chinook salmon and juvenile steelhead that had passed Bonneville Dam by date was calculated from smolt index data obtained from the Fish Passage Center (Figure 3.2). From April 27 through May 13, 2011, when operators were able to hold spill to $100 \mathrm{kcfs}$, $68.4 \%$ of yearling Chinook salmon and $52.2 \%$ of juvenile steelhead had passed Bonneville Dam. By the end of the study on May 30, 2011, 98.6\% of yearling Chinook salmon and 91.4\% of juvenile steelhead had passed Bonneville Dam.

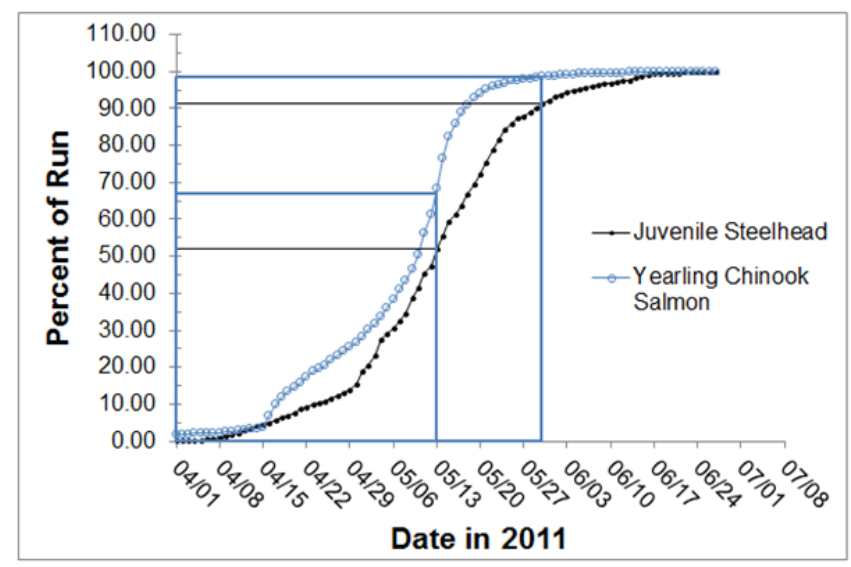

Figure 3.2. Plots of the cumulative percent of juvenile steelhead and yearling Chinook salmon that had passed Bonneville Dam in 2011. 


\subsection{Assessment of Assumptions}

The assessment of assumptions covers tagger effects, tag-lot effects, delayed handling effects, fish size distributions, tag-life corrections, arrival distributions, and downstream mixing.

\subsubsection{Examination of Tagger Effects}

A total of eight different taggers assisted in tagging all yearling Chinook salmon and steelhead smolts associated with the JSATS survival studies at John Day, The Dalles, and Bonneville dams in spring 2011. Analyses found tagger effort was homogenously distributed either across all locations within a replicate release or within the project-specific releases within a replicate (Appendix A). Examination of reach survivals and cumulative survivals from above John Day Dam to below Bonneville Dam found no consistent or reproducible evidence that fish tagged by different staff members had different in-river survival rates (Appendix A). Therefore, fish tagged by all taggers were included in the estimation of survival and other performance measures.

\subsubsection{Examination of Tag-Lot Effects}

Three major tag lots (i.e., 1, 2, and 3-5) were used in the tagging of the yearling Chinook salmon and steelhead smolts during the 2011 JSATS investigations. Overall, tag lots were not homogeneously distributed across all release locations (Appendix A). However, they were homogeneously distributed within each of the below-dam paired releases (i.e., $R_{2}-R_{3}, R_{4}-R_{5}$, and $R_{6}-R_{7}$ ) used in the virtual/pairedrelease design (Appendix A).

After correcting for differences in tag life, there was no consistent or reproducible evidence to indicate differences in survival for fish tagged by the different tag lots. Therefore, fish tagged from all tag lots were used in the estimation of survival and other performance measures.

\subsubsection{Handling Mortality and Tag Shedding}

Fish were held for 24 to $36 \mathrm{~h}$ prior to release. The pre-release tagging mortality in spring was $0.31 \%$ for yearling Chinook salmon smolts and $0.08 \%$ for juvenile steelhead. No tags were shed during the 24-h holding period.

\subsubsection{Examination of Tailrace Release Location Effects on Survival}

We explored the distribution of weighted detections of dam-passed fish ( $V_{1}$ in Figure 2.1) on tailrace autonomous nodes relative to the distribution of reference releases among five locations in the tailrace and examined the effect of tailrace release location on single release survival rates to an array near Vancouver, Washington at rkm 161 (Figure 3.3). The percent of fish detected on three autonomous nodes in the Bonneville tailrace was weighted to equalize sampling effort among node locations. Sampling effort varied because some nodes stopped sampling prematurely because of damage or they were lost. Detectability, as indicated by the percent of detections that only had the minimum number of hits, did not vary among the tailrace locations. 
The uniform distribution of fish releases among five locations in the tailrace appeared to be reasonable given the observed distribution of detections of dam-passed fish $\left(V_{1}-\right.$ Figure 2.1) weighted only for sampling effort (Figure 3.3). Fish that passed the dam were detected at only a slightly higher percentage on the middle node than on nodes on either side of the channel. Survival rates to Vancouver varied from 0.982 to 0.992 for yearling Chinook salmon smolts and from 0.945 to 0.991 for juvenile steelhead. Wide and overlapping 95\% confidence intervals suggest that point estimates of survival rates did not differ significantly among release locations. Low precision is expected given sample sizes of about 150 fish per location over the study season.

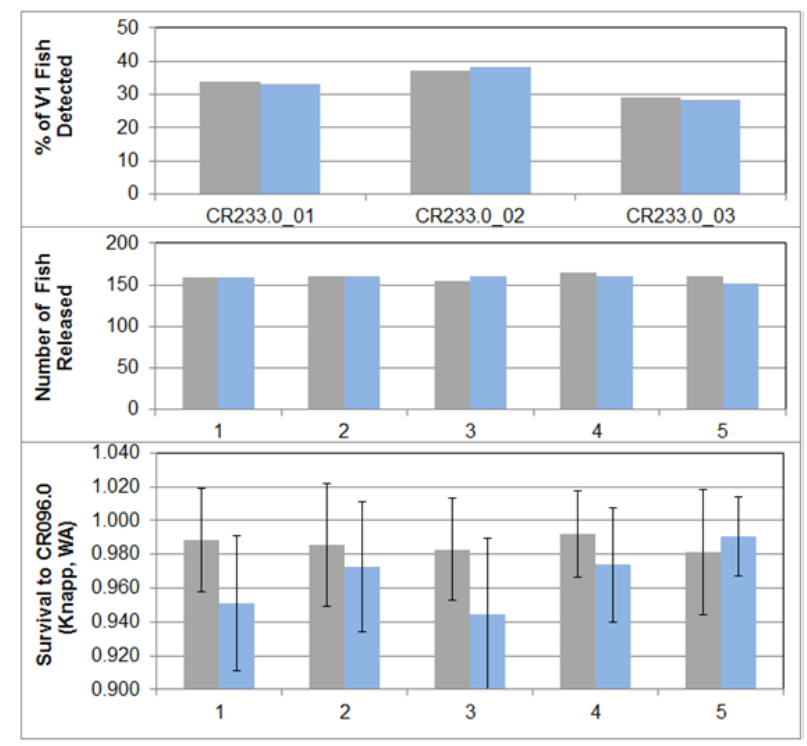

Figure 3.3. Distributions of tailrace detections of $V_{1}$ fish (see Figure 2.1) on autonomous nodes (top), numbers of fish released in the tailrace at five locations (middle), and survival rates by tailrace release location (bottom). Gray bars are for yearling Chinook salmon smolts; blue bars are for juvenile steelhead; vertical bars are 95\% confidence intervals on survival estimates.

\subsubsection{Examination of Time In-River on Survivals of Different Release Groups}

The virtual release formed from the detections of upriver releases at the face of the dam could result in biased survival estimates if fish from varying upriver release locations had differential downriver survival rates. For this reason, reach survivals and cumulative survivals were compared across fish from different upriver release locations. There was no consistent or reproducible evidence to suggest that the amount of time (i.e., distance) in river had a subsequent effect on downriver smolt survival for either yearling Chinook salmon or steelhead (Appendix A). Therefore, in constructing the virtual releases at the face of the dam, fish from all available upriver release locations were used in subsequent survival and other parameter estimation.

\subsubsection{Fish Size Distribution}

Comparison of JSATS-tagged fish with ROR fish sampled at John Day Dam through the Smolt Monitoring Program shows that the length frequency distributions were generally well matched for 
yearling Chinook salmon (Figure 3.4) and steelhead (Figure 3.5). The length distributions for the three yearling Chinook salmon releases (Figure 3.4) and the three steelhead releases (Figure 3.6) were quite similar. Mean lengths for the acoustically tagged yearling Chinook salmon were $148.5 \mathrm{~mm}$ and for the steelhead, $203.2 \mathrm{~mm}$. Mean lengths for yearling Chinook salmon and steelhead sampled by the Fish Passage Center at the Bonneville Dam juvenile sampling facility were $145.4 \mathrm{~mm}$ and $207.2 \mathrm{~mm}$, respectively. Fish size did not change over the course of the study (Figure 3.6).

(a) Bonneville Dam (Release $V_{1}$ )
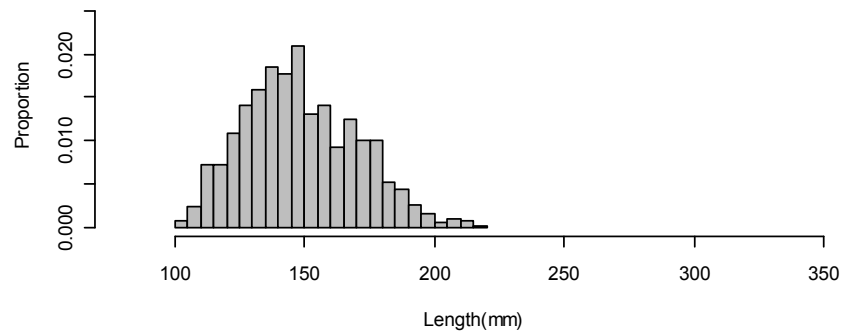

(b) Bonneville Tailrace (Release $R_{2}$ )
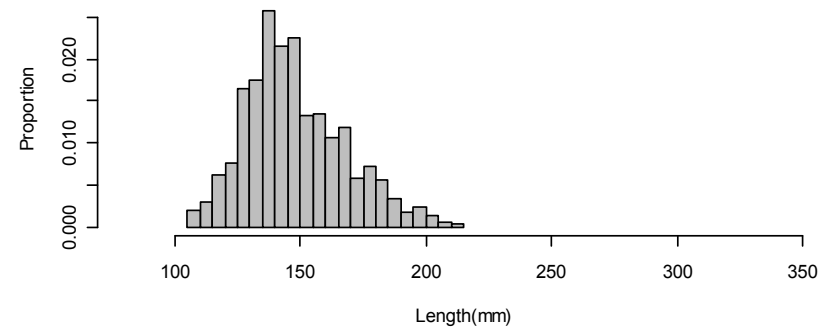

(c) Mid-Reservoir (Release $R_{3}$ )
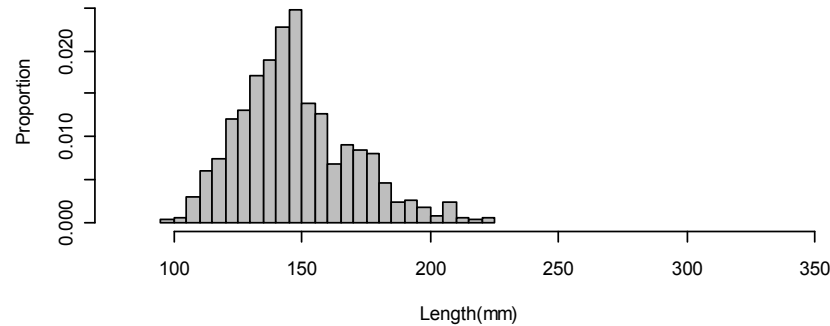

(d) ROR Yearling Chinook at John Day Dam

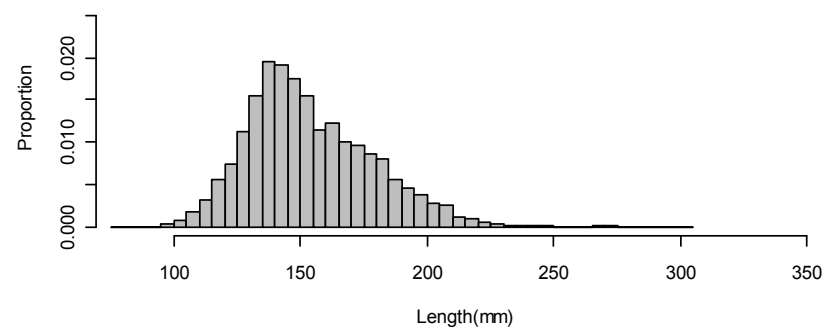

Figure 3.4. Relative frequency distributions for fish lengths $(\mathrm{mm})$ of yearling Chinook salmon smolts used in (a) Release $V_{1}$, (b) Release $R_{2}$, (c) Release $R_{3}$, and (d) ROR fish sampled at John Day Dam by the Fish Passage Center. 
(a) Bonneville Dam (Release $V_{1}$ )

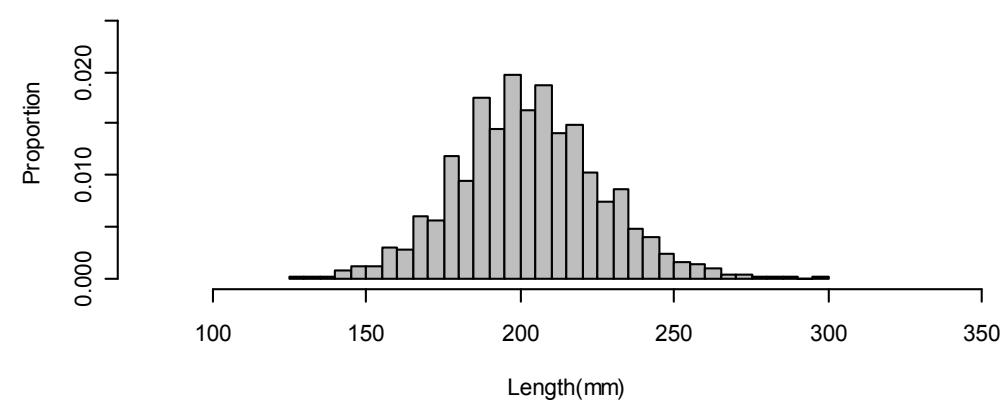

(b) Bonneville Tailrace (Release $R_{2}$ )
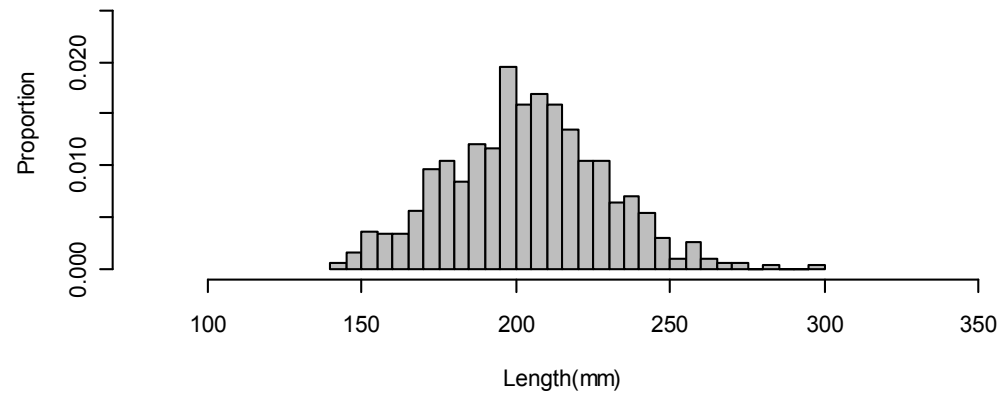

(c) Mid-Reservoir (Release $R_{3}$ )

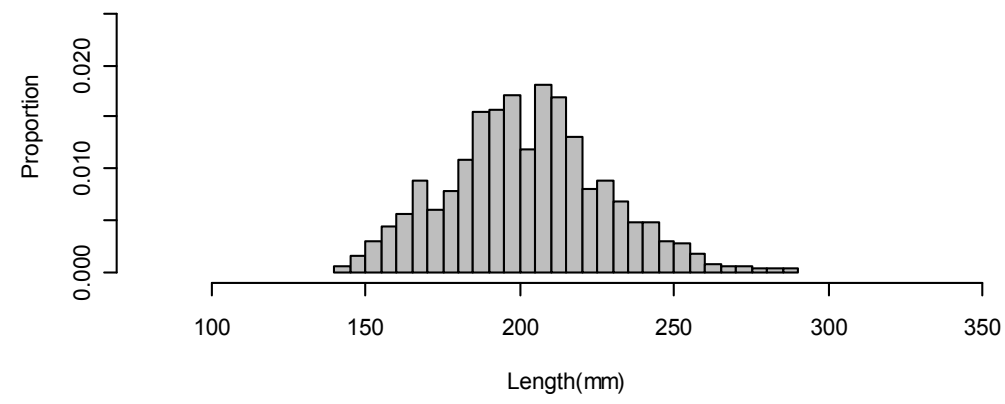

(d) ROR Steelhead at John Day Dam

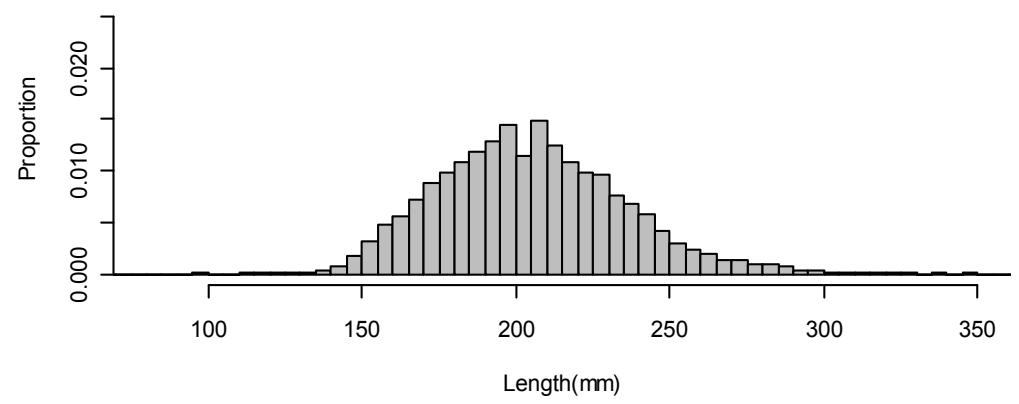

Figure 3.5. Relative frequency distributions for fish lengths $(\mathrm{mm})$ of steelhead smolts used in (a) Release $V_{1}$, (b) Release $R_{2}$, (c) Release $R_{3}$, and (d) ROR fish sampled at John Day Dam by the Fish Passage Center. 
(a) Yearling Chinook salmon smolts

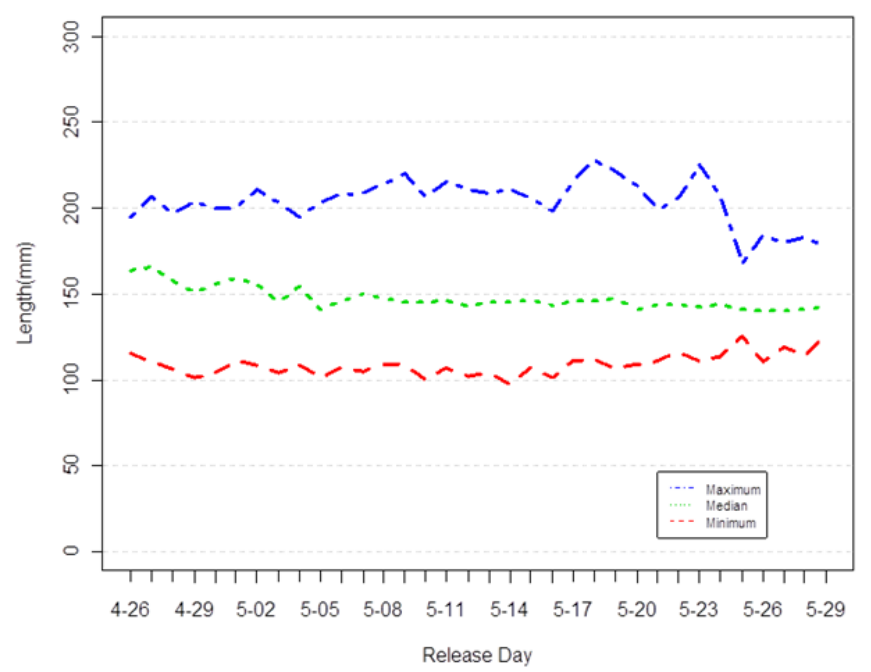

(b) Steelhead smolts

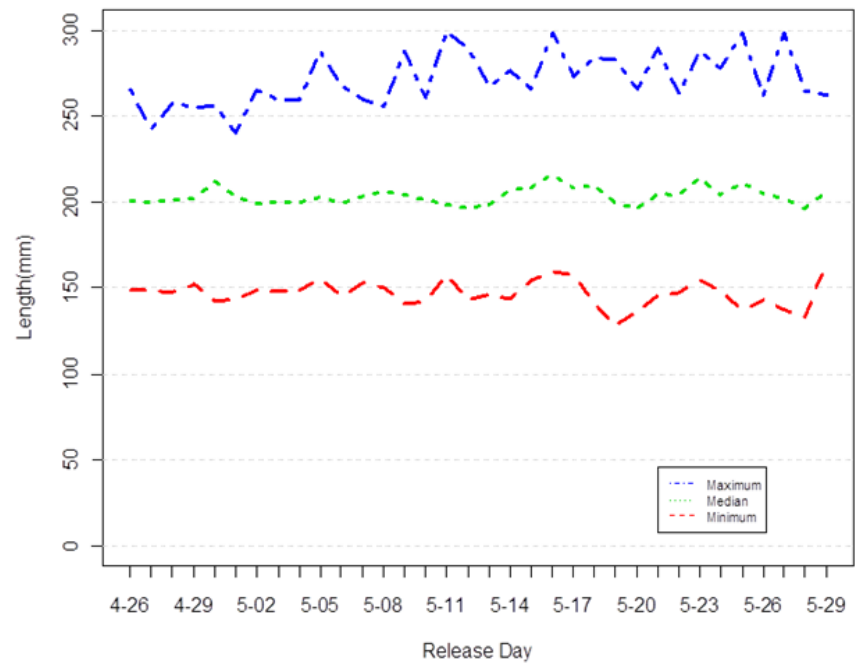

Figure 3.6. Range and median lengths of acoustic-tagged yearling Chinook salmon and steelhead used in the 2011 survival studies. Releases were made daily from 30 April through 31 May at seven release locations: rkm 390, rkm 346, rkm 325, rkm 307, rkm 275, rkm 233, and rkm 161 .

\subsubsection{Tag-Life Corrections}

During the 2011 spring study, five different manufacturing lots of JSATS tags were used in tagging the yearling Chinook salmon and steelhead smolts. Lot 1 was manufactured distinctly from lot 2, which was manufactured distinctly from lots 3-5. From each of these three groupings of tag lots, 50-59 tags were systematically sampled to conduct independent tag-life studies. Vitality curves of Li and Anderson (2009) were fit independently to each of the lots 1, 2, and 3-5 (Figure 3.7). Mantel-Haenszel (1959) tests of homogeneous tag-life distributions found lot 1 was significantly different from lot $2(P=0.0005)$ and lots 3-5 $(P=0.0023)$ but lots 2 and lots 3-5 were not different $(P=0.5698)$ (Figure 3.7, Figure 3.8). Average tag lives were $31.74,30.32$, and 30.52 days for lots 1,2 , and $3-5$, respectively. 
a. Tag lot 1

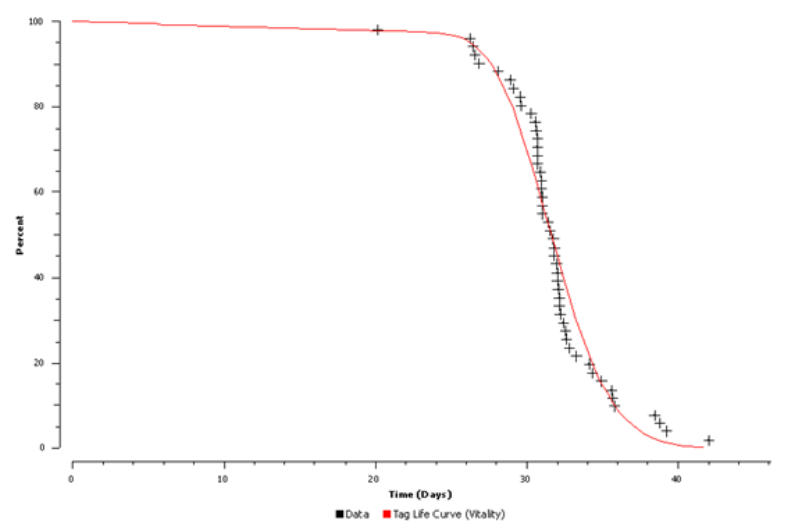

c. Tag lot $3-5$

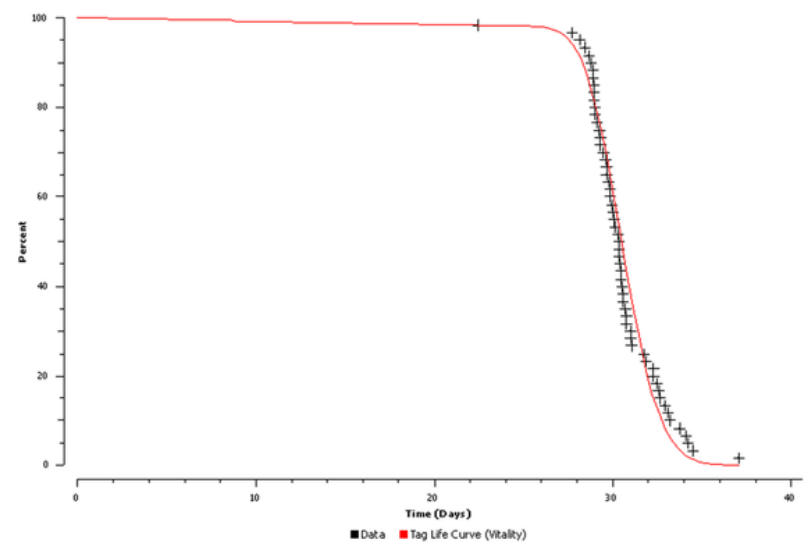

b. Tag lot 2

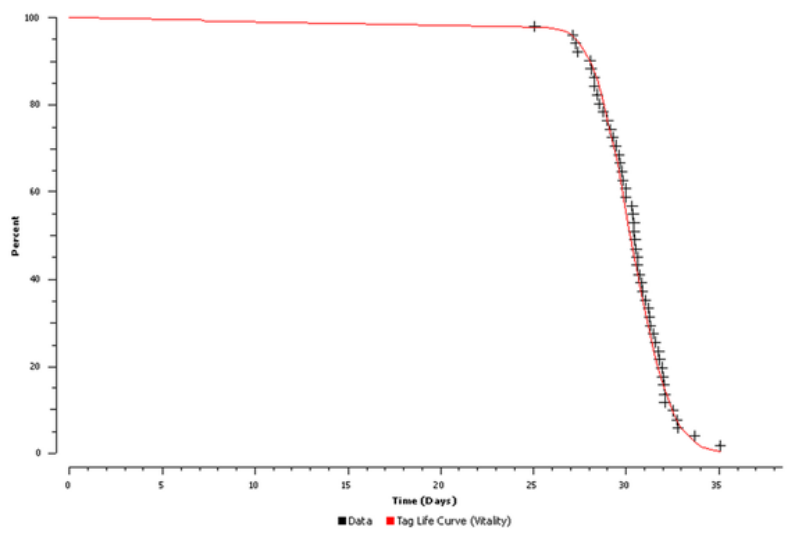

Figure 3.7. Observed time of tag failure and fitted survivorship curves using the vitality model of Li and Anderson (2009) for (a) tag lot 1, (b) tag lot 2, and (c) tag lots 3-5.

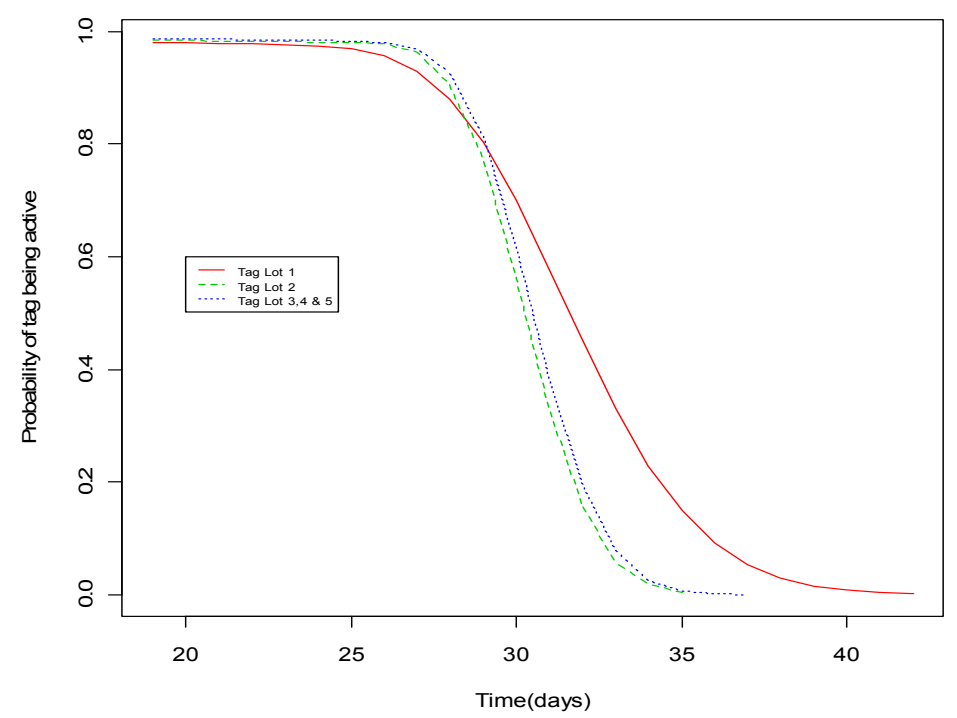

Figure 3.8. Comparison of fitted survivorship curves using the Vitality Model of Li and Anderson (2009) for JSATS tag lots 1, 2, and 3-5 used in the 2011 compliance studies. 


\subsubsection{Arrival Distributions}

The estimated probability an acoustic tag was active when fish arrived at a downstream detection array depends on the tag-life curve and the distribution of observed travel times (Figure 3.9 and Figure 3.10). Examination of the fish arrival distributions to the last detection array used in the survival analyses indicated all fish that arrived had passed through the study area before tag failure became important. The probabilities that acoustic tags were active downstream were calculated by integrating the tag survivorship curve (Figure 3.9 and Figure 3.10) over the observed distribution of fish arrival times (i.e., time from tag activation to arrival). The three separate tag-life survivorship models for tag lots 1,2 , and 3-5 were used to estimate the probabilities of tag failure and provide tag-life-adjusted estimates of smolt survival. The probabilities of a JSATS tag being active at a downstream detection site were specific to release location, tag lot, and species (Table 3.3). In all cases, the probability a tag was active at a downstream detection site as far as rkm 86 for yearling Chinook salmon smolts was $\geq 0.9947$ and $\geq 0.9952$ for steelhead smolts.

Tag lot 1

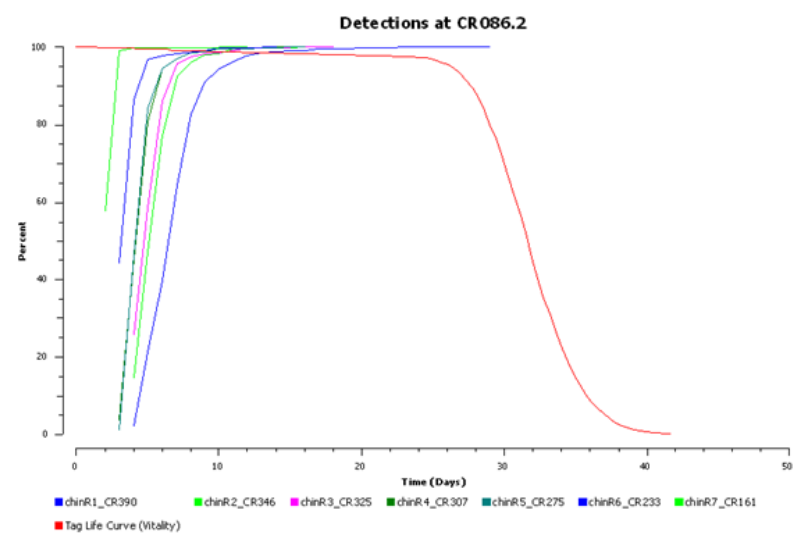

Tag lot 2

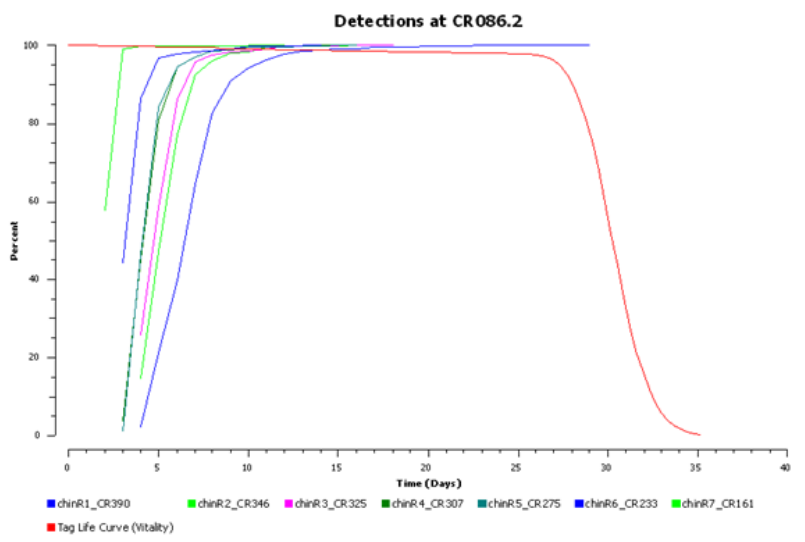

Tag lots 3-5

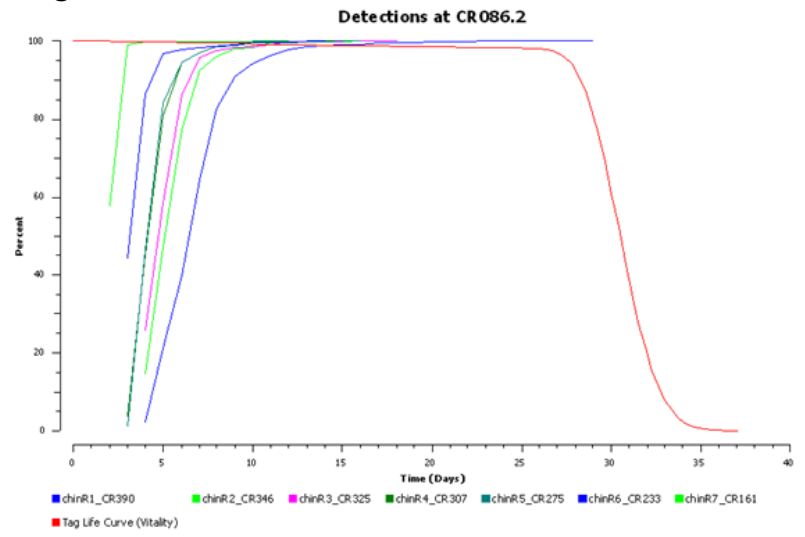

Figure 3.9. Plots of the fitted tag-life survivorship curves for tag lots $1,2,3-5$ and the arrival-time distributions of yearling Chinook salmon smolts from CR390, CR346, CR325, CR307, CR275, CR233, and CR161 at the acoustic-detection array located at rkm 86 (Figure 2.1). 
Tag lot 1

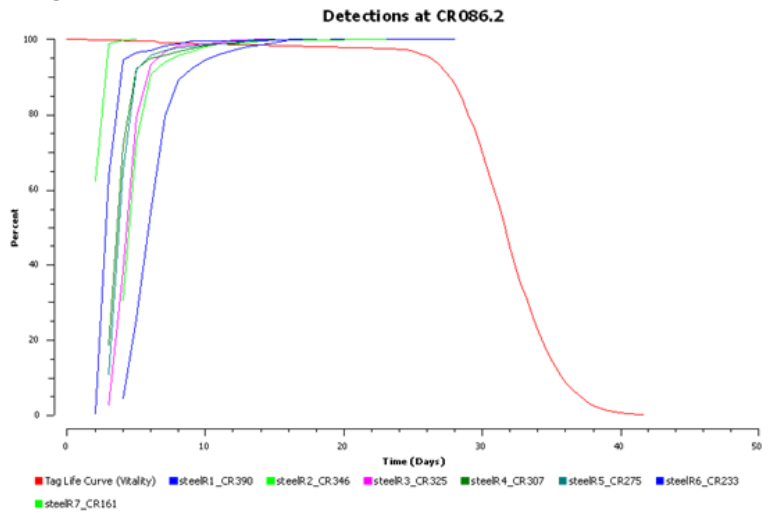

Tag lot 2

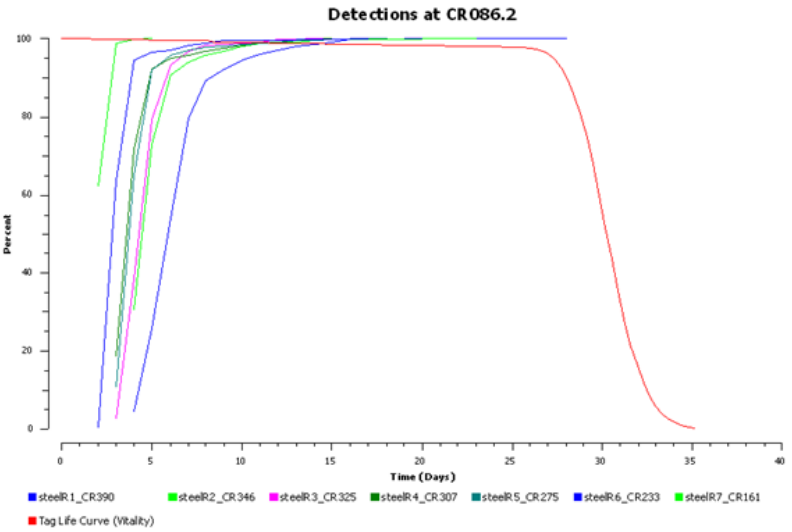

Tag lots $3-5$

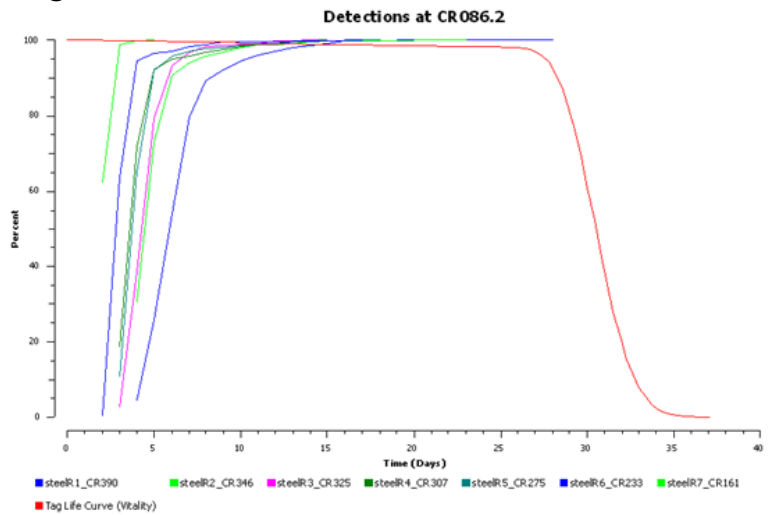

Figure 3.10. Plots of the fitted tag-life survivorship curves for tag lots 1,2,3-5 and the arrival-time distributions of steelhead smolts for releases from CR390, CR346, CR325, CR307, CR275, CR233, and CR161 at the acoustic-detection array located at rkm 86 (Figure 2.1).

\subsubsection{Downstream Mixing}

The virtual release from the face of Bonneville Dam was continuously formed from the smolts arriving throughout day and night. To help induce downstream mixing of the release groups, the $R_{2}$ release was $21 \mathrm{~h}$ before the $R_{3}$ release, based on travel times through that reach in an average year. This release schedule was used for both the yearling Chinook salmon and steelhead smolts. Plots of the arrival timing of the various release groups at downstream detection sites indicate reasonable mixing for both yearling Chinook salmon (Figure 3.11) and steelhead (Figure 3.12) smolts. The survival modes for releases $R_{2}$ and $R_{3}$ were nearly synchronous. The virtual release $\left(V_{1}\right)$ from the face of Bonneville Dam was continuous and, for this reason, its arrival distribution was not plotted in association with those of $R_{2}$ and $R_{3}$. 
Table 3.3. Estimated probabilities $(L)$ of an acoustic tag being active at a downstream detection site for (a) yearling Chinook salmon smolts and (b) steelhead smolts by tag lot and release group. (Standard errors are in parentheses.)

\begin{tabular}{|c|c|c|c|c|}
\hline \multirow[b]{2}{*}{ Release Group } & \multirow[b]{2}{*}{ Tag Lot } & \multicolumn{3}{|c|}{ Detection Site } \\
\hline & & rkm 161 & rkm 113 & rkm 86 \\
\hline \multirow[t]{3}{*}{$V_{1}(\mathrm{Rkm} 390)^{(\mathrm{a})}$} & 1 & $0.9985(0.0011)$ & $0.9977(0.0016)$ & $0.9974(0.0019)$ \\
\hline & 2 & $0.9991(0.0007)$ & $0.9987(0.0010)$ & $0.9985(0.0012)$ \\
\hline & $3-5$ & $0.9995(0.0016)$ & $0.9992(0.0025)$ & $0.9990(0.0031)$ \\
\hline \multirow[t]{3}{*}{$V_{1}(\mathrm{Rkm} \mathrm{346})^{(\mathrm{a})}$} & 1 & $0.9983(0.0014)$ & $0.9978(0.0018)$ & $0.9974(0.0021)$ \\
\hline & 2 & $0.9991(0.0008)$ & $0.9985(0.0012)$ & $0.9984(0.0013)$ \\
\hline & $3-5$ & $0.9995(0.0016)$ & $0.9992(0.0025)$ & $0.9990(0.0032)$ \\
\hline \multirow[t]{3}{*}{$V_{1}\left(\mathrm{Rkm} \mathrm{325)^{( \textrm {a } ) }}\right.$} & 1 & $0.9986(0.0011)$ & $0.9980(0.0016)$ & 0.9977 (0.0019) \\
\hline & 2 & $0.9990(0.0008)$ & $0.9986(0.0011)$ & $0.9983(0.0013)$ \\
\hline & $3-5$ & $0.9995(0.0015)$ & $0.9992(0.0024)$ & $0.9990(0.0032)$ \\
\hline \multirow[t]{3}{*}{$V_{1}\left(\mathrm{Rkm} \mathrm{307)^{( \textrm {a } ) }}\right.$} & 1 & $0.9985(0.0012)$ & $0.9979(0.0018)$ & $0.9975(0.0021)$ \\
\hline & 2 & $0.9990(0.0008)$ & $0.9985(0.0012)$ & $0.9983(0.0014)$ \\
\hline & $3-5$ & $0.9991(0.0017)$ & $0.9992(0.0025)$ & $0.9990(0.0033)$ \\
\hline \multirow{3}{*}{$V_{1}(\mathrm{Rkm} 275)^{(\mathrm{a})}$} & 1 & $0.9983(0.0014)$ & $0.9975(0.0020)$ & $0.9973(0.0022)$ \\
\hline & 2 & $0.9989(0.0009)$ & $0.9984(0.0013)$ & $0.9982(0.0014)$ \\
\hline & $3-5$ & $0.9992(0.0020)$ & $0.9991(0.0029)$ & $0.9989(0.0035)$ \\
\hline \multirow[t]{3}{*}{$R_{2}(\mathrm{Rkm} 233)$} & 1 & -- & $0.9950(0.0041)$ & $0.9947(0.0043)$ \\
\hline & 2 & -- & $0.9966(0.0027)$ & $0.9963(0.0029)$ \\
\hline & $3-5$ & -- & $0.9976(0.0067)$ & $0.9973(0.0075)$ \\
\hline \multirow[t]{3}{*}{$R_{3}(\mathrm{Rkm} 161)$} & 1 & -- & $0.9972(0.0024)$ & $0.9967(0.0027)$ \\
\hline & 2 & -- & $0.9977(0.0018)$ & $0.9974(0.0020)$ \\
\hline & $3-5$ & -- & $0.9982(0.0048)$ & $0.9981(0.0053)$ \\
\hline & & b. Steelhead & & \\
\hline \multirow[t]{3}{*}{$V_{1}(\mathrm{Rkm} 390)^{(\mathrm{a})}$} & 1 & $0.9987(0.0011)$ & $0.9983(0.0016)$ & $0.9978(0.0019)$ \\
\hline & 2 & $0.9991(0.0008)$ & $0.9987(0.0011)$ & $0.9985(0.0013)$ \\
\hline & $3-5$ & $0.9994(0.0017)$ & $0.9992(0.0025)$ & $0.9991(0.0030)$ \\
\hline \multirow[t]{3}{*}{$V_{1}(\operatorname{Rkm} 346)^{(\mathrm{a})}$} & 1 & $0.9985(0.0014)$ & $0.9979(0.0019)$ & $0.9978(0.0021)$ \\
\hline & 2 & $0.9992(0.0008)$ & $0.9987(0.0011)$ & $0.9985(0.0013)$ \\
\hline & $3-5$ & $0.9995(0.0016)$ & $0.9992(0.0026)$ & $0.9990(0.0031)$ \\
\hline \multirow[t]{3}{*}{$V_{1}(\mathrm{Rkm} 325)^{(\mathrm{a})}$} & 1 & $0.9986(0.0013)$ & $0.9981(0.0018)$ & $0.9979(0.0020)$ \\
\hline & 2 & $0.9989(0.0010)$ & $0.9985(0.0013)$ & $0.9985(0.0014)$ \\
\hline & $3-5$ & $0.9994(0.0017)$ & $0.9992(0.0025)$ & $0.9990(0.0032)$ \\
\hline \multirow[t]{3}{*}{$V_{1}(\mathrm{Rkm} \mathrm{307})^{(\mathrm{a})}$} & 1 & $0.9985(0.0014)$ & $0.9978(0.0020)$ & $0.9977(0.0021)$ \\
\hline & 2 & $0.9990(0.0009)$ & $0.9985(0.0013)$ & $0.9984(0.0014)$ \\
\hline & $3-5$ & $0.9993(0.0020)$ & $0.9991(0.0028)$ & $0.9990(0.0033)$ \\
\hline \multirow[t]{3}{*}{$V_{1}(\mathrm{Rkm} \mathrm{275})^{(\mathrm{b})}$} & 1 & $0.9984(0.0015)$ & $0.9978(0.0021)$ & $0.9976(0.0022)$ \\
\hline & 2 & $0.9986(0.0011)$ & $0.9985(0.0013)$ & $0.9983(0.0015)$ \\
\hline & $3-5$ & $0.9994(0.0018)$ & $0.9991(0.0028)$ & $0.9990(0.0033)$ \\
\hline \multirow[t]{3}{*}{$R_{2}(\mathrm{Rkm} 233)$} & 1 & -- & $0.9957(0.0040)$ & $0.9952(0.0044)$ \\
\hline & 2 & -- & $0.9968(0.0028)$ & $0.9966(0.0030)$ \\
\hline & $3-5$ & -- & $0.9976(0.0070)$ & $0.9974(0.0076)$ \\
\hline \multirow[t]{3}{*}{$R_{3}(\mathrm{Rkm} 161)$} & 1 & -- & $0.9972(0.0026)$ & $0.9969(0.0029)$ \\
\hline & 2 & -- & $0.9977(0.0020)$ & $0.9976(0.0022)$ \\
\hline & $3-5$ & -- & $0.9982(0.0053)$ & $0.9981(0.0056)$ \\
\hline
\end{tabular}

(a) Conditional probabilities of a tag being active, given they were active when a fish first arrived at the dam face. 
(a) $\mathrm{rkm} 113$

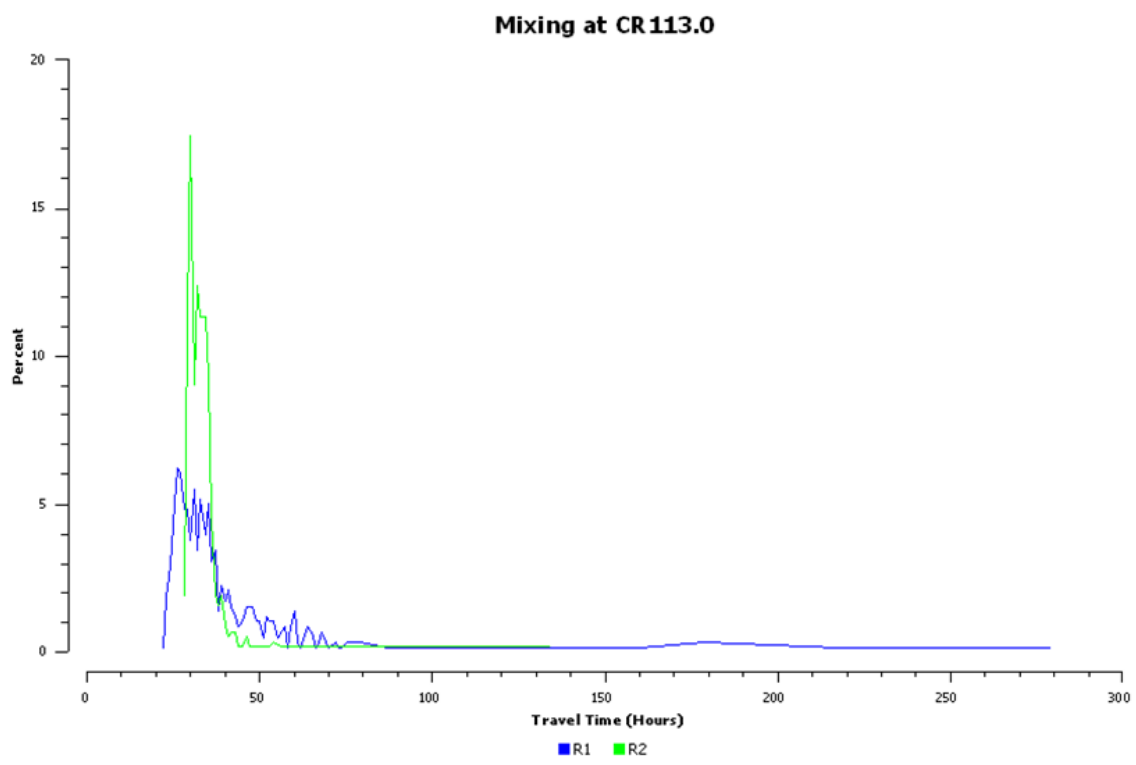

(b) $\mathrm{rkm} 86$

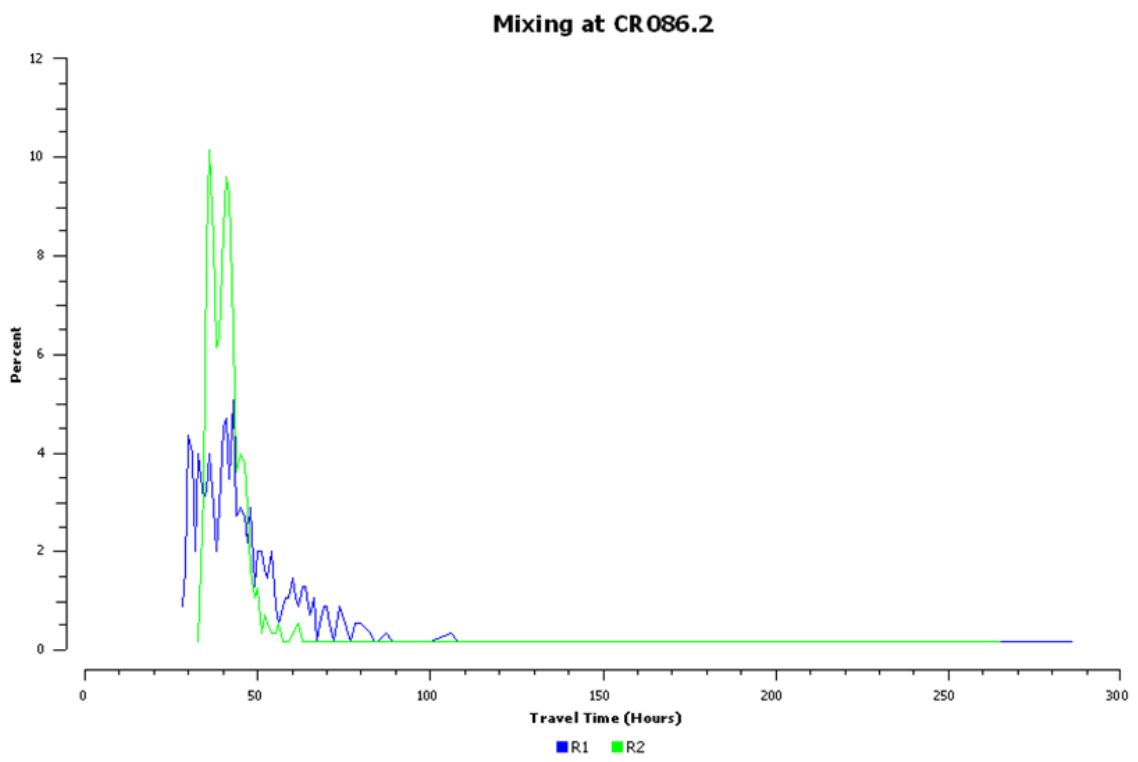

Figure 3.11. Frequency distribution plots of downstream arrival timing (expressed as percentages) for yearling Chinook salmon releases $R_{2}$ and $R_{3}$ at detection arrays located at (a) rkm 113 and (b) rkm 86 (see Figure 2.1). 
(a) $\mathrm{rkm} 113$

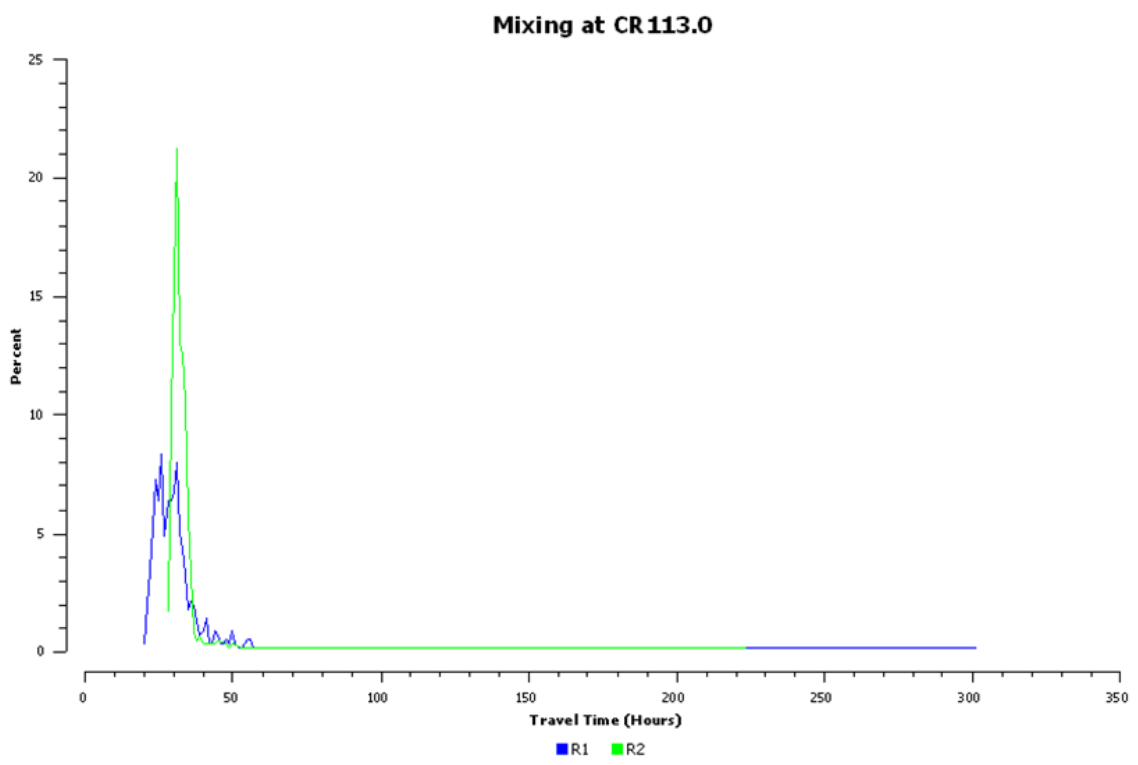

(b) $\mathrm{rkm} 86$

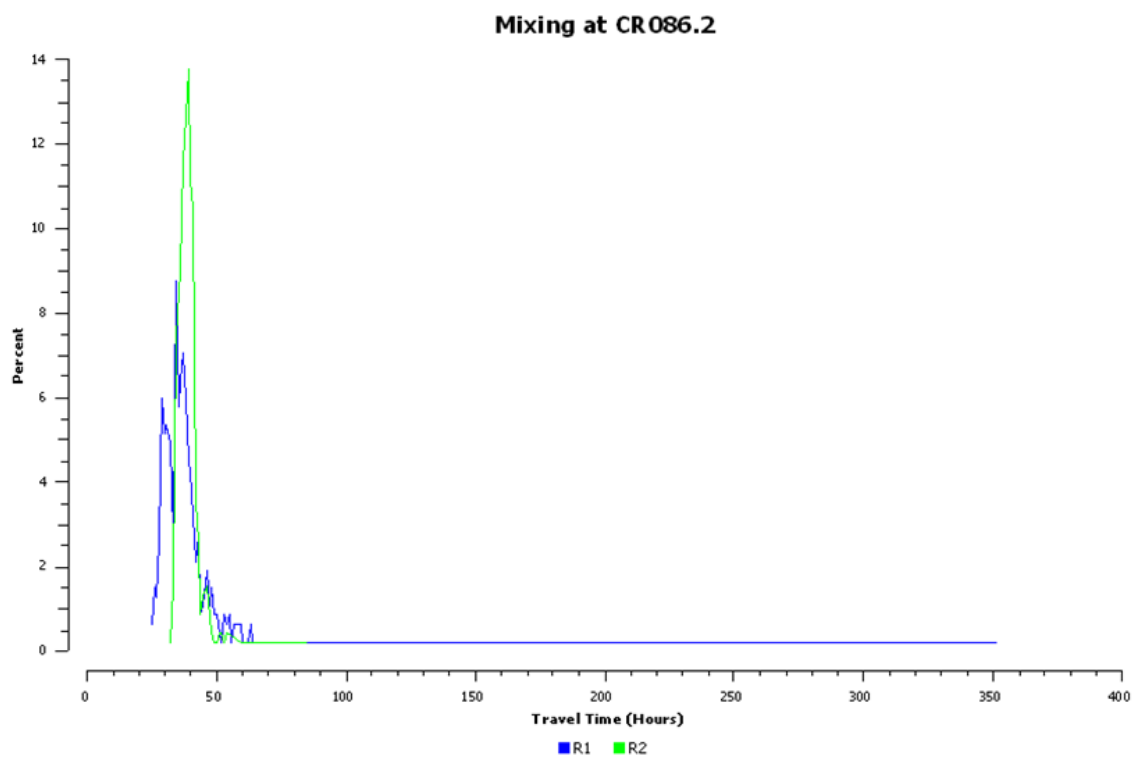

Figure 3.12. Frequency distribution plots of downstream arrival timing (expressed as percentages) for steelhead releases $R_{2}$ and $R_{3}$ at detection arrays located at (a) rkm 113 and (b) rkm 86 (see Figure 2.1).

\subsection{Survival and Passage Performance}

Survival and passage performance metrics include dam passage survival, forebay-to-tailrace passage survival, forebay residence time, tailrace to egress time, SPE, spill + B2CC passage efficiency, and FPE. 


\subsubsection{Dam Passage Survival}

\subsubsection{Yearling Chinook Salmon}

The estimates of dam passage survival for yearling Chinook salmon smolts at Bonneville Dam were calculated for two periods of time. One period was from the beginning of the study on 27 April 2011 through 13 May 2011, while flows were moderate and spill was held at $100 \mathrm{kcfs}$. The second time period was from the beginning to the end of the study on 30 May 2011 and includes the higher flow and spill levels later in the season (Figure 3.1).

For the early part of the study, dam passage survival was estimated to be

$$
\hat{S}_{\text {Dam }}=0.9569
$$

with a standard error of $\widehat{\mathrm{SE}}=0.0042$. This estimate was not corrected for survival between release locations for $R_{2}$ and $R_{3}$, because the paired release estimated survival in that extra reach to be

$$
\frac{0.9942}{0.9857}=1.0086
$$

Therefore, the more reasonable approach was to assume the extra-reach survival between rkm 233 and 161 to be 1.0 and estimate dam passage survival using the virtual release $\left(V_{1}\right)$ to rkm 161 (Error! Not a valid bookmark self-reference.).

Table 3.4. Survival, detection, and $\lambda$ parameters for final model used to estimate dam passage survival for yearling Chinook salmon smolts during the early part of spring (30 April to 13 May 2011).

\begin{tabular}{|c|c|c|c|c|}
\hline \multirow[b]{2}{*}{ Release } & \multicolumn{3}{|c|}{$\hat{S}$} & \multirow{2}{*}{$\begin{array}{c}\hat{\lambda} \\
\text { CR113-CR86.2 } \\
\end{array}$} \\
\hline & CR234-161 & CR161-113 & Release-CR113 & \\
\hline$V_{1}$ & $0.9569(0.0042)$ & $0.9951(0.0033)$ & & $0.9256(0.0060)$ \\
\hline$R_{2}$ & & & $0.9923(0.0088)$ & $0.9305(0.0051)$ \\
\hline \multirow[t]{2}{*}{$R_{3}$} & & & $0.9808(0.0099)$ & $0.9305(0.0051)$ \\
\hline & \multicolumn{2}{|c|}{$\hat{p}$} & & \\
\hline Release & CR161 & CR113 & & \\
\hline$V_{1}$ & $0.9528(0.0044)$ & $0.8102(0.0084)$ & & \\
\hline$R_{2}$ & & $0.8123(0.0217)$ & & \\
\hline$R_{3}$ & & $0.8145(0.0218)$ & & \\
\hline
\end{tabular}
Standard errors in parentheses.

For the entire study period, dam passage survival for yearling Chinook salmon is estimated to be 


$$
\hat{S}_{\text {Dam }}=\frac{0.9584}{\left(\frac{0.9531}{0.9544}\right)}=\frac{0.9584}{0.9986}=0.9597
$$

with a standard error of $\widehat{\mathrm{SE}}=0.0176$ (Error! Not a valid bookmark self-reference.). Likelihood ratio tests indicated the detection probability at CR113 and the $\lambda(=S \cdot p)$ parameters in the last reach were homogeneous between the three release groups, allowing estimation using a reduced model $\left.P\left(\chi_{4}^{2} \geq 2.9220\right)=0.5710\right)$. Because the full model did not achieve the prescribed level of precision in the $2008 \mathrm{BiOp}$, model evaluation was used to find a more parsimonious model that validly equated downstream parameter values between release groups and improved precision. This more parsimonious model also failed to achieve adequate precision as specified in the $2008 \mathrm{BiOp}$.

Table 3.5. Survival, detection, and $\lambda$ parameters for final model used to estimate dam passage survival for yearling Chinook salmon smolts for the entire study period. Standard errors in parentheses.

\begin{tabular}{ccc}
\hline & & $\hat{S}$ \\
\cline { 2 - 3 } Release & CR234-161 & CR161-113 \\
\hline$V_{1}$ & $0.9584(0.0035)$ & $0.9555(0.0057)$ \\
$R_{2}$ & \\
$R_{3}$ & \\
\hline & \multicolumn{2}{c}{$\hat{p}$} \\
\hline Release & CR161 & CR113 \\
\cline { 2 - 3 }$V_{1}$ & $0.8542(0.0051)$ & $0.7571(0.0062)$ \\
$R_{2}$ & & $0.7571(0.0062)$ \\
$R_{3}$ & & $0.7571(0.0062)$ \\
\hline
\end{tabular}

\subsubsection{Steelhead}

For the initial period of the study before high flow levels began (i.e., 30 April-13 May 2011), the dam passage survival for steelhead was estimated to be

$$
\hat{S}_{\text {Dam }}=\frac{0.9527}{\left(\frac{0.9634}{0.9865}\right)}=\frac{0.9527}{0.9766}=0.9755
$$

with an associated standard error of $\widehat{\mathrm{SE}}=0.0180$ (Table 3.6). A likelihood ratio test found that the downstream detection and survival for the three release groups could not be equated $\left(P\left(\chi_{4}^{2} \geq 9.0592\right)=0.0600\right)$ and, as such, a full model was used in parameter estimation. 
For the entire spring study, dam passage survival for steelhead was estimated to be

$$
\hat{S}_{\text {Dam }}=\frac{0.9491}{\left(\frac{0.9247}{0.9398}\right)}=\frac{0.9491}{0.9839}=0.9647
$$

with an estimated standard error of $\widehat{\mathrm{SE}}=0.0212$. A likelihood ratio found the downstream detection and $\lambda(=S \cdot p)$ parameters were not significantly different between the three release groups $\left(P\left(\chi_{4}^{2} \geq 5.1830\right)=0.2690\right)$ and, as such, the estimate of dam passage survival was based on a reduced model (Table 3.7). Despite the reduced model, precision was not adequate to meet the BiOp standard (i.e., $\widehat{\mathrm{SE}}<0.015$ ).

Table 3.6. Survival, detection, and $\lambda$ parameters for final model used to estimate dam passage survival for steelhead smolts during the early part of spring (30 April to 13 May 2011). Standard errors in parentheses.

\begin{tabular}{|c|c|c|c|c|}
\hline \multirow[b]{2}{*}{ Release } & \multicolumn{3}{|c|}{$\hat{S}$} & \multirow{2}{*}{$\begin{array}{c}\hat{\lambda} \\
\text { CR113-CR86.2 }\end{array}$} \\
\hline & CR234-161 & CR161-113 & Release-CR113 & \\
\hline$V_{1}$ & $0.9527(0.0044)$ & $1.0017(0.0042)$ & & $0.8490(0.0082)$ \\
\hline$R_{2}$ & & & $0.9634(0.0134)$ & $0.9634(0.0134)$ \\
\hline \multirow[t]{2}{*}{$R_{3}$} & & & $0.9865(0.0115)$ & $0.9865(0.0115)$ \\
\hline & \multicolumn{2}{|c|}{$\hat{p}$} & & \\
\hline Release & CR161 & CR113 & & \\
\hline$V_{1}$ & $0.9776(0.0031)$ & $0.8049(0.0088)$ & & \\
\hline$R_{2}$ & & $0.8227(0.0221)$ & & \\
\hline$R_{3}$ & & $0.8158(0.0222)$ & & \\
\hline
\end{tabular}

Table 3.7. Survival, detection, and $\lambda$ parameters for final model used to estimate dam passage survival for steelhead smolts for the entire study period. Standard errors in parentheses.

\begin{tabular}{|c|c|c|c|c|}
\hline \multirow[b]{2}{*}{ Release } & \multicolumn{3}{|c|}{$\hat{S}$} & \multirow{2}{*}{$\begin{array}{c}\hat{\lambda} \\
\text { CR113-CR86.2 }\end{array}$} \\
\hline & CR234-161 & CR161-113 & Release-CR113 & \\
\hline$V_{1}$ & $0.9491(0.0036)$ & $0.9594(0.0065)$ & & $0.6199(0.0069)$ \\
\hline$R_{2}$ & & & $0.9247(0.0170)$ & $0.6199(0.0069)$ \\
\hline \multirow[t]{2}{*}{$R_{3}$} & & & $0.9398(0.0156)$ & $0.6199(0.0069)$ \\
\hline & \multicolumn{2}{|c|}{$\hat{p}$} & & \\
\hline Release & CR161 & CR113 & & \\
\hline$V_{1}$ & $0.9164(0.0041)$ & $0.7533(0.0067)$ & & \\
\hline$R_{2}$ & $0.9164(0.0041)$ & $0.7533(0.0067)$ & & \\
\hline$R_{3}$ & $0.9164(0.0041)$ & $0.7533(0.0067)$ & & \\
\hline
\end{tabular}




\subsubsection{Forebay-to-Tailrace Passage Survival}

The estimates of forebay-to-tailrace passage survival were calculated analogously to that of dam passage survival except the virtual-release group $\left(V_{1}\right)$ was composed of fish known to have arrived at the forebay array (i.e., detection array rkm 236, Figure 2.1) rather than at the dam face. The analyses used the same statistical models used in estimating dam passage survival. The full season estimates for yearling Chinook salmon and juvenile steelhead were made from a reduced model because likelihood ratio tests indicated the detection probability at CR113 and the $\lambda(=S \cdot p)$ parameters in the last reach were homogeneous between the three release groups. The full model was used for the early season estimate for yearling Chinook and steelhead.

The estimates of forebay-to-tailrace survival (Table 3.8) were very close to the estimates of dam passage survival, with the greatest difference being 0.0069 across all comparisons. Standard errors were also comparable because sample sizes were nearly the same.

Table 3.8. Summary of the estimates of forebay-to-tailrace survival at Bonneville Dam in 2011 for yearling Chinook salmon and steelhead smolts for early season (30 April-13 May 2011) and the entire study (30 April-31 May 2011). Standard errors in parentheses.

\begin{tabular}{ccc}
\hline Period & Yearling Chinook Salmon & Steelhead \\
\hline Early Season (30 April-13 May) & $0.9579(0.0042)$ & $0.9752(0.0180)$ \\
Season-Wide (30 April-31 May) & $0.9528(0.0175)$ & $0.9589(0.0211)$ \\
\hline
\end{tabular}

\subsubsection{Forebay Residence Time}

The forebay residence times were based on the times from the first detection at the forebay (BRZ) array to the last detection at the double array in front of Bonneville Dam. The forebay array was located $2 \mathrm{~km}$ upstream of the dam.

The majority of the yearling Chinook salmon and steelhead had a forebay residence time of $\leq 1 \mathrm{~h}$ with a mode between 0 and $0.5 \mathrm{~h}$ (Figure 3.13). Median residence times were $0.55 \mathrm{~h}$ and $0.85 \mathrm{~h}$ for yearling Chinook salmon and steelhead, respectively (Table 3.9). Mean forebay residence time for yearling Chinook salmon smolts was estimated to be $5.34 \mathrm{~h}(\widehat{\mathrm{SE}}=0.46)$ and for steelhead smolts, $7.00 \mathrm{~h}$ $(\widehat{\mathrm{SE}}=0.43)$. 
(a) Yearling Chinook salmon

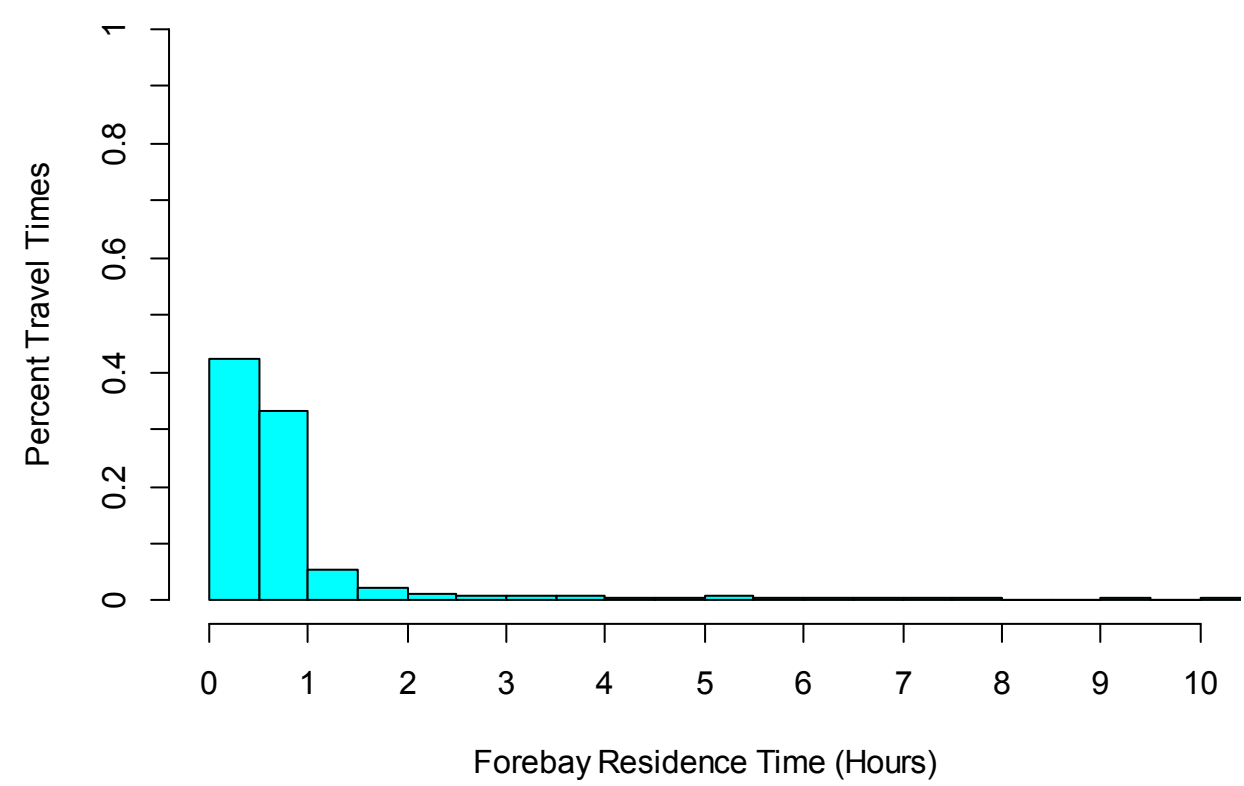

(b) Steelhead

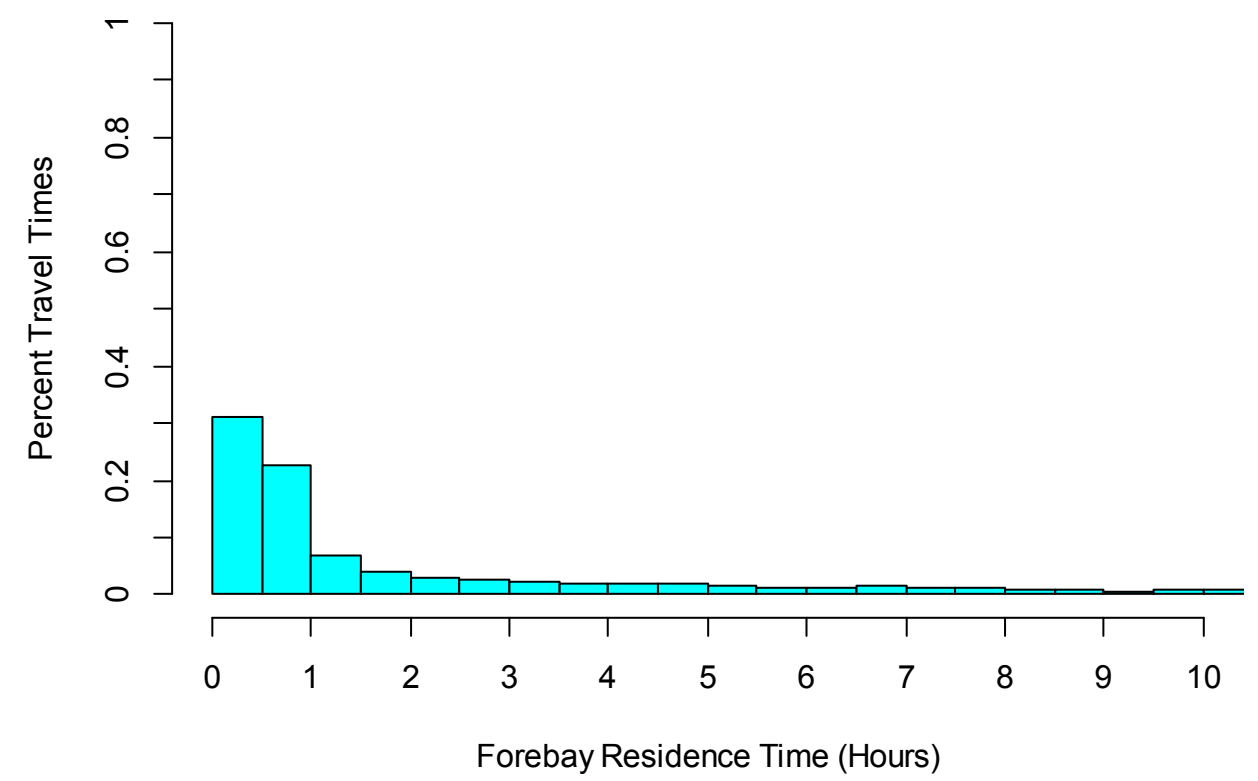

Figure 3.13. Distribution of forebay residence times for (a) yearling Chinook salmon and (b) steelhead smolts at Bonneville Dam, 2011.

Table 3.9. Estimated mean and median forebay residence times (h) and mean and median tailrace egress times (h) for yearling Chinook salmon and steelhead smolts at Bonneville Dam in 2011.

\begin{tabular}{lcccc}
\hline & \multicolumn{2}{c}{ Yearling Chinook Salmon } & \multicolumn{2}{c}{ Steelhead } \\
\cline { 2 - 5 } Performance Measure & Mean & Median & Mean & Median \\
\hline Forebay Residence Time & $5.34 \mathrm{~h}(0.46)$ & $0.55 \mathrm{~h}$ & $7.00 \mathrm{~h}(0.43)$ & $0.85 \mathrm{~h}$ \\
Tailrace Egress Time & $1.89 \mathrm{~h}(0.19)$ & $0.38 \mathrm{~h}$ & $3.77 \mathrm{~h}(0.32)$ & $0.39 \mathrm{~h}$ \\
\hline
\end{tabular}




\subsubsection{Tailrace Egress Time}

The tailrace egress time was calculated based on the time from the last detection of fish at the double array at the face of Bonneville Dam to the last detection at the BRZ tailrace array. The tailrace array was located $1 \mathrm{~km}$ below the dam. The majority of the yearling Chinook salmon and steelhead had a tailrace regress time of $\leq 0.5 \mathrm{~h}$ (Figure 3.14). Mean tailrace egress time for yearling Chinook salmon smolts was estimated to be $1.89 \mathrm{~h}(\widehat{\mathrm{SE}}=0.19)$. For steelhead smolts, mean tailrace egress time was estimated to be $3.77 \mathrm{~h}(\widehat{\mathrm{SE}}=0.32)$. Median egress times were $0.38 \mathrm{~h}$ for yearling Chinook salmon and $0.39 \mathrm{~h}$ for steelhead (Table 3.9).

(a) Yearling Chinook salmon

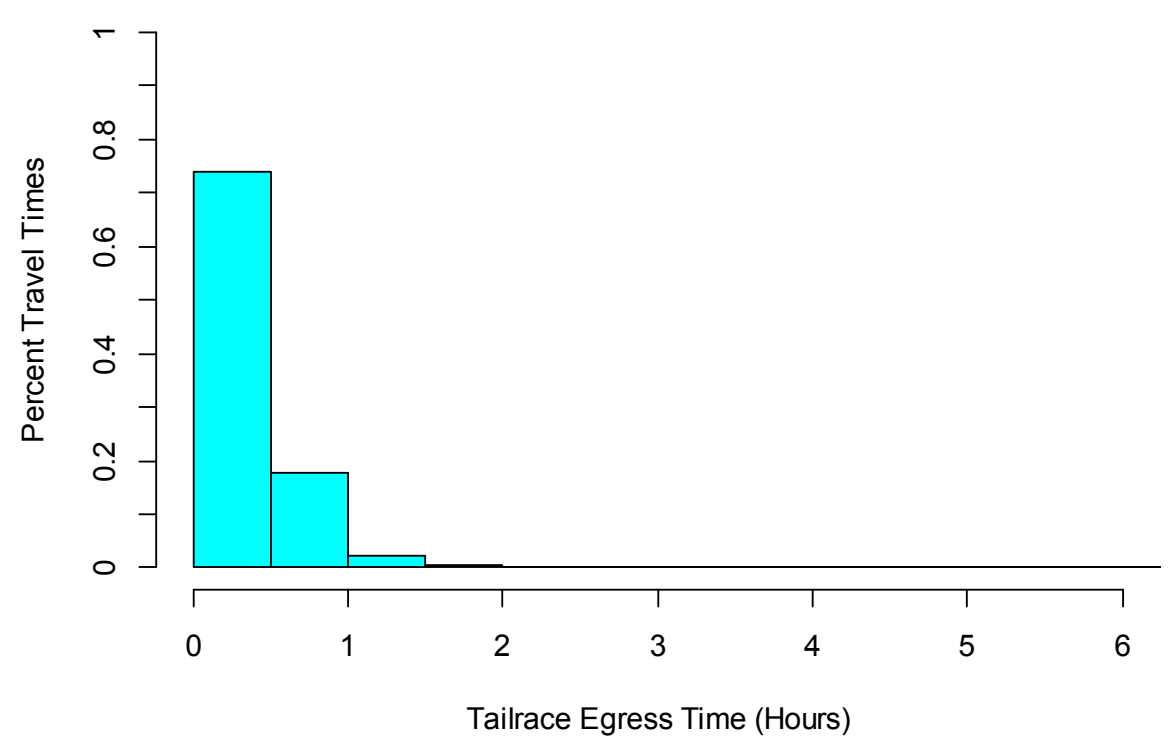

(b) Steelhead

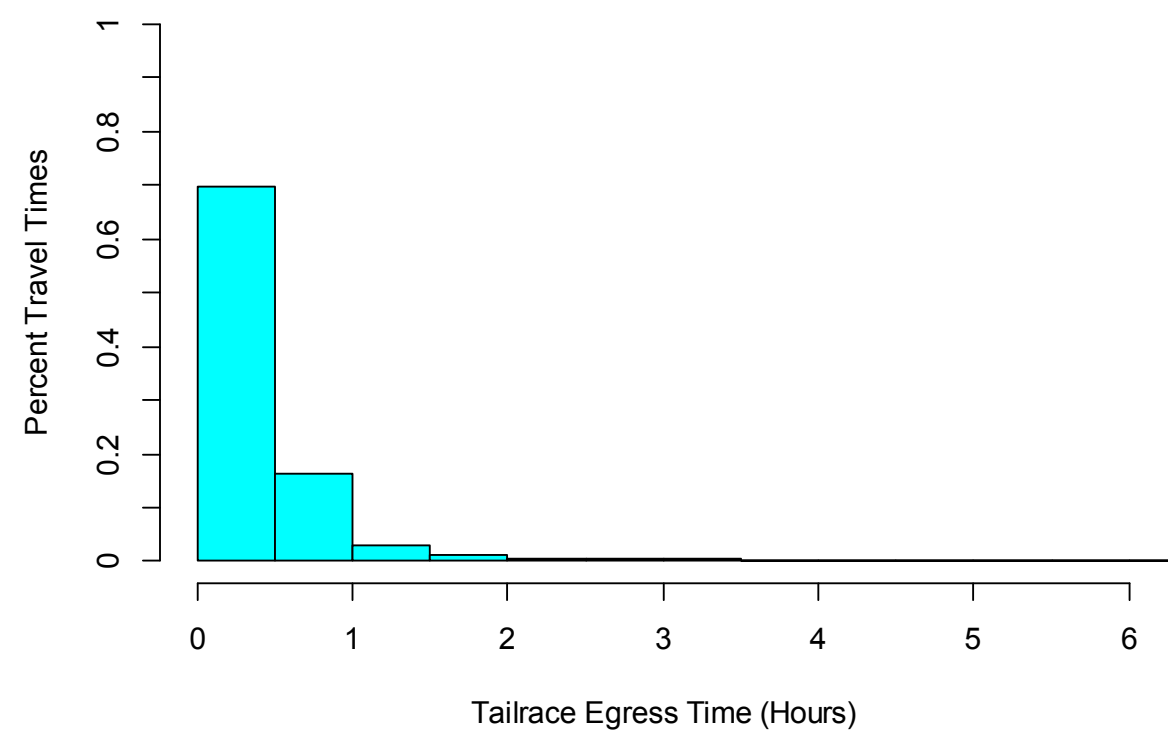

Figure 3.14. Distribution of tailrace egress times for (a) yearling Chinook salmon and (b) steelhead smolts at Bonneville Dam, 2011. 


\subsubsection{Spill Passage Efficiency}

SPE is defined as the fraction of the fish that passed through a hydro project by the spillway. The double-detection array at the face of Bonneville Dam was used to identify and track fish as they entered the forebay. Using the observed counts and assuming a common detection probability at all routes, SPE was calculated using a binomial sampling model. For yearling Chinook smolts, SPE $=$ $0.5660(\widehat{\mathrm{SE}}=0.0067)$, and for steelhead smolts, $\mathrm{SPE}=0.5443(\widehat{\mathrm{SE}}=0.0066)$.

\subsubsection{Spill + B2CC Passage Efficiency}

The 2008 Fish Accords required an estimate of spill + B2CC passage efficiency, which the Fish Accords referred to as spill passage efficiency. We calculated this metric by dividing the numbers of fish tracked passing the spillway and B2CC by the total number passing the dam, assuming a common detection probability at all routes and a binomial sampling model. For yearling Chinook salmon smolts, the estimate of this proportion was $0.5959(\widehat{\mathrm{SE}}=0.0066)$; for juvenile steelhead, it was

$0.6406(\widehat{\mathrm{SE}}=0.0064)$.

\subsubsection{Fish Passage Efficiency}

FPE is the fraction of the fish that passed through a hydropower project by the spillway, the B1 sluiceway, the B2CC, and the B2JBS. As with SPE, the double-detection array at the face of Bonneville Dam was used to identify and track fish as they entered the dam. Using the observed counts and assuming a common detection probability at all passage routes, FPE was calculated using a binomial sampling model. For yearling Chinook salmon smolts at Bonneville Dam in 2011, FPE is estimated to be $\mathrm{FPE}=0.7070(\widehat{\mathrm{SE}}=0.0061)$, and for steelhead smolts, $\mathrm{FPE}=0.7401(\widehat{\mathrm{SE}}=0.0058)$. 


\subsection{Discussion}

The discussion describes the effect of high flow conditions on the study results for 2011, study performance, and compares results for 2010 and 2011.

\subsection{Study Conduct}

The large spring runoffs in 2011 resulted in higher flow volumes and more spill at Bonneville Dam than initially planned. The conditions affected the 2011 JSATS compliance studies at Bonneville Dam in three ways. Most notably, the summer subyearling Chinook salmon compliance study was cancelled. Secondly, the planned $100 \mathrm{kcfs}$ spill level was interrupted beginning on 13 May 2011 with spill levels exceeding $200 \mathrm{kcfs}$ by the end of the spring investigations (Figure 3.1). Detection probabilities at the below-Bonneville-Dam hydrophone arrays were much lower than anticipated. Detection probabilities at CR161 ranged from 0.85 to 0.95 , while prior experience experienced +0.95 . At CR113, observed detection probabilities ranged from 0.75 to 0.82 rather than the 0.90 that was anticipated. These lower detection probabilities resulted in lower precision for the estimates of dam passage survival than required by the BiOp. The estimated standard errors from the virtual/paired-release design ranged from 0.0176 to 0.0212 instead of being $\leq 0.0150$.

The Pacific Northwest is anticipating spring 2012 to be similar to spring 2011. If so, the study design will need to compensate for higher flow volumes and anticipated lower detection probabilities next year. Planned actions to improve detection probabilities in 2012 include increasing the numbers of $R_{2}$ and $R_{3}$ released fish from 800 to 1000 per site, deploying two additional autonomous nodes at each survival detection array, and reducing the pulse repetition rate for tags implanted in $R_{2}$ and $R_{3}$ fish from $3 \mathrm{~s}$ to $2 \mathrm{~s}$.

\subsection{Study Performance}

The high flows and greater spill during the latter part of the compliance studies did not necessarily appear to improve dam passage survivals. For steelhead smolts, the estimate of dam passage survival was lower for the entire season compared to the early season but not significantly so (see Section 3.3.1). For yearling Chinook salmon smolts, the estimate of dam passage survival was greater for the season-wide estimate than the early season estimate, but not significantly so. The yearling Chinook salmon estimate of dam passage survival missed the $2008 \mathrm{BiOp}$ criterion of $S \geq 0.96$ by a fraction of a percentage point, with a value of 0.9597 , using data from the entire spring study. For the steelhead smolts, both the early and entire season estimates of dam passage survival exceeded the threshold of 0.96 , but neither estimate had a standard error $\leq 0.015$.

\subsection{Cross-Year Summary}

In 2010, no formal compliance studies were performed at Bonneville Dam, but available equipment was used to estimate survival from the face of the dam to a hydrophone array $81 \mathrm{~km}$ below the dam (CR153) using a single release-recapture model. In essence, it was the virtual release $V_{1}$ by itself without correction for any extra-mortality between the tailrace and the downstream detection array. Hence, the single-release estimates using just the virtual releases at the dam face should be conservative. 
The compliance results for 2010 and 2011, using either single-release or virtual/paired-release models, are summarized in Table 4.1. For 2011, the season-wide estimates are reported in Table 4.1. For yearling Chinook salmon, the season-wide estimate is higher than the early season estimate of dam passage survival. For steelhead smolts, the pattern is reversed. These 2011 values represent dam passage survival under the prevailing conditions in 2011, which included standard spring operating conditions at Bonneville Dam, followed by mandatory changes in dam operations due to emergency flood conditions.

Table 4.1. Summary of 2010 and 2011 estimates of dam passage survival using best available information from either a conservative single-release model or the virtual/paired-release model by fish stock. Season-wide estimates reported for 2011.

\begin{tabular}{|c|c|c|c|}
\hline Year & Yearling Chinook Salmon & Steelhead & Subyearling Chinook Salmon \\
\hline 2010 & $0.952(0.0040)^{(\mathrm{a})}$ & $0.945(0.0043)^{(\mathrm{a})}$ & $0.958(0.0055)^{(\mathrm{a})}$ \\
\hline 2011 & $0.9597(0.0176)$ & $0.9647(0.0212)$ & N/A \\
\hline
\end{tabular}




\subsection{References}

3 Treaty Tribes-Action Agencies. 2008. Memorandum of Agreement Among the Umatilla, Warm Springs and Yakama Tribes, Bonneville Power Administration, U.S. Army Corps of Engineers, and U.S. Bureau of Reclamation, Portland, Oregon, April 4, 2008. Available at

http://www.salmonrecovery.gov/ColumbiaBasinFishAccords.aspx.

Burnham KP, DR Anderson, GC White, C Brownie, and KH Pollock. 1987. "Design and analysis methods for fish survival experiments based on release-recapture." American Fisheries Society Monograph 5.

Columbia Basin Surgical Protocol Steering Committee. 2011. Surgical Protocols for Implanting JSATS Transmitters into Juvenile Salmonids for Studies Conducted for the U.S. Army Corps of Engineers. V1, 21 pp. U.S. Army Corps of Engineers, Portland District, Portland, Oregon.

Li T and JJ Anderson. 2009. "The vitality model: A way to understand population survival and demographic heterogeneity." Theoretical Population Biology 76:118-131.

Mantel N and W Haenszel. 1959. "Statistical Aspects of the Analysis of Data from Retrospective Studies of Disease." Journal of the National Cancer Institute 22:719-748.

Martinson R, G Kovalchuk, and D Ballinger. 2006. "Monitoring of downstream salmon and steelhead at federal hydroelectric facilities." 2005-2006 Annual Report, Project No. 198712700, BPA Report DOE/BP-00022085-2, Portland, Oregon.

Seber GAF. 1982. The Estimation of Animal Abundance. MacMillan, New York.

Skalski JR, GE Johnson, and TJ Carlson. 2010a. Compliance monitoring of juvenile yearling Chinook salmon and steelhead survival and passage at The Dalles Dam, Spring 2010. PNNL-19819, summary report submitted to the U.S. Army Corps of Engineers, Portland District, Portland, Oregon, by Pacific Northwest National Laboratory, Richland, Washington.

Skalski JR, RL Townsend, TW Steig, and S Hemstrom. 2010b. "Comparison of two alternative approaches for estimating dam passage survival using acoustic-tagged sockeye salmon smolts." North American Journal of Fisheries Management 30:831-839.

Townsend RL, JR Skalski, P Dillingham, and TW Steig. 2006. "Correcting bias in survival estimation resulting from tag failure in acoustic and radiotelemetry studies." Journal of Agricultural Biology and Environmental Statistics 11(2):183-196.

Weiland MA, GR Ploskey, JS Hughes, Z Deng, T Fu, TJ Monter, GE Johnson, F Khan, MC Wilberding, AW Cushing, SA Zimmerman, DM Faber, KM Carter, JW Boyd, RL Townsend, JR Skalski, J Kim, ES Fischer, and MM Meyer. 2010. Acoustic Telemetry Evaluation of Juvenile Salmonid Passage and Survival Proportions at John Day Dam, 2009. PNNL-19422, draft final report submitted to the U.S. Army Corps of Engineers, Portland District, Portland, Oregon, by Pacific Northwest National Laboratory, Richland, Washington. 
Appendix A

Tests of Assumptions 


\section{Appendix A}

\section{Tests of Assumptions}

\section{A.1 Tagger Effects}

All of the data from the seven releases associated with the three-dam study were examined for tagger effects. This was done because of the interrelationship between the multiple releases and estimation of dam passage survival at a specific location and to increase the statistical power to detect effects.

To minimize any tagger effects that might go undetected, tagger effort should be balanced across release locations and within replicates. A total of eight taggers participated in the tagging of yearling Chinook salmon and steelhead. Tagger effort was found to be balanced across the seven release locations regardless whether the data were pooled across species $\left(P\left(\chi_{42}^{2} \geq 27.70\right)=0.9562\right)$ or analyzed separately by yearling Chinook salmon $\left(P\left(\chi_{42}^{2} \geq 22.68\right)=0.9935\right)$ or steelhead $\left(P\left(\chi_{42}^{2} \geq 10.62\right)=1.00\right)$ (Table A.1).

Tagger effort was also examined within each the 32 replicate releases conducted over the course of the season (Table A.2). Tagger effort was found to be balanced within replicates 1, 2, 5, 6, 9, 10, 13, 14, $17,18,21,22,25,26,29$, and $30(P \geq 0.9982)$. To accommodate staff time off during the month-long study, tagger effort was conditionally balanced within the individual project releases (i.e., R1-R3, R4-R5, and R6-R7) for the remaining replicates $(P \geq 0.7459)$ (Table A.2). This conditional and unconditional balance within replicates is the reason for the overall balance observed in Table A.1. To minimize the number of contingency tables presented, results in Table A.2 are pooled across species.

To test for tagger effects, reach survivals and cumulative survivals were calculated for fish tagged by different staff members on a release location (i.e., R1, .., R7) and species basis (Table A.3). Of the 56 tests of homogeneous reach survivals, 7 were found to be significant at $\alpha=0.10$ (i.e., $12.5 \%$ ). By chance alone, we might expect $10 \%$ of 56 tests (i.e., 5.6) to be significant at $\alpha=0.10$ when no effect exists. There was no consistent pattern, with two taggers responsible for 2 of 7 significant results each, and three taggers responsible for 1 significant result each. Similarly, only 2 of $54(3.7 \%)$ tests of the homogeneous cumulative survivals were found to be significant at $\alpha=0.10$. Therefore, fish tagged by all taggers were considered acceptable for the survival analyses. 
Table A.1. Numbers of yearling Chinook salmon and steelhead tagged by each staff member by release locations (R1, R2, .., R7). Chi-square tests of homogeneity were not significant.

a. Yearling Chinook salmon and steelhead releases pooled

\begin{tabular}{ccccccccc}
\hline \multirow{2}{*}{$\begin{array}{c}\text { Release } \\
\text { Location }\end{array}$} & \multicolumn{7}{c}{ Tagger } \\
\cline { 2 - 9 } & Amanda & Kate & Kathleen & Kyle & MaryBeth & Rhonda & Shon & Tyrell \\
\hline R1-CR390 & 581 & 576 & 668 & 569 & 528 & 456 & 899 & 820 \\
R2-CR346 & 279 & 254 & 302 & 263 & 293 & 227 & 388 & 383 \\
R3-CR325 & 193 & 173 & 197 & 176 & 196 & 148 & 248 & 265 \\
R4-CR307 & 195 & 176 & 197 & 168 & 200 & 150 & 249 & 264 \\
R5-CR275 & 190 & 172 & 195 & 176 & 201 & 152 & 242 & 271 \\
R6-CR233 & 189 & 179 & 190 & 179 & 196 & 150 & 246 & 261 \\
R7-CR161 & 192 & 178 & 196 & 179 & 191 & 141 & 246 & 265 \\
\hline & & & & & & $P\left(\chi_{42}^{2} \geq 27.70\right)=0.9562$
\end{tabular}

b. Yearling Chinook salmon

\begin{tabular}{ccccccccc}
\hline \multirow{2}{*}{$\begin{array}{c}\text { Release } \\
\text { Location }\end{array}$} & \multicolumn{7}{c}{ Tagger } \\
\cline { 2 - 8 } & Amanda & Kate & Kathleen & Kyle & MaryBeth & Rhonda & Shon & Tyrell \\
\hline R1-CR390 & 280 & 292 & 335 & 284 & 252 & 216 & 447 & 404 \\
R2-CR346 & 136 & 127 & 147 & 133 & 149 & 113 & 197 & 191 \\
R3-CR325 & 98 & 88 & 97 & 84 & 99 & 73 & 125 & 135 \\
R4-CR307 & 95 & 85 & 98 & 84 & 102 & 77 & 123 & 135 \\
R5-CR275 & 95 & 84 & 93 & 86 & 104 & 76 & 122 & 139 \\
R6-CR233 & 94 & 90 & 97 & 86 & 101 & 75 & 125 & 130 \\
R7-CR161 & 93 & 91 & 102 & 90 & 97 & 67 & 122 & 132 \\
\hline & & & & & & & $P\left(\chi_{42}^{2} \geq 22.68\right)=0.9935$
\end{tabular}

c. Steelhead

\begin{tabular}{ccccccccc}
\hline \multirow{2}{*}{$\begin{array}{c}\text { Release } \\
\text { Location }\end{array}$} & \multicolumn{7}{c}{ Tagger } \\
\cline { 2 - 8 } & Amanda & Kate & Kathleen & Kyle & MaryBeth & Rhonda & Shon & Tyrell \\
\hline R1-CR390 & 301 & 284 & 333 & 285 & 276 & 240 & 452 & 416 \\
R2-CR346 & 143 & 127 & 155 & 130 & 144 & 114 & 191 & 192 \\
R3-CR325 & 95 & 85 & 100 & 92 & 97 & 75 & 123 & 130 \\
R4-CR307 & 100 & 91 & 99 & 84 & 98 & 73 & 126 & 129 \\
R5-CR275 & 95 & 88 & 102 & 90 & 97 & 76 & 120 & 132 \\
R6-CR233 & 95 & 89 & 93 & 93 & 95 & 75 & 121 & 131 \\
R7-CR161 & 99 & 87 & 94 & 89 & 94 & 74 & 124 & 133 \\
\hline & & & & & & & & $P\left(\chi_{42}^{2} \geq 10.62\right) \doteq 1.00$
\end{tabular}


Table A.2. Contingency tables with number of fish tagged by each staff member per release location within a replicate release. A total of 32 replicate day or nighttime releases were performed over the course of the 2011 investigations. Results of the chi-square tests of homogeneity are presented for each table.

a. Replicate 1

\begin{tabular}{ccccc}
\hline Release & Kate & Kathleen & Kyle & Shon \\
\hline R1-CR390 & 35 & 40 & 31 & 54 \\
R2-CR346 & 14 & 21 & 16 & 25 \\
R3-CR325 & 10 & 14 & 10 & 16 \\
R4-CR307 & 10 & 14 & 11 & 15 \\
R5-CR275 & 11 & 12 & 13 & 14 \\
R6-CR233 & 10 & 12 & 12 & 16 \\
R7-CR161 & 9 & 12 & 11 & 18 \\
\hline Chi-square $=2.7577$ & DF $=18$ & & $P$-value $=1$
\end{tabular}

b. Replicate 2

\begin{tabular}{ccccc}
\hline Release & Kate & Kathleen & Kyle & Shon \\
\hline R1-CR390 & 36 & 44 & 32 & 51 \\
R2-CR346 & 17 & 20 & 14 & 24 \\
R3-CR325 & 12 & 12 & 10 & 16 \\
R4-CR307 & 12 & 12 & 11 & 15 \\
R5-CR275 & 10 & 14 & 11 & 15 \\
R6-CR233 & 11 & 12 & 11 & 15 \\
R7-CR161 & 10 & 12 & 11 & 15 \\
\hline Chi-square $=1.2674$ & DF $=18$ & & $P$-value $=1$
\end{tabular}

c. Replicate 3

\begin{tabular}{cccccccccc}
\hline Release & Amanda & Kate & Kathleen & Kyle & MaryBeth & Rhonda & Shon & Tyrell & $P$-value \\
\hline R1-CR390 & 0 & 39 & 44 & 34 & 0 & 0 & 49 & 0 & 0 \\
R2-CR346 & 0 & 15 & 19 & 18 & 0 & 0 & 24 & 0.9677 \\
R3-CR325 & 0 & 9 & 14 & 10 & 0 & 0 & 17 & 0 & 0 \\
\hline R4-CR307 & 0 & 11 & 12 & 10 & 0 & 0 & 17 & 0 & 0.9948 \\
R5-CR275 & 0 & 12 & 12 & 10 & 0 & 0 & 16 & 0 & 19 \\
\hline R6-CR233 & 10 & 0 & 0 & 0 & 11 & 10 & 0 & 0.8460 \\
R7-CR161 & 11 & 0 & 0 & 0 & 13 & 7 & 0 & P-value $<0.0001$
\end{tabular}

d. Replicate 4

\begin{tabular}{|c|c|c|c|c|c|c|c|c|c|}
\hline Release & Amanda & Kate & Kathleen & Kyle & MaryBeth & Rhonda & Shon & Tyrell & $P$-value \\
\hline R1-CR390 & 0 & 34 & 42 & 37 & 0 & 0 & 49 & 0 & \multirow{3}{*}{0.9977} \\
\hline R2-CR346 & 0 & 14 & 21 & 17 & 0 & 0 & 24 & 0 & \\
\hline R3-CR325 & 0 & 10 & 12 & 11 & 0 & 0 & 17 & 0 & \\
\hline R4-CR307 & 0 & 9 & 13 & 12 & 0 & 0 & 16 & 0 & \multirow{2}{*}{0.9318} \\
\hline R5-CR275 & 0 & 11 & 11 & 11 & 0 & 0 & 17 & 0 & \\
\hline R6-CR233 & 12 & 0 & 0 & 0 & 13 & 8 & 0 & 17 & \multirow{2}{*}{0.7459} \\
\hline R7-CR161 & 12 & 0 & 0 & 0 & 9 & 11 & 0 & 18 & \\
\hline
\end{tabular}


Table A.2. (contd)

e. Replicate 5

\begin{tabular}{ccccc}
\hline Release & Amanda & MaryBeth & Rhonda & Tyrell \\
\hline R1-CR390 & 37 & 31 & 24 & 71 \\
R2-CR346 & 16 & 18 & 15 & 26 \\
R3-CR325 & 11 & 11 & 10 & 18 \\
R4-CR307 & 10 & 11 & 9 & 20 \\
R5-CR275 & 11 & 11 & 9 & 19 \\
R6-CR233 & 12 & 12 & 9 & 17 \\
R7-CR161 & 13 & 11 & 9 & 16 \\
\hline Chi-square $=4.8581$ & DF $=18$ & \multicolumn{2}{c}{$P$-value $=0.9991$}
\end{tabular}

f. Replicate 6

\begin{tabular}{ccccc}
\hline Release & Amanda & MaryBeth & Rhonda & Tyrell \\
\hline R1-CR390 & 37 & 40 & 29 & 58 \\
R2-CR346 & 17 & 17 & 14 & 28 \\
R3-CR325 & 11 & 10 & 10 & 19 \\
R4-CR307 & 12 & 11 & 9 & 18 \\
R5-CR275 & 11 & 10 & 10 & 19 \\
R6-CR233 & 11 & 13 & 9 & 17 \\
R7-CR161 & 12 & 10 & 9 & 16 \\
\hline Chi-square $=1.5118$ & DF $=18$ & & $P$-value $=1$
\end{tabular}

g. Replicate 7

\begin{tabular}{cccccccccc}
\hline Release & Amanda & Kate & Kathleen & Kyle & MaryBeth & Rhonda & Shon & Tyrell & $P$-value \\
\hline R1-CR390 & 36 & 0 & 0 & 0 & 37 & 29 & 0 & 62 \\
R2-CR346 & 19 & 0 & 0 & 0 & 18 & 12 & 0 & 27 & 0.9966 \\
R3-CR325 & 12 & 0 & 0 & 0 & 12 & 9 & 0 & 17 & 15 \\
\hline R4-CR307 & 12 & 0 & 0 & 0 & 12 & 10 & 0 & 0.9449 \\
R5-CR275 & 12 & 0 & 0 & 0 & 13 & 8 & 0 & 17 & 0 \\
\hline R6-CR233 & 0 & 11 & 12 & 10 & 0 & 0 & 17 & 0.9176 \\
R7-CR161 & 0 & 10 & 15 & 10 & 0 & 0 & 15 & 0 \\
\hline Chi-square $=493.4409$ & & \multicolumn{7}{c}{$\mathrm{DF}=42$} &
\end{tabular}

h. Replicate 8

\begin{tabular}{|c|c|c|c|c|c|c|c|c|c|}
\hline Release & Amanda & Kate & Kathleen & Kyle & MaryBeth & Rhonda & Shon & Tyrell & $P$-value \\
\hline R1-CR390 & 36 & 0 & 0 & 0 & 37 & 30 & 0 & 61 & \multirow{3}{*}{0.9970} \\
\hline R2-CR346 & 15 & 0 & 0 & 0 & 17 & 14 & 0 & 28 & \\
\hline R3-CR325 & 12 & 0 & 0 & 0 & 11 & 8 & 0 & 16 & \\
\hline R4-CR307 & 13 & 0 & 0 & 0 & 12 & 10 & 0 & 15 & \multirow{2}{*}{0.9747} \\
\hline R5-CR275 & 12 & 0 & 0 & 0 & 12 & 9 & 0 & 17 & \\
\hline R6-CR233 & 0 & 10 & 13 & 11 & 0 & 0 & 15 & 0 & \multirow{2}{*}{0.9910} \\
\hline R7-CR161 & 0 & 10 & 14 & 10 & 0 & 0 & 16 & 0 & \\
\hline
\end{tabular}


Table A.2. (contd)

i. Replicate 9

\begin{tabular}{ccccc}
\hline Release & Kate & Kathleen & Kyle & Shon \\
\hline R1-CR390 & 35 & 43 & 38 & 48 \\
R2-CR346 & 16 & 20 & 16 & 24 \\
R3-CR325 & 10 & 13 & 11 & 16 \\
R4-CR307 & 11 & 14 & 9 & 16 \\
R5-CR275 & 11 & 13 & 10 & 16 \\
R6-CR233 & 10 & 11 & 11 & 15 \\
R7-CR161 & 11 & 12 & 11 & 16 \\
\hline Chi-square $=1.2239$ & DF $=18$ & & $P$-value $=1$
\end{tabular}

j. Replicate 10

\begin{tabular}{ccccc}
\hline Release & Kate & Kathleen & Kyle & Shon \\
\hline R1-CR390 & 33 & 43 & 36 & 52 \\
R2-CR346 & 14 & 21 & 16 & 25 \\
R3-CR325 & 11 & 14 & 10 & 15 \\
R4-CR307 & 10 & 14 & 10 & 16 \\
R5-CR275 & 8 & 13 & 11 & 15 \\
R6-CR233 & 10 & 13 & 12 & 15 \\
R7-CR161 & 10 & 14 & 11 & 15 \\
\hline Chi-square $=1.0171$ & DF $=18$ & & $P$-value $=1$
\end{tabular}

k. Replicate 11

\begin{tabular}{cccccccccc}
\hline Release & Amanda & Kate & Kathleen & Kyle & MaryBeth & Rhonda & Shon & Tyrell & $P$-value \\
\hline R1-CR390 & 0 & 34 & 43 & 36 & 0 & 0 & 51 & 0 & 0 \\
R2-CR346 & 0 & 16 & 21 & 15 & 0 & 0 & 24 & 0.9939 \\
R3-CR325 & 0 & 12 & 11 & 11 & 0 & 0 & 16 & 0 & 0 \\
\hline R4-CR307 & 0 & 11 & 14 & 10 & 0 & 0 & 15 & 0 \\
R5-CR275 & 0 & 10 & 15 & 11 & 0 & 0 & 14 & 0.9832 \\
\hline R6-CR233 & 12 & 0 & 0 & 0 & 12 & 10 & 0 & 15 \\
R7-CR161 & 13 & 0 & 0 & 0 & 12 & 9 & 0 & 16 \\
\hline Chi-square $=491.1992$ & & & DF $=42$ & & & 0.9900 \\
\end{tabular}

1. Replicate 12

\begin{tabular}{|c|c|c|c|c|c|c|c|c|c|}
\hline Release & Amanda & Kate & Kathleen & Kyle & MaryBeth & Rhonda & Shon & Tyrell & $P$-value \\
\hline R1-CR390 & 0 & 34 & 46 & 36 & 0 & 0 & 48 & 0 & \multirow{3}{*}{0.9999} \\
\hline R2-CR346 & 0 & 15 & 21 & 17 & 0 & 0 & 23 & 0 & \\
\hline R3-CR325 & 0 & 11 & 13 & 11 & 0 & 0 & 15 & 0 & \\
\hline R4-CR307 & 0 & 13 & 14 & 10 & 0 & 0 & 13 & 0 & \multirow{2}{*}{0.8539} \\
\hline R5-CR275 & 0 & 12 & 11 & 13 & 0 & 0 & 13 & 0 & \\
\hline R6-CR233 & 13 & 0 & 0 & 0 & 11 & 9 & 0 & 16 & \multirow{2}{*}{0.9295} \\
\hline R7-CR161 & 12 & 0 & 0 & 0 & 12 & 7 & 0 & 18 & \\
\hline
\end{tabular}


Table A.2. (contd)

m. Replicate 13

\begin{tabular}{cccccc}
\hline Release & Amanda & MaryBeth & Rhonda & Shon & Tyrell \\
\hline R1-CR390 & 34 & 0 & 27 & 50 & 51 \\
R2-CR346 & 19 & 17 & 16 & 0 & 24 \\
R3-CR325 & 12 & 11 & 10 & 0 & 17 \\
R4-CR307 & 12 & 12 & 9 & 0 & 17 \\
R5-CR275 & 12 & 12 & 9 & 0 & 17 \\
R6-CR233 & 13 & 13 & 7 & 0 & 17 \\
R7-CR161 & 12 & 11 & 8 & 0 & 18 \\
\hline Chi-square $=140.8547$ & DF $=24$ & & \multicolumn{2}{c}{$P$-value $<0.0001$}
\end{tabular}

n. Replicate 14

\begin{tabular}{cccccc}
\hline Release & Amanda & MaryBeth & Rhonda & Shon & Tyrell \\
\hline R1-CR390 & 35 & 0 & 31 & 48 & 50 \\
R2-CR346 & 18 & 19 & 14 & 0 & 23 \\
R3-CR325 & 13 & 12 & 9 & 0 & 16 \\
R4-CR307 & 13 & 13 & 10 & 0 & 14 \\
R5-CR275 & 12 & 12 & 9 & 0 & 17 \\
R6-CR233 & 12 & 11 & 10 & 0 & 17 \\
R7-CR161 & 14 & 13 & 7 & 0 & 16 \\
\hline Chi-square $=137.8706$ & DF $=24$ & & \multicolumn{2}{c}{$P$-value $<0.0001$}
\end{tabular}

o. Replicate 15

\begin{tabular}{|c|c|c|c|c|c|c|c|c|c|}
\hline Release & Amanda & Kate & Kathleen & Kyle & MaryBeth & Rhonda & Shon & Tyrell & $P$-value \\
\hline R1-CR390 & 41 & 0 & 0 & 0 & 39 & 32 & 0 & 52 & \multirow{3}{*}{0.9873} \\
\hline R2-CR346 & 20 & 0 & 0 & 0 & 20 & 13 & 0 & 23 & \\
\hline R3-CR325 & 13 & 0 & 0 & 0 & 11 & 8 & 0 & 18 & \\
\hline R4-CR307 & 13 & 0 & 0 & 0 & 12 & 8 & 0 & 17 & \multirow{2}{*}{0.9345} \\
\hline R5-CR275 & 14 & 0 & 0 & 0 & 11 & 10 & 0 & 15 & \\
\hline R6-CR233 & 0 & 13 & 11 & 10 & 0 & 0 & 16 & 0 & \multirow{2}{*}{0.9161} \\
\hline R7-CR161 & 0 & 10 & 12 & 11 & 0 & 0 & 17 & 0 & \\
\hline Chi-square $=$ & 4.3843 & & & $\mathrm{DF}=4$ & & & & & $<0.0001$ \\
\hline
\end{tabular}

p. Replicate 16

\begin{tabular}{|c|c|c|c|c|c|c|c|c|c|}
\hline Release & Amanda & Kate & Kathleen & Kyle & MaryBeth & Rhonda & Shon & Tyrell & $P$-value \\
\hline R1-CR390 & 40 & 0 & 0 & 0 & 39 & 32 & 0 & 52 & \multirow{3}{*}{0.9959} \\
\hline R2-CR346 & 17 & 0 & 0 & 0 & 17 & 15 & 0 & 26 & \\
\hline R3-CR325 & 13 & 0 & 0 & 0 & 12 & 8 & 0 & 17 & \\
\hline R4-CR307 & 12 & 0 & 0 & 0 & 12 & 9 & 0 & 17 & \multirow{2}{*}{0.9933} \\
\hline R5-CR275 & 12 & 0 & 0 & 0 & 12 & 8 & 0 & 18 & \\
\hline R6-CR233 & 0 & 11 & 11 & 10 & 0 & 0 & 15 & 0 & \multirow{2}{*}{0.9883} \\
\hline R7-CR161 & 0 & 12 & 10 & 11 & 0 & 0 & 15 & 0 & \\
\hline Chi-square $=$ & 4.8889 & & & $F=42$ & & & & & $<0.0001$ \\
\hline
\end{tabular}


Table A.2. (contd)

q. $\quad$ Replicate 17

\begin{tabular}{ccccc}
\hline Release & Kate & Kathleen & Kyle & Shon \\
\hline R1-CR390 & 32 & 42 & 33 & 55 \\
R2-CR346 & 15 & 17 & 18 & 23 \\
R3-CR325 & 12 & 10 & 12 & 16 \\
R4-CR307 & 11 & 11 & 11 & 17 \\
R5-CR275 & 12 & 9 & 12 & 17 \\
R6-CR233 & 11 & 12 & 10 & 16 \\
R7-CR161 & 12 & 10 & 11 & 15 \\
\hline Chi-square $=3.1892$ & DF $=18$ & & $P$-value $=1$
\end{tabular}

r. Replicate 18

\begin{tabular}{ccccc}
\hline Release & Kate & Kathleen & Kyle & Shon \\
\hline R1-CR390 & 36 & 42 & 35 & 50 \\
R2-CR346 & 17 & 16 & 16 & 26 \\
R3-CR325 & 11 & 11 & 12 & 15 \\
R4-CR307 & 12 & 11 & 9 & 18 \\
R5-CR275 & 11 & 11 & 11 & 16 \\
R6-CR233 & 12 & 11 & 13 & 14 \\
R7-CR161 & 12 & 12 & 12 & 14 \\
\hline Chi-square $=2.7843$ & DF $=18$ & \multicolumn{2}{c}{$P$-value $=1$}
\end{tabular}

s. Replicate 19

\begin{tabular}{|c|c|c|c|c|c|c|c|c|c|}
\hline Release & Amanda & Kate & Kathleen & Kyle & MaryBeth & Rhonda & Shon & Tyrell & $P$-value \\
\hline R1-CR390 & 0 & 41 & 36 & 38 & 0 & 0 & 49 & 0 & \multirow{3}{*}{0.9882} \\
\hline R2-CR346 & 0 & 17 & 18 & 16 & 0 & 0 & 25 & 0 & \\
\hline R3-CR325 & 0 & 11 & 12 & 13 & 0 & 0 & 14 & 0 & \\
\hline R4-CR307 & 0 & 11 & 11 & 12 & 0 & 0 & 16 & 0 & \multirow{2}{*}{0.9352} \\
\hline R5-CR275 & 0 & 13 & 12 & 10 & 0 & 0 & 15 & 0 & \\
\hline R6-CR233 & 14 & 0 & 0 & 0 & 12 & 8 & 0 & 16 & \multirow{2}{*}{0.9704} \\
\hline R7-CR161 & 12 & 0 & 0 & 0 & 12 & 9 & 0 & 17 & \\
\hline Chi-square $=$ & 2.9525 & & & $F=42$ & & & & & $<0.0001$ \\
\hline
\end{tabular}

t. Replicate 20

\begin{tabular}{|c|c|c|c|c|c|c|c|c|c|}
\hline Release & Amanda & Kate & Kathleen & Kyle & MaryBeth & Rhonda & Shon & Tyrell & $P$-value \\
\hline R1-CR390 & 0 & 39 & 37 & 36 & 0 & 0 & 52 & 0 & \multirow{3}{*}{0.9996} \\
\hline R2-CR346 & 0 & 18 & 16 & 17 & 0 & 0 & 24 & 0 & \\
\hline R3-CR325 & 0 & 11 & 12 & 12 & 0 & 0 & 15 & 0 & \\
\hline R4-CR307 & 0 & 12 & 12 & 12 & 0 & 0 & 14 & 0 & \multirow{2}{*}{0.9836} \\
\hline R5-CR275 & 0 & 11 & 13 & 11 & 0 & 0 & 15 & 0 & \\
\hline R6-CR233 & 12 & 0 & 0 & 0 & 12 & 10 & 0 & 16 & \multirow{2}{*}{0.9705} \\
\hline R7-CR161 & 12 & 0 & 0 & 0 & 12 & 8 & 0 & 17 & \\
\hline Chi-square $=$ & 0.2024 & & & $F=42$ & & & & & $<0.0001$ \\
\hline
\end{tabular}


Table A.2. (contd)

u. Replicate 21

\begin{tabular}{ccccc}
\hline Release & Amanda & MaryBeth & Rhonda & Tyrell \\
\hline R1-CR390 & 41 & 41 & 29 & 53 \\
R2-CR346 & 20 & 18 & 14 & 24 \\
R3-CR325 & 12 & 13 & 9 & 16 \\
R4-CR307 & 13 & 14 & 8 & 15 \\
R5-CR275 & 11 & 15 & 8 & 16 \\
R6-CR233 & 11 & 14 & 10 & 15 \\
R7-CR161 & 11 & 12 & 8 & 17 \\
\hline Chi-square $=1.8491$ & DF $=18$ & & $P$-value $=1$
\end{tabular}

v. Replicate 22

\begin{tabular}{ccccc}
\hline Release & Amanda & MaryBeth & Rhonda & Tyrell \\
\hline R1-CR390 & 39 & 40 & 32 & 48 \\
R2-CR346 & 20 & 18 & 15 & 23 \\
R3-CR325 & 10 & 15 & 10 & 15 \\
R4-CR307 & 12 & 14 & 9 & 15 \\
R5-CR275 & 12 & 14 & 8 & 16 \\
R6-CR233 & 10 & 13 & 10 & 17 \\
R7-CR161 & 12 & 11 & 10 & 17 \\
\hline Chi-square $=2.6222$ & \multicolumn{2}{c}{ DF $=18$} & $P$-value $=1$
\end{tabular}

w. Replicate 23

\begin{tabular}{|c|c|c|c|c|c|c|c|c|c|}
\hline Release & Amanda & Kate & Kathleen & Kyle & MaryBeth & Rhonda & Shon & Tyrell & $P$-value \\
\hline R1-CR390 & 41 & 0 & 0 & 0 & 41 & 30 & 0 & 52 & \multirow{3}{*}{0.9994} \\
\hline R2-CR346 & 18 & 0 & 0 & 0 & 20 & 15 & 0 & 23 & \\
\hline R3-CR325 & 12 & 0 & 0 & 0 & 14 & 9 & 0 & 15 & \\
\hline R4-CR307 & 13 & 0 & 0 & 0 & 12 & 10 & 0 & 15 & \multirow{2}{*}{0.9949} \\
\hline $\mathrm{R} 5-\mathrm{CR} 275$ & 12 & 0 & 0 & 0 & 12 & 10 & 0 & 16 & \\
\hline R6-CR233 & 0 & 10 & 11 & 12 & 0 & 0 & 16 & 0 & \multirow{2}{*}{0.9904} \\
\hline R7-CR161 & 0 & 11 & 11 & 11 & 0 & 0 & 17 & 0 & \\
\hline \multicolumn{4}{|c|}{ Chi-square $=490.2628$} & $\overline{\mathrm{DF}}=4$ & & & & & $<0.0001$ \\
\hline
\end{tabular}

\section{x. Replicate 24}

\begin{tabular}{cccccccccc}
\hline Release & Amanda & Kate & Kathleen & Kyle & MaryBeth & Rhonda & Shon & Tyrell & $P$-value \\
\hline R1-CR390 & 40 & 0 & 0 & 0 & 45 & 27 & 0 & 52 & 0 \\
R2-CR346 & 16 & 0 & 0 & 0 & 22 & 14 & 0 & 23 & 0.9923 \\
R3-CR325 & 12 & 0 & 0 & 0 & 12 & 9 & 0 & 17 \\
\hline R4-CR307 & 12 & 0 & 0 & 0 & 13 & 8 & 0 & 17 & 0.9590 \\
R5-CR275 & 11 & 0 & 0 & 0 & 12 & 10 & 0 & 17 \\
\hline R6-CR233 & 0 & 12 & 13 & 11 & 0 & 0 & 14 & 0 \\
R7-CR161 & 0 & 11 & 12 & 12 & 0 & 0 & 15 & 0 & 0.9836 \\
\hline Chi-square $=491.5424$ & & DF $=42$ & & & & $<0.0001$
\end{tabular}


Table A.2. (contd)

y. Replicate 25

\begin{tabular}{ccccc}
\hline Release & Kate & Kathleen & Kyle & Shon \\
\hline R1-CR390 & 39 & 47 & 36 & 40 \\
R2-CR346 & 16 & 16 & 16 & 26 \\
R3-CR325 & 10 & 13 & 11 & 16 \\
R4-CR307 & 12 & 11 & 10 & 17 \\
R5-CR275 & 10 & 12 & 11 & 17 \\
R6-CR233 & 12 & 12 & 11 & 15 \\
R7-CR161 & 11 & 11 & 11 & 12 \\
\hline Chi-square $=5.3708$ & DF $=18$ & \multicolumn{2}{c}{$P$-value $=0.9982$}
\end{tabular}

z. Replicate 26

\begin{tabular}{ccccc}
\hline Release & Kate & Kathleen & Kyle & Shon \\
\hline R1-CR390 & 36 & 38 & 37 & 53 \\
R2-CR346 & 16 & 20 & 16 & 24 \\
R3-CR325 & 11 & 13 & 11 & 15 \\
R4-CR307 & 10 & 13 & 11 & 16 \\
R5-CR275 & 11 & 13 & 11 & 15 \\
R6-CR233 & 11 & 11 & 11 & 16 \\
R7-CR161 & 10 & 10 & 8 & 12 \\
\hline Chi-square $=1.0206$ & DF $=18$ & \multicolumn{2}{c}{$P$-value $=1$}
\end{tabular}

aa. Replicate 27

\begin{tabular}{|c|c|c|c|c|c|c|c|c|c|}
\hline Release & Amanda & Kate & Kathleen & Kyle & MaryBeth & Rhonda & Shon & Tyrell & $P$-value \\
\hline R1-CR390 & 0 & 35 & 40 & 35 & 0 & 0 & 54 & 0 & \multirow{3}{*}{0.9981} \\
\hline R2-CR346 & 0 & 18 & 17 & 17 & 0 & 0 & 23 & 0 & \\
\hline R3-CR325 & 0 & 12 & 12 & 11 & 0 & 0 & 15 & 0 & \\
\hline R4-CR307 & 0 & 10 & 10 & 11 & 0 & 0 & 14 & 0 & \multirow{2}{*}{0.9924} \\
\hline R5-CR275 & 0 & 10 & 11 & 10 & 0 & 0 & 14 & 0 & \\
\hline R6-CR233 & 12 & 0 & 0 & 0 & 13 & 11 & 0 & 14 & \multirow{2}{*}{0.9939} \\
\hline R7-CR161 & 12 & 0 & 0 & 0 & 13 & 10 & 0 & 15 & \\
\hline Chi-square $=$ & 0.2391 & & & $\mathrm{DF}=4$ & & & & & $<0.0001$ \\
\hline
\end{tabular}

bb. Replicate 28

\begin{tabular}{|c|c|c|c|c|c|c|c|c|c|}
\hline Release & Amanda & Kate & Kathleen & Kyle & MaryBeth & Rhonda & Shon & Tyrell & $P$-value \\
\hline R1-CR390 & 0 & 38 & 41 & 39 & 0 & 0 & 46 & 0 & \multirow{3}{*}{0.9984} \\
\hline R2-CR346 & 0 & 16 & 18 & 18 & 0 & 0 & 24 & 0 & \\
\hline R3-CR325 & 0 & 10 & 11 & 10 & 0 & 0 & 14 & 0 & \\
\hline R4-CR307 & 0 & 11 & 11 & 9 & 0 & 0 & 14 & 0 & \multirow{2}{*}{0.9284} \\
\hline R5-CR275 & 0 & 9 & 13 & 10 & 0 & 0 & 13 & 0 & \\
\hline R6-CR233 & 12 & 0 & 0 & 0 & 12 & 9 & 0 & 16 & \multirow{2}{*}{0.8987} \\
\hline R7-CR161 & 10 & 0 & 0 & 0 & 15 & 10 & 0 & 15 & \\
\hline Chi-square $=$ & 8.3536 & & & $=42$ & & & & & $<0.0001$ \\
\hline
\end{tabular}


Table A.2. (contd)

cc. Replicate 29

\begin{tabular}{ccccc}
\hline Release & Amanda & MaryBeth & Rhonda & Tyrell \\
\hline R1-CR390 & 37 & 43 & 34 & 50 \\
R2-CR346 & 18 & 18 & 16 & 24 \\
R3-CR325 & 13 & 14 & 8 & 15 \\
R4-CR307 & 12 & 13 & 9 & 16 \\
R5-CR275 & 12 & 12 & 10 & 15 \\
R6-CR233 & 11 & 12 & 10 & 16 \\
R7-CR161 & 12 & 12 & 10 & 16 \\
\hline Chi-square $=1.2964$ & DF $=18$ & \multicolumn{2}{c}{$P$-value $=1$}
\end{tabular}

dd. Replicate 30

\begin{tabular}{ccccc}
\hline Release & Amanda & MaryBeth & Rhonda & Tyrell \\
\hline R1-CR390 & 21 & 21 & 16 & 24 \\
R2-CR346 & 17 & 21 & 16 & 22 \\
R3-CR325 & 12 & 13 & 10 & 15 \\
R4-CR307 & 12 & 12 & 10 & 16 \\
R5-CR275 & 11 & 14 & 10 & 15 \\
R6-CR233 & 12 & 12 & 10 & 16 \\
R7-CR161 & 12 & 13 & 9 & 16 \\
\hline Chi-square $=0.9309$ & DF $=18$ & \multicolumn{2}{c}{$P$-value $=1$}
\end{tabular}

ee. Replicate 31

\begin{tabular}{|c|c|c|c|c|c|c|c|c|c|}
\hline Release & Amanda & Kate & Kathleen & Kyle & MaryBeth & Rhonda & Shon & Tyrell & $P$-value \\
\hline R1-CR390 & 33 & 0 & 0 & 0 & 35 & 26 & 0 & 44 & \multirow{3}{*}{1.0000} \\
\hline R2-CR346 & 14 & 0 & 0 & 0 & 16 & 11 & 0 & 19 & \\
\hline R3-CR325 & 12 & 0 & 0 & 0 & 12 & 10 & 0 & 16 & \\
\hline R4-CR307 & 12 & 0 & 0 & 0 & 13 & 11 & 0 & 19 & \multirow{2}{*}{0.9684} \\
\hline R5-CR275 & 12 & 0 & 0 & 0 & 15 & 11 & 0 & 17 & \\
\hline R6-CR233 & 0 & 13 & 13 & 13 & 0 & 0 & 16 & 0 & \multirow{2}{*}{0.9986} \\
\hline R7-CR161 & 0 & 14 & 15 & 14 & 0 & 0 & 17 & 0 & \\
\hline Chi-sc & $\mathrm{e}=473.8$ & & & $\overline{\mathrm{DF}}=42$ & & & & & $<0.0001$ \\
\hline
\end{tabular}

ff. Replicate 32

\begin{tabular}{|c|c|c|c|c|c|c|c|c|c|}
\hline Release & Amanda & Kate & Kathleen & Kyle & MaryBeth & Rhonda & Shon & Tyrell & $P$-value \\
\hline R1-CR390 & 33 & 0 & 0 & 0 & 39 & 28 & 0 & 40 & \multirow{3}{*}{0.9976} \\
\hline R2-CR346 & 15 & 0 & 0 & 0 & 17 & 13 & 0 & 20 & \\
\hline R3-CR325 & 13 & 0 & 0 & 0 & 13 & 11 & 0 & 18 & \\
\hline R4-CR307 & 12 & 0 & 0 & 0 & 14 & 11 & 0 & 18 & \multirow{2}{*}{0.9925} \\
\hline R5-CR275 & 13 & 0 & 0 & 0 & 14 & 13 & 0 & 20 & \\
\hline R6-CR233 & 0 & 12 & 12 & 11 & 0 & 0 & 15 & 0 & \multirow{2}{*}{0.9958} \\
\hline R7-CR161 & 0 & 15 & 14 & 14 & 0 & 0 & 17 & 0 & \\
\hline
\end{tabular}


Table A.3. Estimates of reach survival and cumulative survival for (a) yearling Chinook salmon smolts and (b) steelhead, along with $P$-values associated with the $F$-tests of homogeneous survival across fish tagged by different staff members.

a. Yearling Chinook salmon smolts

1) Release 1 - Reach survival

\begin{tabular}{|c|c|c|c|c|c|c|c|c|c|c|c|c|c|c|}
\hline & \multicolumn{2}{|c|}{ Release to CR349 } & \multicolumn{2}{|c|}{ CR349 to CR325 } & \multicolumn{2}{|c|}{ CR325 to CR309 } & \multicolumn{2}{|c|}{ CR309 to CR275 } & \multicolumn{2}{|c|}{ CR275 to CR234 } & \multicolumn{2}{|c|}{ CR234 to CR161 } & \multicolumn{2}{|c|}{ CR161 to CR113 } \\
\hline & $\hat{S}$ & $\widehat{\mathrm{SE}}$ & $\hat{S}$ & $\widehat{\mathrm{SE}}$ & $\hat{S}$ & $\widehat{\mathrm{SE}}$ & $\hat{S}$ & $\widehat{\mathrm{SE}}$ & $\hat{S}$ & $\widehat{\mathrm{SE}}$ & $\hat{S}$ & $\widehat{\mathrm{SE}}$ & $\hat{S}$ & $\widehat{\mathrm{SE}}$ \\
\hline Amanda & 0.9823 & 0.0079 & 0.9636 & 0.0113 & 0.9968 & 0.0039 & 0.9579 & 0.0125 & 0.9958 & 0.0042 & 0.9908 & 0.0132 & 0.9345 & 0.0297 \\
\hline Kate & 0.9795 & 0.0083 & 0.9613 & 0.0115 & 0.9965 & 0.0037 & 0.9561 & 0.0125 & 0.9958 & 0.0042 & 0.9874 & 0.0123 & 0.9435 & 0.0255 \\
\hline Kathleen & 0.9731 & 0.0088 & 0.9601 & 0.0109 & 0.9935 & 0.0046 & 0.9493 & 0.0126 & 0.9888 & 0.0064 & 0.9399 & 0.0162 & 0.9447 & 0.0278 \\
\hline Kyle & 0.9824 & 0.0078 & 0.9501 & 0.0131 & 0.9731 & 0.0101 & 0.9688 & 0.0109 & 1.0000 & 0.0000 & 0.9502 & 0.0154 & 0.9874 & 0.0248 \\
\hline MaryBeth & 0.9643 & 0.0117 & 0.9628 & 0.0122 & 1.0011 & 0.0006 & 0.9650 & 0.0123 & 0.9951 & 0.0049 & 0.9379 & 0.0194 & 0.9355 & 0.0343 \\
\hline Rhonda & 0.9815 & 0.0092 & 0.9573 & 0.0140 & 0.9955 & 0.0051 & 0.9604 & 0.0141 & 0.9886 & 0.0080 & 0.9497 & 0.0209 & 0.9252 & 0.0373 \\
\hline Shon & 0.9799 & 0.0066 & 0.9703 & 0.0081 & 0.9881 & 0.0053 & 0.9811 & 0.0067 & 0.9949 & 0.0036 & 0.9441 & 0.0127 & 0.9993 & 0.0187 \\
\hline Tyrell & 0.9802 & 0.0069 & 0.9622 & 0.0096 & 0.9951 & 0.0038 & 0.9602 & 0.0101 & 0.9970 & 0.0030 & 0.9455 & 0.0139 & 0.9529 & 0.0228 \\
\hline$P$-value & \multicolumn{2}{|c|}{0.8084} & \multicolumn{2}{|c|}{0.9719} & \multicolumn{2}{|c|}{0.0087} & \multicolumn{2}{|c|}{0.6973} & \multicolumn{2}{|c|}{0.7485} & \multicolumn{2}{|c|}{0.0858} & \multicolumn{2}{|c|}{0.5196} \\
\hline
\end{tabular}

2) Release 1 - Cumulative survival

\begin{tabular}{|c|c|c|c|c|c|c|c|c|c|c|c|c|c|c|}
\hline & \multicolumn{2}{|c|}{ Release to CR349 } & \multicolumn{2}{|c|}{ Release to CR325 } & \multicolumn{2}{|c|}{ Release to CR309 } & \multicolumn{2}{|c|}{ Release to CR275 } & \multicolumn{2}{|c|}{ Release to CR234 } & \multicolumn{2}{|c|}{ Release to CR161 } & \multicolumn{2}{|c|}{ Release to CR113 } \\
\hline & $\hat{S}$ & $\widehat{\mathrm{SE}}$ & $\hat{S}$ & $\widehat{\mathrm{SE}}$ & $\hat{S}$ & $\widehat{\mathrm{SE}}$ & $\hat{S}$ & $\widehat{\mathrm{SE}}$ & $\hat{S}$ & $\widehat{\mathrm{SE}}$ & $\hat{S}$ & $\widehat{\mathrm{SE}}$ & $\hat{S}$ & $\widehat{\mathrm{SE}}$ \\
\hline Amanda & 0.9823 & 0.0079 & 0.9465 & 0.0135 & 0.9435 & 0.0139 & 0.9038 & 0.0176 & 0.9000 & 0.0179 & 0.8917 & 0.0213 & 0.8332 & 0.0301 \\
\hline Kate & 0.9795 & 0.0083 & 0.9416 & 0.0138 & 0.9382 & 0.0141 & 0.8970 & 0.0179 & 0.8932 & 0.0181 & 0.8820 & 0.0210 & 0.8321 & 0.0275 \\
\hline Kathleen & 0.9731 & 0.0088 & 0.9343 & 0.0136 & 0.9282 & 0.0141 & 0.8812 & 0.0178 & 0.8713 & 0.0183 & 0.8190 & 0.0223 & 0.7737 & 0.0296 \\
\hline Kyle & 0.9824 & 0.0078 & 0.9334 & 0.0149 & 0.9083 & 0.0172 & 0.8799 & 0.0193 & 0.8799 & 0.0193 & 0.8361 & 0.0228 & 0.8255 & 0.0296 \\
\hline MaryBeth & 0.9643 & 0.0117 & 0.9284 & 0.0163 & 0.9294 & 0.0163 & 0.8969 & 0.0192 & 0.8926 & 0.0195 & 0.8371 & 0.0252 & 0.7831 & 0.0351 \\
\hline Rhonda & 0.9815 & 0.0092 & 0.9395 & 0.0163 & 0.9353 & 0.0169 & 0.8983 & 0.0208 & 0.8880 & 0.0215 & 0.8433 & 0.0276 & 0.7802 & 0.0374 \\
\hline Shon & 0.9799 & 0.0066 & 0.9508 & 0.0102 & 0.9395 & 0.0113 & 0.9218 & 0.0127 & 0.9171 & 0.0131 & 0.8658 & 0.0170 & 0.8652 & 0.0223 \\
\hline Tyrell & 0.9802 & 0.0069 & 0.9431 & 0.0115 & 0.9385 & 0.0120 & 0.9012 & 0.0149 & 0.8985 & 0.0150 & 0.8496 & 0.0189 & 0.8096 & 0.0251 \\
\hline$P$-value & \multicolumn{2}{|c|}{0.8084} & \multicolumn{2}{|c|}{0.9613} & \multicolumn{2}{|c|}{0.7767} & \multicolumn{2}{|c|}{0.7912} & \multicolumn{2}{|c|}{0.7700} & \multicolumn{2}{|c|}{0.2749} & \multicolumn{2}{|c|}{0.3320} \\
\hline
\end{tabular}


Table A.3. (contd)

3) Release 2 - Reach survival

\begin{tabular}{|c|c|c|c|c|c|c|c|c|c|c|c|c|}
\hline & \multicolumn{2}{|c|}{ Release to CR325 } & \multicolumn{2}{|c|}{ CR325 to CR309 } & \multicolumn{2}{|c|}{ CR309 to CR275 } & \multicolumn{2}{|c|}{ CR275 to CR234 } & \multicolumn{2}{|c|}{ CR234 to CR161 } & \multicolumn{2}{|c|}{ CR161 to CR113 } \\
\hline & $\hat{S}$ & $\widehat{\mathrm{SE}}$ & $\hat{S}$ & $\widehat{\mathrm{SE}}$ & $\hat{S}$ & $\widehat{\mathrm{SE}}$ & $\hat{S}$ & $\widehat{\mathrm{SE}}$ & $\hat{S}$ & $\widehat{\mathrm{SE}}$ & $\hat{S}$ & $\widehat{\mathrm{SE}}$ \\
\hline Amanda & 1.0005 & 0.0004 & 0.9853 & 0.0106 & 0.9474 & 0.0194 & 1.0000 & 0.0000 & 0.9568 & 0.0211 & 0.9785 & 0.0364 \\
\hline Kate & 1.0000 & 0.0000 & 1.0000 & 0.0000 & 0.9616 & 0.0173 & 0.9908 & 0.0091 & 0.9540 & 0.0243 & 0.9583 & 0.0450 \\
\hline Kathleen & 1.0001 & 0.0001 & 0.9931 & 0.0069 & 0.9046 & 0.0244 & 0.9919 & 0.0080 & 0.9154 & 0.0274 & 0.9372 & 0.0382 \\
\hline Kyle & 0.9932 & 0.0075 & 0.9690 & 0.0153 & 0.9459 & 0.0201 & 0.9911 & 0.0089 & 0.9676 & 0.0191 & 1.0046 & 0.0362 \\
\hline MaryBeth & 0.9879 & 0.0095 & 0.9783 & 0.0124 & 0.9731 & 0.0137 & 0.9919 & 0.0080 & 0.9643 & 0.0219 & 0.9551 & 0.0370 \\
\hline Rhonda & 0.9827 & 0.0124 & 0.9908 & 0.0094 & 0.9725 & 0.0157 & 1.0000 & 0.0000 & 0.9351 & 0.0285 & 0.9268 & 0.0414 \\
\hline Shon & 0.9746 & 0.0112 & 1.0002 & 0.0002 & 0.9690 & 0.0126 & 0.9942 & 0.0058 & 0.9585 & 0.0174 & 0.9448 & 0.0325 \\
\hline Tyrell & 0.9898 & 0.0074 & 0.9895 & 0.0076 & 0.9523 & 0.0158 & 0.9937 & 0.0063 & 0.9546 & 0.0219 & 0.9101 & 0.0350 \\
\hline$P$-value & \multicolumn{2}{|c|}{0.2701} & \multicolumn{2}{|c|}{0.3361} & \multicolumn{2}{|c|}{0.1281} & \multicolumn{2}{|c|}{0.9480} & \multicolumn{2}{|c|}{0.7861} & \multicolumn{2}{|c|}{0.7442} \\
\hline
\end{tabular}

4) Release 2-Cumulative survival

\begin{tabular}{|c|c|c|c|c|c|c|c|c|c|c|c|c|}
\hline & \multicolumn{2}{|c|}{ Release to CR325 } & \multicolumn{2}{|c|}{ Release to CR309 } & \multicolumn{2}{|c|}{ Release to CR275 } & \multicolumn{2}{|c|}{ Release to CR234 } & \multicolumn{2}{|c|}{ Release to CR161 } & \multicolumn{2}{|c|}{ Release to CR113 } \\
\hline & $\hat{S}$ & $\widehat{\mathrm{SE}}$ & $\hat{S}$ & $\widehat{\mathrm{SE}}$ & $\hat{S}$ & $\widehat{\mathrm{SE}}$ & $\hat{S}$ & $\widehat{\mathrm{SE}}$ & $\hat{S}$ & $\widehat{\mathrm{SE}}$ & $\hat{S}$ & $\widehat{\mathrm{SE}}$ \\
\hline Amanda & 1.0005 & 0.0004 & 0.9857 & 0.0103 & 0.9338 & 0.0213 & 0.9338 & 0.0213 & 0.8935 & 0.0284 & 0.8743 & 0.0403 \\
\hline Kate & 1.0000 & 0.0000 & 1.0000 & 0.0000 & 0.9616 & 0.0173 & 0.9528 & 0.0188 & 0.9089 & 0.0293 & 0.8710 & 0.0457 \\
\hline Kathleen & 1.0001 & 0.0001 & 0.9932 & 0.0068 & 0.8984 & 0.0250 & 0.8912 & 0.0257 & 0.8158 & 0.0339 & 0.7646 & 0.0420 \\
\hline Kyle & 0.9932 & 0.0075 & 0.9624 & 0.0165 & 0.9104 & 0.0249 & 0.9023 & 0.0258 & 0.8730 & 0.0303 & 0.8770 & 0.0419 \\
\hline MaryBeth & 0.9879 & 0.0095 & 0.9664 & 0.0148 & 0.9405 & 0.0196 & 0.9329 & 0.0205 & 0.8996 & 0.0284 & 0.8592 & 0.0384 \\
\hline Rhonda & 0.9827 & 0.0124 & 0.9737 & 0.0151 & 0.9469 & 0.0211 & 0.9469 & 0.0211 & 0.8854 & 0.0334 & 0.8206 & 0.0439 \\
\hline Shon & 0.9746 & 0.0112 & 0.9748 & 0.0112 & 0.9445 & 0.0164 & 0.9391 & 0.0170 & 0.9001 & 0.0231 & 0.8504 & 0.0345 \\
\hline Tyrell & 0.9898 & 0.0074 & 0.9793 & 0.0104 & 0.9326 & 0.0182 & 0.9267 & 0.0189 & 0.8846 & 0.0271 & 0.8050 & 0.0352 \\
\hline$P$-value & \multicolumn{2}{|c|}{0.2701} & \multicolumn{2}{|c|}{0.3867} & \multicolumn{2}{|c|}{0.4513} & \multicolumn{2}{|c|}{0.4331} & \multicolumn{2}{|c|}{0.4395} & \multicolumn{2}{|c|}{0.4395} \\
\hline
\end{tabular}


Table A.3. (contd)

5) Release 3 - Reach survival

\begin{tabular}{|c|c|c|c|c|c|c|c|c|c|c|}
\hline & \multicolumn{2}{|c|}{ Release to CR309 } & \multicolumn{2}{|c|}{ CR309 to CR275 } & \multicolumn{2}{|c|}{ CR275 to CR234 } & \multicolumn{2}{|c|}{ CR234 to CR161 } & \multicolumn{2}{|c|}{ CR161 to CR113 } \\
\hline & $\hat{S}$ & $\widehat{\mathrm{SE}}$ & $\hat{S}$ & $\widehat{\mathrm{SE}}$ & $\hat{S}$ & $\widehat{\mathrm{SE}}$ & $\hat{S}$ & $\widehat{\mathrm{SE}}$ & $\hat{S}$ & $\widehat{\mathrm{SE}}$ \\
\hline Amanda & 0.9803 & 0.0143 & 0.9375 & 0.0250 & 0.9882 & 0.0117 & 0.9612 & 0.0261 & 0.9579 & 0.0593 \\
\hline Kate & 0.9886 & 0.0113 & 0.9791 & 0.0162 & 0.9744 & 0.0179 & 0.9209 & 0.0308 & 1.0148 & 0.0412 \\
\hline Kathleen & 1.0000 & 0.0000 & 0.9592 & 0.0202 & 0.9888 & 0.0112 & 0.9506 & 0.0240 & 1.0080 & 0.0294 \\
\hline Kyle & 1.0000 & 0.0000 & 0.9413 & 0.0259 & 0.9865 & 0.0134 & 0.8863 & 0.0363 & 1.0341 & 0.0272 \\
\hline MaryBeth & 0.9899 & 0.0101 & 0.9796 & 0.0143 & 1.0000 & 0.0000 & 0.9901 & 0.0156 & 0.9946 & 0.0488 \\
\hline Rhonda & 0.9738 & 0.0192 & 0.9565 & 0.0246 & 1.0000 & 0.0000 & 0.9418 & 0.0333 & 1.0445 & 0.0708 \\
\hline Shon & 0.9763 & 0.0137 & 0.9597 & 0.0181 & 0.9904 & 0.0096 & 0.9298 & 0.0273 & 0.9241 & 0.0363 \\
\hline Tyrell & 0.9798 & 0.0128 & 0.9147 & 0.0246 & 1.0000 & 0.0000 & 0.9734 & 0.0219 & 0.9332 & 0.0431 \\
\hline$P$-value & \multicolumn{2}{|c|}{0.7449} & \multicolumn{2}{|c|}{0.4098} & \multicolumn{2}{|c|}{0.7639} & \multicolumn{2}{|c|}{0.2063} & \multicolumn{2}{|c|}{0.4650} \\
\hline
\end{tabular}

6) Release 3 - Cumulative survival

\begin{tabular}{|c|c|c|c|c|c|c|c|c|c|c|}
\hline & \multicolumn{2}{|c|}{ Release to CR309 } & \multicolumn{2}{|c|}{ Release to CR275 } & \multicolumn{2}{|c|}{ Release to CR234 } & \multicolumn{2}{|c|}{ Release to CR161 } & \multicolumn{2}{|c|}{ Release to CR113 } \\
\hline & $\hat{S}$ & $\widehat{\mathrm{SE}}$ & $\hat{S}$ & $\widehat{\mathrm{SE}}$ & $\hat{S}$ & $\widehat{\mathrm{SE}}$ & $\hat{S}$ & $\widehat{\mathrm{SE}}$ & $\hat{S}$ & $\widehat{\mathrm{SE}}$ \\
\hline Amanda & 0.9803 & 0.0143 & 0.9190 & 0.0277 & 0.9082 & 0.0292 & 0.8729 & 0.0367 & 0.8362 & 0.0593 \\
\hline Kate & 0.9886 & 0.0113 & 0.9680 & 0.0195 & 0.9432 & 0.0247 & 0.8685 & 0.0369 & 0.8814 & 0.0505 \\
\hline Kathleen & 1.0000 & 0.0000 & 0.9592 & 0.0202 & 0.9485 & 0.0225 & 0.9016 & 0.0312 & 0.9087 & 0.0397 \\
\hline Kyle & 1.0000 & 0.0000 & 0.9413 & 0.0259 & 0.9286 & 0.0281 & 0.8230 & 0.0419 & 0.8511 & 0.0483 \\
\hline MaryBeth & 0.9899 & 0.0101 & 0.9697 & 0.0172 & 0.9697 & 0.0172 & 0.9601 & 0.0228 & 0.9549 & 0.0494 \\
\hline Rhonda & 0.9738 & 0.0192 & 0.9315 & 0.0296 & 0.9315 & 0.0296 & 0.8773 & 0.0417 & 0.9163 & 0.0720 \\
\hline Shon & 0.9763 & 0.0137 & 0.9370 & 0.0219 & 0.9280 & 0.0231 & 0.8628 & 0.0332 & 0.7973 & 0.0406 \\
\hline Tyrell & 0.9798 & 0.0128 & 0.8963 & 0.0262 & 0.8963 & 0.0262 & 0.8725 & 0.0322 & 0.8142 & 0.0441 \\
\hline$P$-value & \multicolumn{2}{|c|}{0.7449} & \multicolumn{2}{|c|}{0.3474} & \multicolumn{2}{|c|}{0.5715} & \multicolumn{2}{|c|}{0.2765} & \multicolumn{2}{|c|}{0.3432} \\
\hline
\end{tabular}


Table A.3. (contd)

7) Release 4-Reach survival

\begin{tabular}{|c|c|c|c|c|c|c|c|c|}
\hline & \multicolumn{2}{|c|}{ Release to CR275 } & \multicolumn{2}{|c|}{ CR275 to CR234 } & \multicolumn{2}{|c|}{ CR234 to CR161 } & \multicolumn{2}{|c|}{ CR161 to CR113 } \\
\hline & $\hat{S}$ & $\widehat{\mathrm{SE}}$ & $\hat{S}$ & $\widehat{\mathrm{SE}}$ & $\hat{S}$ & $\widehat{\mathrm{SE}}$ & $\hat{S}$ & $\widehat{\mathrm{SE}}$ \\
\hline Amanda & 1.0015 & 0.0016 & 0.9880 & 0.0120 & 0.9347 & 0.0336 & 0.8793 & 0.0537 \\
\hline Kate & 0.9765 & 0.0164 & 1.0000 & 0.0000 & 0.9878 & 0.0181 & 0.9584 & 0.0470 \\
\hline Kathleen & 1.0016 & 0.0013 & 0.9780 & 0.0154 & 0.9818 & 0.0193 & 0.9711 & 0.0369 \\
\hline Kyle & 0.9881 & 0.0118 & 1.0000 & 0.0000 & 0.9252 & 0.0312 & 0.9399 & 0.0418 \\
\hline MaryBeth & 1.0011 & 0.0011 & 0.9891 & 0.0108 & 0.9273 & 0.0324 & 0.8360 & 0.0514 \\
\hline Rhonda & 0.9870 & 0.0129 & 1.0000 & 0.0000 & 0.9554 & 0.0263 & 1.0181 & 0.0456 \\
\hline Shon & 0.9924 & 0.0081 & 0.9912 & 0.0087 & 0.9448 & 0.0233 & 0.9949 & 0.0436 \\
\hline Tyrell & 0.9711 & 0.0146 & 0.9917 & 0.0083 & 0.9704 & 0.0197 & 0.9724 & 0.0419 \\
\hline$P$-value & \multicolumn{2}{|c|}{0.2677} & \multicolumn{2}{|c|}{0.7656} & \multicolumn{2}{|c|}{0.5274} & \multicolumn{2}{|c|}{0.0888} \\
\hline
\end{tabular}

8) Release 4-Cumulative survival

\begin{tabular}{|c|c|c|c|c|c|c|c|c|}
\hline & \multicolumn{2}{|c|}{ Release to CR275 } & \multicolumn{2}{|c|}{ Release to CR234 } & \multicolumn{2}{|c|}{ Release to CR161 } & \multicolumn{2}{|c|}{ Release to CR113 } \\
\hline & $\hat{S}$ & $\widehat{\mathrm{SE}}$ & $\hat{S}$ & $\widehat{\mathrm{SE}}$ & $\hat{S}$ & $\widehat{\mathrm{SE}}$ & $\hat{S}$ & $\widehat{\mathrm{SE}}$ \\
\hline Amanda & 1.0015 & 0.0016 & 0.9895 & 0.0105 & 0.9249 & 0.0347 & 0.8133 & 0.0517 \\
\hline Kate & 0.9765 & 0.0164 & 0.9765 & 0.0164 & 0.9645 & 0.0240 & 0.9244 & 0.0476 \\
\hline Kathleen & 1.0016 & 0.0013 & 0.9796 & 0.0143 & 0.9617 & 0.0235 & 0.9340 & 0.0381 \\
\hline Kyle & 0.9881 & 0.0118 & 0.9881 & 0.0118 & 0.9142 & 0.0328 & 0.8593 & 0.0465 \\
\hline MaryBeth & 1.0011 & 0.0011 & 0.9902 & 0.0098 & 0.9182 & 0.0333 & 0.7676 & 0.0498 \\
\hline Rhonda & 0.9870 & 0.0129 & 0.9870 & 0.0129 & 0.9430 & 0.0287 & 0.9600 & 0.0494 \\
\hline Shon & 0.9924 & 0.0081 & 0.9837 & 0.0114 & 0.9294 & 0.0254 & 0.9247 & 0.0454 \\
\hline Tyrell & 0.9711 & 0.0146 & 0.9630 & 0.0163 & 0.9344 & 0.0247 & 0.9086 & 0.0426 \\
\hline$P$-value & \multicolumn{2}{|c|}{0.2677} & \multicolumn{2}{|c|}{0.8464} & \multicolumn{2}{|c|}{0.8839} & \multicolumn{2}{|c|}{0.0441} \\
\hline
\end{tabular}


Table A.3. (contd)

9) Release 5-Reach survival

\begin{tabular}{|c|c|c|c|c|c|c|}
\hline & \multicolumn{2}{|c|}{ Release to CR234 } & \multicolumn{2}{|c|}{ CR234 to CR161 } & \multicolumn{2}{|c|}{ CR161 to CR113 } \\
\hline & $\hat{S}$ & $\widehat{\mathrm{SE}}$ & $\hat{S}$ & $\widehat{\mathrm{SE}}$ & $\hat{S}$ & $\widehat{\mathrm{SE}}$ \\
\hline Amanda & 0.9895 & 0.0105 & 0.9439 & 0.0356 & 0.8632 & 0.0641 \\
\hline Kate & 0.9881 & 0.0118 & 0.9482 & 0.0268 & 0.9876 & 0.0405 \\
\hline Kathleen & 0.9892 & 0.0107 & 0.9293 & 0.0283 & 1.0372 & 0.0474 \\
\hline Kyle & 0.9884 & 0.0116 & 0.9513 & 0.0263 & 0.9501 & 0.0414 \\
\hline MaryBeth & 0.9808 & 0.0135 & 0.9799 & 0.0211 & 0.9605 & 0.0530 \\
\hline Rhonda & 0.9737 & 0.0184 & 0.9749 & 0.0246 & 0.9679 & 0.0542 \\
\hline Shon & 0.9836 & 0.0115 & 0.9358 & 0.0250 & 0.9707 & 0.0456 \\
\hline Tyrell & 0.9712 & 0.0142 & 0.9235 & 0.0307 & 0.9268 & 0.0492 \\
\hline$P$-value & \multicolumn{2}{|c|}{0.9496} & \multicolumn{2}{|c|}{0.8070} & \multicolumn{2}{|c|}{0.4299} \\
\hline
\end{tabular}

10) Release 5 - Cumulative survival

\begin{tabular}{|c|c|c|c|c|c|c|}
\hline & \multicolumn{2}{|c|}{ Release to CR234 } & \multicolumn{2}{|c|}{ Release to CR161 } & \multicolumn{2}{|c|}{ Release to CR113 } \\
\hline & $\hat{S}$ & $\widehat{\mathrm{SE}}$ & $\hat{S}$ & $\widehat{\mathrm{SE}}$ & $\hat{S}$ & $\widehat{\mathrm{SE}}$ \\
\hline Amanda & 0.9895 & 0.0105 & 0.9340 & 0.0366 & 0.8062 & 0.0597 \\
\hline Kate & 0.9881 & 0.0118 & 0.9369 & 0.0287 & 0.9253 & 0.0448 \\
\hline Kathleen & 0.9892 & 0.0107 & 0.9193 & 0.0297 & 0.9535 & 0.0518 \\
\hline Kyle & 0.9884 & 0.0116 & 0.9403 & 0.0283 & 0.8933 & 0.0444 \\
\hline MaryBeth & 0.9808 & 0.0135 & 0.9610 & 0.0246 & 0.9231 & 0.0520 \\
\hline Rhonda & 0.9737 & 0.0184 & 0.9493 & 0.0299 & 0.9188 & 0.0547 \\
\hline Shon & 0.9836 & 0.0115 & 0.9205 & 0.0269 & 0.8935 & 0.0471 \\
\hline Tyrell & 0.9712 & 0.0142 & 0.8969 & 0.0326 & 0.8313 & 0.0468 \\
\hline$P$-value & \multicolumn{2}{|c|}{0.9496} & \multicolumn{2}{|c|}{0.8755} & \multicolumn{2}{|c|}{0.4359} \\
\hline
\end{tabular}


Table A.3. (contd)

11) Release 6 - Reach survival

\begin{tabular}{|c|c|c|c|c|}
\hline & \multicolumn{2}{|c|}{ Release to CR161 } & \multicolumn{2}{|c|}{ CR161 to CR113 } \\
\hline & $\hat{S}$ & $\widehat{\mathrm{SE}}$ & $\hat{S}$ & $\widehat{\mathrm{SE}}$ \\
\hline Amanda & 0.9735 & 0.0224 & 0.9394 & 0.0400 \\
\hline Kate & 1.0350 & 0.0142 & 0.9185 & 0.0467 \\
\hline Kathleen & 0.9569 & 0.0232 & 0.9860 & 0.0300 \\
\hline Kyle & 0.9648 & 0.0237 & 0.9481 & 0.0440 \\
\hline MaryBeth & 0.9798 & 0.0177 & 0.9094 & 0.0373 \\
\hline Rhonda & 0.9528 & 0.0264 & 1.0702 & 0.0530 \\
\hline Shon & 0.9919 & 0.0152 & 0.9680 & 0.0400 \\
\hline Tyrell & 1.0044 & 0.0132 & 0.9561 & 0.0404 \\
\hline$P$-value & \multicolumn{2}{|c|}{0.0697} & \multicolumn{2}{|c|}{0.1837} \\
\hline
\end{tabular}

12) Release 6 - Cumulative survival

\begin{tabular}{|c|c|c|c|c|}
\hline & \multicolumn{2}{|c|}{ Release to CR161 } & \multicolumn{2}{|c|}{ Release to CR113 } \\
\hline & $\hat{S}$ & $\widehat{\mathrm{SE}}$ & $\hat{S}$ & $\widehat{\mathrm{SE}}$ \\
\hline Amanda & 0.9735 & 0.0224 & 0.9145 & 0.0395 \\
\hline Kate & 1.0350 & 0.0142 & 0.9507 & 0.0385 \\
\hline Kathleen & 0.9569 & 0.0232 & 0.9436 & 0.0336 \\
\hline Kyle & 0.9648 & 0.0237 & 0.9147 & 0.0448 \\
\hline MaryBeth & 0.9798 & 0.0177 & 0.8911 & 0.0374 \\
\hline Rhonda & 0.9528 & 0.0264 & 1.0196 & 0.0559 \\
\hline Shon & 0.9919 & 0.0152 & 0.9601 & 0.0385 \\
\hline Tyrell & 1.0044 & 0.0132 & 0.9603 & 0.0378 \\
\hline$P$-value & \multicolumn{2}{|c|}{0.0697} & \multicolumn{2}{|c|}{0.4992} \\
\hline
\end{tabular}


Table A.3. (contd)

13) Release 7 - Reach survival

\begin{tabular}{|c|c|c|}
\hline & \multicolumn{2}{|c|}{ Release to CR113 } \\
\hline & $\hat{S}$ & $\widehat{\mathrm{SE}}$ \\
\hline Amanda & 0.9238 & 0.0481 \\
\hline Kate & 0.9590 & 0.0466 \\
\hline Kathleen & 0.9316 & 0.0382 \\
\hline Kyle & 0.9757 & 0.0473 \\
\hline MaryBeth & 0.9770 & 0.0328 \\
\hline Rhonda & 0.9454 & 0.0397 \\
\hline Shon & 0.9465 & 0.0321 \\
\hline Tyrell & 0.9221 & 0.0366 \\
\hline$P$-value & \multicolumn{2}{|c|}{0.9611} \\
\hline
\end{tabular}

b. Steelhead salmon smolts

14) Release 1-Reach survival

\begin{tabular}{|c|c|c|c|c|c|c|c|c|c|c|c|c|c|c|}
\hline & \multicolumn{2}{|c|}{ Release to CR349 } & \multicolumn{2}{|c|}{ CR349 to CR325 } & \multicolumn{2}{|c|}{ CR325 to CR309 } & \multicolumn{2}{|c|}{ CR309 to CR275 } & \multicolumn{2}{|c|}{ CR275 to CR234 } & \multicolumn{2}{|c|}{ CR234 to CR161 } & \multicolumn{2}{|c|}{ CR161 to CR113 } \\
\hline & $\hat{S}$ & $\widehat{\mathrm{SE}}$ & $\hat{S}$ & $\widehat{\mathrm{SE}}$ & $\hat{S}$ & $\widehat{\mathrm{SE}}$ & $\hat{S}$ & $\widehat{\mathrm{SE}}$ & $\hat{S}$ & $\widehat{\mathrm{SE}}$ & $\hat{S}$ & $\widehat{\mathrm{SE}}$ & $\hat{S}$ & $\widehat{\mathrm{SE}}$ \\
\hline Amanda & 0.9601 & 0.0113 & 0.9860 & 0.0070 & 0.9934 & 0.0051 & 0.9768 & 0.0098 & 0.9826 & 0.0086 & 0.9573 & 0.0150 & 0.8991 & 0.0293 \\
\hline Kate & 0.9508 & 0.0128 & 0.9814 & 0.0083 & 0.9962 & 0.0039 & 0.9849 & 0.0086 & 0.9651 & 0.0121 & 0.9382 & 0.0159 & 1.0187 & 0.0308 \\
\hline Kathleen & 0.9369 & 0.0133 & 0.9873 & 0.0064 & 0.9901 & 0.0057 & 0.9683 & 0.0102 & 0.9887 & 0.0065 & 0.9645 & 0.0129 & 1.0048 & 0.0323 \\
\hline Kyle & 0.9686 & 0.0104 & 0.9601 & 0.0118 & 0.9886 & 0.0065 & 0.9781 & 0.0093 & 0.9872 & 0.0073 & 0.9612 & 0.0140 & 0.9568 & 0.0304 \\
\hline MaryBeth & 0.9783 & 0.0088 & 0.9634 & 0.0115 & 0.9882 & 0.0069 & 0.9829 & 0.0088 & 0.9817 & 0.0091 & 0.9491 & 0.0178 & 0.9302 & 0.0380 \\
\hline Rhonda & 0.9584 & 0.0129 & 0.9739 & 0.0106 & 0.9955 & 0.0046 & 0.9972 & 0.0047 & 0.9892 & 0.0076 & 0.9270 & 0.0190 & 0.9763 & 0.0341 \\
\hline Shon & 0.9515 & 0.0101 & 0.9696 & 0.0083 & 0.9952 & 0.0034 & 0.9819 & 0.0068 & 0.9840 & 0.0065 & 0.9368 & 0.0129 & 1.0022 & 0.0231 \\
\hline Tyrell & 0.9736 & 0.0079 & 0.9778 & 0.0073 & 0.9954 & 0.0036 & 0.9688 & 0.0092 & 0.9818 & 0.0074 & 0.9495 & 0.0131 & 0.9490 & 0.0285 \\
\hline$P$-value & \multicolumn{2}{|c|}{0.1645} & \multicolumn{2}{|c|}{0.2884} & \multicolumn{2}{|c|}{0.8869} & \multicolumn{2}{|c|}{0.3137} & \multicolumn{2}{|c|}{0.5454} & \multicolumn{2}{|c|}{0.6392} & \multicolumn{2}{|c|}{0.0930} \\
\hline
\end{tabular}


Table A.3. (contd)

15) Release 1 - Cumulative survival

\begin{tabular}{|c|c|c|c|c|c|c|c|c|c|c|c|c|c|c|}
\hline & \multicolumn{2}{|c|}{ Release to CR349 } & \multicolumn{2}{|c|}{ Release to CR325 } & \multicolumn{2}{|c|}{ Release to CR309 } & \multicolumn{2}{|c|}{ Release to CR275 } & \multicolumn{2}{|c|}{ Release to CR234 } & \multicolumn{2}{|c|}{ Release to CR161 } & \multicolumn{2}{|c|}{ Release to CR113 } \\
\hline & $\hat{S}$ & $\widehat{\mathrm{SE}}$ & $\hat{S}$ & $\widehat{\mathrm{SE}}$ & $\hat{S}$ & $\widehat{\mathrm{SE}}$ & $\hat{S}$ & $\widehat{\mathrm{SE}}$ & $\hat{S}$ & $\widehat{\mathrm{SE}}$ & $\hat{S}$ & $\widehat{\mathrm{SE}}$ & $\hat{S}$ & $\widehat{\mathrm{SE}}$ \\
\hline Amanda & 0.9601 & 0.0113 & 0.9467 & 0.0130 & 0.9405 & 0.0138 & 0.9186 & 0.0161 & 0.9027 & 0.0172 & 0.8641 & 0.0213 & 0.7769 & 0.0302 \\
\hline Kate & 0.9508 & 0.0128 & 0.9331 & 0.0148 & 0.9296 & 0.0152 & 0.9155 & 0.0170 & 0.8836 & 0.0191 & 0.8289 & 0.0227 & 0.8444 & 0.0341 \\
\hline Kathleen & 0.9369 & 0.0133 & 0.9251 & 0.0144 & 0.9159 & 0.0152 & 0.8869 & 0.0175 & 0.8769 & 0.0180 & 0.8458 & 0.0207 & 0.8499 & 0.0333 \\
\hline Kyle & 0.9686 & 0.0104 & 0.9299 & 0.0151 & 0.9193 & 0.0161 & 0.8992 & 0.0179 & 0.8877 & 0.0187 & 0.8533 & 0.0218 & 0.8164 & 0.0323 \\
\hline MaryBeth & 0.9783 & 0.0088 & 0.9424 & 0.0141 & 0.9313 & 0.0152 & 0.9153 & 0.0170 & 0.8986 & 0.0182 & 0.8528 & 0.0235 & 0.7933 & 0.0369 \\
\hline Rhonda & 0.9584 & 0.0129 & 0.9334 & 0.0161 & 0.9292 & 0.0166 & 0.9266 & 0.0171 & 0.9167 & 0.0178 & 0.8497 & 0.0240 & 0.8296 & 0.0362 \\
\hline Shon & 0.9515 & 0.0101 & 0.9225 & 0.0126 & 0.9181 & 0.0129 & 0.9015 & 0.0141 & 0.8870 & 0.0149 & 0.8310 & 0.0181 & 0.8328 & 0.0259 \\
\hline Tyrell & 0.9736 & 0.0079 & 0.9519 & 0.0105 & 0.9476 & 0.0110 & 0.9180 & 0.0137 & 0.9013 & 0.0146 & 0.8557 & 0.0183 & 0.8121 & 0.0289 \\
\hline$P$-value & \multicolumn{2}{|c|}{0.1645} & \multicolumn{2}{|c|}{0.7891} & \multicolumn{2}{|c|}{0.7715} & \multicolumn{2}{|c|}{0.7262} & \multicolumn{2}{|c|}{0.8003} & \multicolumn{2}{|c|}{0.9448} & \multicolumn{2}{|c|}{0.7588} \\
\hline
\end{tabular}

16) Release 2 - Reach survival

\begin{tabular}{|c|c|c|c|c|c|c|c|c|c|c|c|c|}
\hline & \multicolumn{2}{|c|}{ Release to CR325 } & \multicolumn{2}{|c|}{ CR325 to CR309 } & \multicolumn{2}{|c|}{ CR309 to CR275 } & \multicolumn{2}{|c|}{ CR275 to CR234 } & \multicolumn{2}{|c|}{ CR234 to CR161 } & \multicolumn{2}{|c|}{ CR161 to CR113 } \\
\hline & $\hat{S}$ & $\widehat{\mathrm{SE}}$ & $\hat{S}$ & $\widehat{\mathrm{SE}}$ & $\hat{S}$ & $\widehat{\mathrm{SE}}$ & $\hat{S}$ & $\widehat{\mathrm{SE}}$ & $\hat{S}$ & $\widehat{\mathrm{SE}}$ & $\hat{S}$ & $\widehat{\mathrm{SE}}$ \\
\hline Amanda & 1.0003 & 0.0003 & 0.9930 & 0.0072 & 0.9726 & 0.0140 & 0.9918 & 0.0082 & 0.9640 & 0.0180 & 0.9567 & 0.0359 \\
\hline Kate & 1.0003 & 0.0003 & 0.9840 & 0.0112 & 0.9780 & 0.0138 & 0.9735 & 0.0151 & 0.9147 & 0.0270 & 0.9356 & 0.0464 \\
\hline Kathleen & 0.9940 & 0.0064 & 0.9671 & 0.0145 & 0.9814 & 0.0116 & 0.9847 & 0.0107 & 0.9642 & 0.0170 & 1.0251 & 0.0483 \\
\hline Kyle & 0.9927 & 0.0077 & 0.9841 & 0.0111 & 0.9868 & 0.0112 & 0.9735 & 0.0151 & 0.9184 & 0.0283 & 0.8859 & 0.0446 \\
\hline MaryBeth & 1.0001 & 0.0001 & 0.9860 & 0.0098 & 0.9718 & 0.0139 & 1.0000 & 0.0000 & 0.9377 & 0.0227 & 0.9253 & 0.0386 \\
\hline Rhonda & 0.9916 & 0.0087 & 0.9908 & 0.0091 & 0.9732 & 0.0153 & 1.0000 & 0.0000 & 0.9456 & 0.0245 & 0.9540 & 0.0556 \\
\hline Shon & 0.9897 & 0.0074 & 0.9892 & 0.0076 & 0.9951 & 0.0054 & 0.9942 & 0.0058 & 0.9082 & 0.0220 & 0.9816 & 0.0336 \\
\hline Tyrell & 0.9952 & 0.0052 & 0.9839 & 0.0092 & 0.9532 & 0.0156 & 0.9933 & 0.0066 & 0.9433 & 0.0206 & 0.9399 & 0.0453 \\
\hline$P$-value & \multicolumn{2}{|c|}{0.7902} & \multicolumn{2}{|c|}{0.7547} & \multicolumn{2}{|c|}{0.4981} & \multicolumn{2}{|c|}{0.4474} & \multicolumn{2}{|c|}{0.5105} & \multicolumn{2}{|c|}{0.5348} \\
\hline
\end{tabular}


Table A.3. (contd)

17) Release 2 - Cumulative survival

\begin{tabular}{|c|c|c|c|c|c|c|c|c|c|c|c|c|}
\hline & \multicolumn{2}{|c|}{ Release to CR325 } & \multicolumn{2}{|c|}{ Release to CR309 } & \multicolumn{2}{|c|}{ Release to CR275 } & \multicolumn{2}{|c|}{ Release to CR234 } & \multicolumn{2}{|c|}{ Release to CR161 } & \multicolumn{2}{|c|}{ Release to CR113 } \\
\hline & $\hat{S}$ & $\widehat{\mathrm{SE}}$ & $\hat{S}$ & $\widehat{\mathrm{SE}}$ & $\hat{S}$ & $\widehat{\mathrm{SE}}$ & $\hat{S}$ & $\widehat{\mathrm{SE}}$ & $\hat{S}$ & $\widehat{\mathrm{SE}}$ & $\hat{S}$ & $\widehat{\mathrm{SE}}$ \\
\hline Amanda & 1.0003 & 0.0003 & 0.9932 & 0.0070 & 0.9660 & 0.0154 & 0.9580 & 0.0168 & 0.9236 & 0.0236 & 0.8836 & 0.0386 \\
\hline Kate & 1.0003 & 0.0003 & 0.9843 & 0.0110 & 0.9626 & 0.0173 & 0.9370 & 0.0216 & 0.8571 & 0.0321 & 0.8019 & 0.0487 \\
\hline Kathleen & 0.9940 & 0.0064 & 0.9613 & 0.0155 & 0.9434 & 0.0188 & 0.9290 & 0.0206 & 0.8957 & 0.0254 & 0.9182 & 0.0496 \\
\hline Kyle & 0.9927 & 0.0077 & 0.9769 & 0.0132 & 0.9641 & 0.0170 & 0.9385 & 0.0211 & 0.8619 & 0.0329 & 0.7635 & 0.0455 \\
\hline MaryBeth & 1.0001 & 0.0001 & 0.9861 & 0.0098 & 0.9583 & 0.0167 & 0.9583 & 0.0167 & 0.8986 & 0.0268 & 0.8315 & 0.0409 \\
\hline Rhonda & 0.9916 & 0.0087 & 0.9825 & 0.0123 & 0.9561 & 0.0192 & 0.9561 & 0.0192 & 0.9041 & 0.0296 & 0.8625 & 0.0559 \\
\hline Shon & 0.9897 & 0.0074 & 0.9791 & 0.0104 & 0.9743 & 0.0116 & 0.9686 & 0.0126 & 0.8797 & 0.0242 & 0.8634 & 0.0371 \\
\hline Tyrell & 0.9952 & 0.0052 & 0.9792 & 0.0103 & 0.9333 & 0.0182 & 0.9271 & 0.0188 & 0.8745 & 0.0260 & 0.8220 & 0.0445 \\
\hline$P$-value & \multicolumn{2}{|c|}{0.7902} & \multicolumn{2}{|c|}{0.7126} & \multicolumn{2}{|c|}{0.7533} & \multicolumn{2}{|c|}{0.6753} & \multicolumn{2}{|c|}{0.7042} & \multicolumn{2}{|c|}{0.3265} \\
\hline
\end{tabular}

18) Release 3 - Reach survival

\begin{tabular}{|c|c|c|c|c|c|c|c|c|c|c|}
\hline & \multicolumn{2}{|c|}{ Release to CR309 } & \multicolumn{2}{|c|}{ CR309 to CR275 } & \multicolumn{2}{|c|}{ CR275 to CR234 } & \multicolumn{2}{|c|}{ CR234 to CR161 } & \multicolumn{2}{|c|}{ CR161 to CR113 } \\
\hline & $\hat{S}$ & $\widehat{\mathrm{SE}}$ & $\hat{S}$ & $\widehat{\mathrm{SE}}$ & $\hat{S}$ & $\widehat{\mathrm{SE}}$ & $\hat{S}$ & $\widehat{\mathrm{SE}}$ & $\hat{S}$ & $\widehat{\mathrm{SE}}$ \\
\hline Amanda & 0.9895 & 0.0105 & 0.9727 & 0.0186 & 0.9733 & 0.0186 & 0.9683 & 0.0232 & 1.0272 & 0.0569 \\
\hline Kate & 1.0000 & 0.0000 & 0.9431 & 0.0256 & 0.9730 & 0.0189 & 0.9396 & 0.0280 & 1.0006 & 0.0656 \\
\hline Kathleen & 1.0000 & 0.0000 & 0.9943 & 0.0104 & 0.9655 & 0.0196 & 0.9375 & 0.0273 & 1.0068 & 0.0559 \\
\hline Kyle & 0.9891 & 0.0108 & 0.9231 & 0.0279 & 1.0000 & 0.0000 & 0.9773 & 0.0215 & 0.9583 & 0.0563 \\
\hline MaryBeth & 1.0003 & 0.0004 & 0.9728 & 0.0181 & 0.9747 & 0.0177 & 0.8820 & 0.0361 & 1.0958 & 0.0930 \\
\hline Rhonda & 0.9733 & 0.0186 & 0.9589 & 0.0232 & 1.0000 & 0.0000 & 0.9720 & 0.0258 & 0.9622 & 0.0677 \\
\hline Shon & 0.9919 & 0.0081 & 0.9773 & 0.0141 & 0.9813 & 0.0131 & 0.9592 & 0.0211 & 0.9937 & 0.0471 \\
\hline Tyrell & 0.9846 & 0.0108 & 0.9720 & 0.0156 & 0.9806 & 0.0136 & 0.9542 & 0.0219 & 0.9348 & 0.0474 \\
\hline$P$-value & \multicolumn{2}{|c|}{0.6295} & \multicolumn{2}{|c|}{0.2810} & \multicolumn{2}{|c|}{0.7382} & \multicolumn{2}{|c|}{0.2099} & \multicolumn{2}{|c|}{0.7317} \\
\hline
\end{tabular}


Table A.3. (contd)

19) Release 3 - Cumulative survival

\begin{tabular}{|c|c|c|c|c|c|c|c|c|c|c|}
\hline & \multicolumn{2}{|c|}{ Release to CR309 } & \multicolumn{2}{|c|}{ Release to CR275 } & \multicolumn{2}{|c|}{ Release to CR234 } & \multicolumn{2}{|c|}{ Release to CR161 } & \multicolumn{2}{|c|}{ Release to CR113 } \\
\hline & $\hat{S}$ & $\widehat{\mathrm{SE}}$ & $\hat{S}$ & $\widehat{\mathrm{SE}}$ & $\hat{S}$ & $\widehat{\mathrm{SE}}$ & $\hat{S}$ & $\widehat{\mathrm{SE}}$ & $\hat{S}$ & $\widehat{\mathrm{SE}}$ \\
\hline Amanda & 0.9895 & 0.0105 & 0.9625 & 0.0210 & 0.9368 & 0.0250 & 0.9072 & 0.0325 & 0.9319 & 0.0585 \\
\hline Kate & 1.0000 & 0.0000 & 0.9431 & 0.0256 & 0.9176 & 0.0298 & 0.8622 & 0.0380 & 0.8627 & 0.0675 \\
\hline Kathleen & 1.0000 & 0.0000 & 0.9943 & 0.0104 & 0.9600 & 0.0196 & 0.9000 & 0.0320 & 0.9062 & 0.0576 \\
\hline Kyle & 0.9891 & 0.0108 & 0.9130 & 0.0294 & 0.9130 & 0.0294 & 0.8923 & 0.0348 & 0.8551 & 0.0577 \\
\hline MaryBeth & 1.0003 & 0.0004 & 0.9731 & 0.0179 & 0.9485 & 0.0225 & 0.8365 & 0.0396 & 0.9167 & 0.0870 \\
\hline Rhonda & 0.9733 & 0.0186 & 0.9333 & 0.0288 & 0.9333 & 0.0288 & 0.9072 & 0.0369 & 0.8729 & 0.0677 \\
\hline Shon & 0.9919 & 0.0081 & 0.9693 & 0.0161 & 0.9512 & 0.0194 & 0.9124 & 0.0274 & 0.9067 & 0.0489 \\
\hline Tyrell & 0.9846 & 0.0108 & 0.9570 & 0.0186 & 0.9385 & 0.0211 & 0.8954 & 0.0288 & 0.8370 & 0.0484 \\
\hline$P$-value & \multicolumn{2}{|c|}{0.6295} & \multicolumn{2}{|c|}{0.2229} & \multicolumn{2}{|c|}{0.8869} & \multicolumn{2}{|c|}{0.7561} & \multicolumn{2}{|c|}{0.9586} \\
\hline
\end{tabular}

20) Release 4 - Reach survival

\begin{tabular}{|c|c|c|c|c|c|c|c|c|}
\hline & \multicolumn{2}{|c|}{ Release to CR275 } & \multicolumn{2}{|c|}{ CR275 to CR234 } & \multicolumn{2}{|c|}{ CR234 to CR161 } & \multicolumn{2}{|c|}{ CR161 to CR113 } \\
\hline & $\hat{S}$ & $\widehat{\mathrm{SE}}$ & $\hat{S}$ & $\widehat{\mathrm{SE}}$ & $\hat{S}$ & $\widehat{\mathrm{SE}}$ & $\hat{S}$ & $\widehat{\mathrm{SE}}$ \\
\hline Amanda & 0.9800 & 0.0140 & 1.0000 & 0.0000 & 0.9111 & 0.0317 & 0.8392 & 0.0507 \\
\hline Kate & 0.9915 & 0.0111 & 0.9753 & 0.0172 & 0.8974 & 0.0347 & 0.9228 & 0.0503 \\
\hline Kathleen & 1.0016 & 0.0013 & 0.9783 & 0.0152 & 0.9455 & 0.0250 & 0.9886 & 0.0495 \\
\hline Kyle & 0.9903 & 0.0121 & 0.9857 & 0.0142 & 0.9226 & 0.0315 & 0.9437 & 0.0558 \\
\hline MaryBeth & 0.9917 & 0.0104 & 0.9878 & 0.0121 & 0.9592 & 0.0236 & 0.9492 & 0.0574 \\
\hline Rhonda & 1.0033 & 0.0034 & 0.9831 & 0.0168 & 0.9613 & 0.0288 & 0.9322 & 0.0600 \\
\hline Shon & 0.9694 & 0.0157 & 0.9825 & 0.0123 & 0.9466 & 0.0237 & 0.9462 & 0.0459 \\
\hline Tyrell & 0.9678 & 0.0175 & 0.9612 & 0.0190 & 0.9630 & 0.0209 & 0.9974 & 0.0569 \\
\hline$P$-value & \multicolumn{2}{|c|}{0.2631} & \multicolumn{2}{|c|}{0.7965} & \multicolumn{2}{|c|}{0.5862} & \multicolumn{2}{|c|}{0.5751} \\
\hline
\end{tabular}


Table A.3. (contd)

21) Release 4 - Cumulative survival

\begin{tabular}{|c|c|c|c|c|c|c|c|c|}
\hline & \multicolumn{2}{|c|}{ Release to CR275 } & \multicolumn{2}{|c|}{ Release to CR234 } & \multicolumn{2}{|c|}{ Release to CR161 } & \multicolumn{2}{|c|}{ Release to CR113 } \\
\hline & $\hat{S}$ & $\widehat{\mathrm{SE}}$ & $\hat{S}$ & $\widehat{\mathrm{SE}}$ & $\hat{S}$ & $\widehat{\mathrm{SE}}$ & $\hat{S}$ & $\widehat{\mathrm{SE}}$ \\
\hline Amanda & 0.9800 & 0.0140 & 0.9800 & 0.0140 & 0.8929 & 0.0336 & 0.7493 & 0.0510 \\
\hline Kate & 0.9915 & 0.0111 & 0.9670 & 0.0187 & 0.8678 & 0.0375 & 0.8008 & 0.0534 \\
\hline Kathleen & 1.0016 & 0.0013 & 0.9798 & 0.0141 & 0.9264 & 0.0279 & 0.9158 & 0.0518 \\
\hline Kyle & 0.9903 & 0.0121 & 0.9762 & 0.0166 & 0.9007 & 0.0344 & 0.8500 & 0.0580 \\
\hline MaryBeth & 0.9917 & 0.0104 & 0.9796 & 0.0143 & 0.9396 & 0.0269 & 0.8919 & 0.0574 \\
\hline Rhonda & 1.0033 & 0.0034 & 0.9863 & 0.0136 & 0.9481 & 0.0313 & 0.8838 & 0.0597 \\
\hline Shon & 0.9694 & 0.0157 & 0.9524 & 0.0190 & 0.9015 & 0.0289 & 0.8530 & 0.0472 \\
\hline Tyrell & 0.9678 & 0.0175 & 0.9302 & 0.0224 & 0.8958 & 0.0290 & 0.8935 & 0.0565 \\
\hline$P$-value & \multicolumn{2}{|c|}{0.2631} & \multicolumn{2}{|c|}{0.2717} & \multicolumn{2}{|c|}{0.6473} & \multicolumn{2}{|c|}{0.4050} \\
\hline
\end{tabular}

22) Release 5 - Reach survival

\begin{tabular}{|c|c|c|c|c|c|c|}
\hline & \multicolumn{2}{|c|}{ Release to CR234 } & \multicolumn{2}{|c|}{ CR234 to CR161 } & \multicolumn{2}{|c|}{ CR161 to CR113 } \\
\hline & $\hat{S}$ & $\widehat{\mathrm{SE}}$ & $\hat{S}$ & $\widehat{\mathrm{SE}}$ & $\hat{S}$ & $\widehat{\mathrm{SE}}$ \\
\hline Amanda & 0.9895 & 0.0105 & 0.9602 & 0.0243 & 0.9177 & 0.0466 \\
\hline Kate & 0.9659 & 0.0193 & 0.9664 & 0.0243 & 0.9081 & 0.0536 \\
\hline Kathleen & 0.9804 & 0.0137 & 0.8727 & 0.0358 & 0.8720 & 0.0495 \\
\hline Kyle & 1.0000 & 0.0000 & 0.9673 & 0.0228 & 0.9061 & 0.0480 \\
\hline MaryBeth & 0.9897 & 0.0103 & 0.9436 & 0.0251 & 0.9521 & 0.0499 \\
\hline Rhonda & 0.9868 & 0.0131 & 0.8860 & 0.0380 & 0.9851 & 0.0484 \\
\hline Shon & 0.9917 & 0.0083 & 0.9342 & 0.0249 & 0.9445 & 0.0533 \\
\hline Tyrell & 0.9773 & 0.0130 & 0.9559 & 0.0206 & 1.0495 & 0.0510 \\
\hline$P$-value & \multicolumn{2}{|c|}{0.6971} & \multicolumn{2}{|c|}{0.0880} & \multicolumn{2}{|c|}{0.2866} \\
\hline
\end{tabular}


Table A.3. (contd)

23) Release 5 - Cumulative survival

\begin{tabular}{|c|c|c|c|c|c|c|}
\hline & \multicolumn{2}{|c|}{ Release to CR234 } & \multicolumn{2}{|c|}{ Release to CR161 } & \multicolumn{2}{|c|}{ Release to CR113 } \\
\hline & $\hat{S}$ & $\widehat{\mathrm{SE}}$ & $\hat{S}$ & $\widehat{\mathrm{SE}}$ & $\hat{S}$ & $\widehat{\mathrm{SE}}$ \\
\hline Amanda & 0.9895 & 0.0105 & 0.9501 & 0.0261 & 0.8719 & 0.0472 \\
\hline Kate & 0.9659 & 0.0193 & 0.9334 & 0.0300 & 0.8477 & 0.0541 \\
\hline Kathleen & 0.9804 & 0.0137 & 0.8556 & 0.0371 & 0.7461 & 0.0509 \\
\hline Kyle & 1.0000 & 0.0000 & 0.9673 & 0.0228 & 0.8765 & 0.0481 \\
\hline MaryBeth & 0.9897 & 0.0103 & 0.9339 & 0.0267 & 0.8892 & 0.0517 \\
\hline Rhonda & 0.9868 & 0.0131 & 0.8743 & 0.0392 & 0.8612 & 0.0557 \\
\hline Shon & 0.9917 & 0.0083 & 0.9264 & 0.0259 & 0.8750 & 0.0534 \\
\hline Tyrell & 0.9773 & 0.0130 & 0.9342 & 0.0237 & 0.9804 & 0.0518 \\
\hline$P$-value & \multicolumn{2}{|c|}{0.6971} & \multicolumn{2}{|c|}{0.1194} & \multicolumn{2}{|c|}{0.1531} \\
\hline
\end{tabular}

24) Release 6 - Reach survival

\begin{tabular}{|c|c|c|c|c|}
\hline & \multicolumn{2}{|c|}{ Release to CR161 } & \multicolumn{2}{|c|}{ CR161 to CR113 } \\
\hline & $\hat{S}$ & $\widehat{\mathrm{SE}}$ & $\hat{S}$ & $\widehat{\mathrm{SE}}$ \\
\hline Amanda & 0.9728 & 0.0222 & 0.7971 & 0.0469 \\
\hline Kate & 1.0103 & 0.0053 & 0.9490 & 0.0501 \\
\hline Kathleen & 0.9562 & 0.0242 & 0.9724 & 0.0563 \\
\hline Kyle & 0.9438 & 0.0261 & 1.0223 & 0.0562 \\
\hline MaryBeth & 0.9529 & 0.0264 & 0.9205 & 0.0541 \\
\hline Rhonda & 0.9518 & 0.0308 & 0.9206 & 0.0700 \\
\hline Shon & 0.9458 & 0.0235 & 1.0321 & 0.0462 \\
\hline Tyrell & 0.9668 & 0.0193 & 0.9900 & 0.0343 \\
\hline$P$-value & \multicolumn{2}{|c|}{0.5359} & \multicolumn{2}{|c|}{0.0487} \\
\hline
\end{tabular}


Table A.3. (contd)

25) Release 6 - Cumulative survival

\begin{tabular}{|c|c|c|c|c|}
\hline & \multicolumn{2}{|c|}{ Release to CR161 } & \multicolumn{2}{|c|}{ Release to CR113 } \\
\hline & $\hat{S}$ & $\widehat{\mathrm{SE}}$ & $\hat{S}$ & $\widehat{\mathrm{SE}}$ \\
\hline Amanda & 0.9728 & 0.0222 & 0.7754 & 0.0460 \\
\hline Kate & 1.0103 & 0.0053 & 0.9588 & 0.0482 \\
\hline Kathleen & 0.9562 & 0.0242 & 0.9298 & 0.0565 \\
\hline Kyle & 0.9438 & 0.0261 & 0.9649 & 0.0574 \\
\hline MaryBeth & 0.9529 & 0.0264 & 0.8772 & 0.0536 \\
\hline Rhonda & 0.9518 & 0.0308 & 0.8762 & 0.0683 \\
\hline Shon & 0.9458 & 0.0235 & 0.9762 & 0.0472 \\
\hline Tyrell & 0.9668 & 0.0193 & 0.9571 & 0.0348 \\
\hline$P$-value & \multicolumn{2}{|c|}{0.5359} & \multicolumn{2}{|c|}{0.1042} \\
\hline
\end{tabular}

26) Release 7 - Reach survival

\begin{tabular}{|c|c|c|}
\hline & \multicolumn{2}{|c|}{ Release to CR113 } \\
\hline & $\hat{S}$ & $\widehat{\mathrm{SE}}$ \\
\hline Amanda & 0.8905 & 0.0440 \\
\hline Kate & 0.9473 & 0.0501 \\
\hline Kathleen & 0.9415 & 0.0479 \\
\hline Kyle & 0.9668 & 0.0443 \\
\hline MaryBeth & 0.9002 & 0.0464 \\
\hline Rhonda & 0.9230 & 0.0578 \\
\hline Shon & 0.9080 & 0.0468 \\
\hline Tyrell & 0.8905 & 0.0440 \\
\hline$P$-value & \multicolumn{2}{|c|}{0.9540} \\
\hline
\end{tabular}




\section{A.2 Examination of Tag-Lot Effects}

Three different tag lots were used in the tagging of the yearling Chinook salmon and steelhead smolts. Overall, the tag lots were not evenly distributed among the seven release locations (Table A.4). However, closer examination found the below-dam release pairs (i.e., $R_{2}-R_{3}, R_{4}-R_{5}$, and $R_{6}-R_{7}$ ) to be homogeneous with regard to tag-lot allocation $(P \geq 0.9415)$. This pairwise homogeneity is particularly important in the virtual/paired-release design where the downstream pair is used to estimate the extra-reach mortality needed to adjust the survival estimate from the virtual forebay release.

Tests of homogeneous reach survivals across tag lots by release locations were performed (Table A.5). These tests looked for any tag-lot effects not accounted for by the tag-lot-specific tag-life corrections. Of the 56 tests of homogeneous reach survivals across tag lots, 11 were significant at $P \leq 0.10$ (i.e., 19\%). However, there was no particular pattern to the lot-specific reach survivals. Tag lot 1 had the lowest survival in 3 of the 11 significant tests; lot 2 had the lower survival in 3 tests, and lots $3-5$ had the lowest survival in 5 tests.

In the 54 tests of homogeneous cumulative survival, 9 were significant at $P \leq 0.10$ (i.e., $16.7 \%$ ). However, the tests of cumulative survival are not independent within an analysis of a release group. For example, 7 of the 9 significant results all occurred within the $R_{1}$ release of steelhead. Also in that case, tag lot 1 had the lowest survivals in 2 of the 7 instances, while tag lot 2 had the lowest survival in 5 instances.

We conclude that tag lots corrected for tag life have no significant effect on observed smolt survivals. Therefore, fish tagged from all tag lots should be used in the analyses. 
Table A.4. Numbers of tags used per tag lot at each release location for (a) yearling Chinook salmon and (b) steelhead smolts in the 2011 Juvenile Salmon Acoustic Telemetry System (JSATS) survival study. Chi-square tests of homogeneity performed for the overall table and pairwise comparisons of the below-dam release pairs.

a. Yearling Chinook salmon

\begin{tabular}{ccccc}
\hline & \multicolumn{3}{c}{ Tag lot } & \\
\cline { 2 - 4 } Release Location & 1 & 2 & $3,4,5$ & $P$-value \\
\hline R1-CR390 & 706 & 501 & 1303 & \\
\hline R2-CR346 & 226 & 302 & 665 & \multirow{2}{*}{0.9801} \\
R3-CR325 & 150 & 200 & 449 & \\
\hline R4-CR307 & 150 & 149 & 500 & \multirow{2}{*}{0.9805} \\
R5-CR275 & 150 & 146 & 503 & \\
\hline R6-CR233 & 100 & 150 & 548 & \multirow{2}{*}{0.9323} \\
R7-CR161 & 96 & 146 & 552 & \\
\hline Chi-square $=211.77$ & & DF $=12$ & & $<0.0001$
\end{tabular}

b. Steelhead

\begin{tabular}{crcrc}
\hline & \multicolumn{3}{c}{ Tag lot } & \\
\cline { 2 - 4 } Release Location & 1 & 2 & $3,4,5$ & $P$-value \\
\hline R1-CR390 & 698 & 498 & 1391 & \\
\hline R2-CR346 & 228 & 302 & 666 & \multirow{2}{*}{0.9415} \\
R3-CR325 & 150 & 197 & 450 & \\
\hline R4-CR307 & 150 & 150 & 500 & \multirow{2}{*}{1.0000} \\
R5-CR275 & 150 & 150 & 500 & \\
\hline R6-CR233 & 99 & 146 & 547 & \multirow{2}{*}{0.9681} \\
R7-CR161 & 100 & 150 & 544 & \\
\hline Chi-square $=178.67$ & & DF $=12$ & & $<0.0001$
\end{tabular}


Table A.5. Estimates of reach survival and cumulative survival for (a) yearling Chinook salmon and (b) steelhead smolts, along with $P$-values associated with the $F$-tests of homogeneous survival across tag lots.

a. Yearling Chinook salmon smolts

1) Release 1 - Reach survival

\begin{tabular}{|c|c|c|c|c|c|c|c|c|c|c|c|c|c|c|}
\hline & \multicolumn{2}{|c|}{ Release to CR349 } & \multicolumn{2}{|c|}{ CR349 to CR325 } & \multicolumn{2}{|c|}{ CR325 to CR309 } & \multicolumn{2}{|c|}{ CR309 to CR275 } & \multicolumn{2}{|c|}{ CR275 to CR234 } & \multicolumn{2}{|c|}{ CR234 to CR161 } & \multicolumn{2}{|c|}{ CR161 to CR113 } \\
\hline & $\hat{S}$ & $\widehat{\mathrm{SE}}$ & $\hat{S}$ & $\widehat{\mathrm{SE}}$ & $\hat{S}$ & $\widehat{\mathrm{SE}}$ & $\hat{S}$ & $\widehat{\mathrm{SE}}$ & $\hat{S}$ & $\widehat{\mathrm{SE}}$ & $\hat{S}$ & $\widehat{\mathrm{SE}}$ & $\hat{S}$ & $\widehat{\mathrm{SE}}$ \\
\hline Lot 1 & 0.9802 & 0.0052 & 0.9578 & 0.0077 & 0.9924 & 0.0034 & 0.9664 & 0.0071 & 0.9937 & 0.0032 & 0.9587 & 0.0081 & 1.0025 & 0.0041 \\
\hline Lot 2 & 0.9801 & 0.0063 & 0.9528 & 0.0096 & 0.9914 & 0.0043 & 0.9501 & 0.0101 & 0.9954 & 0.0032 & 0.9570 & 0.0107 & 0.9839 & 0.0124 \\
\hline Lot $3,4,5$ & 0.9762 & 0.0042 & 0.9672 & 0.0050 & 0.9922 & 0.0027 & 0.9665 & 0.0053 & 0.9951 & 0.0022 & 0.9719 & 0.0095 & 0.9512 & 0.0226 \\
\hline$P$-value & \multicolumn{2}{|c|}{0.8312} & \multicolumn{2}{|c|}{0.4029} & \multicolumn{2}{|c|}{0.9774} & \multicolumn{2}{|c|}{0.2268} & \multicolumn{2}{|c|}{0.9067} & \multicolumn{2}{|c|}{0.4775} & \multicolumn{2}{|c|}{0.0520} \\
\hline
\end{tabular}

2) Release 1 - Cumulative survival

\begin{tabular}{|c|c|c|c|c|c|c|c|c|c|c|c|c|c|c|}
\hline & \multicolumn{2}{|c|}{ Release to CR349 } & \multicolumn{2}{|c|}{ Release to CR325 } & \multicolumn{2}{|c|}{ Release to CR309 } & \multicolumn{2}{|c|}{ Release to CR275 } & \multicolumn{2}{|c|}{ Release to CR234 } & \multicolumn{2}{|c|}{ Release to CR161 } & \multicolumn{2}{|c|}{ Release to CR 113} \\
\hline & $\hat{S}$ & $\widehat{\mathrm{SE}}$ & $\hat{S}$ & $\widehat{\mathrm{SE}}$ & $\hat{S}$ & $\widehat{\mathrm{SE}}$ & $\hat{S}$ & $\widehat{\mathrm{SE}}$ & $\hat{S}$ & $\widehat{\mathrm{SE}}$ & $\hat{S}$ & $\widehat{\mathrm{SE}}$ & $\hat{S}$ & $\widehat{\mathrm{SE}}$ \\
\hline Lot 1 & 0.9802 & 0.0052 & 0.9389 & 0.0090 & 0.9317 & 0.0095 & 0.9004 & 0.0113 & 0.8947 & 0.0116 & 0.8577 & 0.0133 & 0.8598 & 0.0138 \\
\hline Lot 2 & 0.9801 & 0.0063 & 0.9338 & 0.0111 & 0.9258 & 0.0117 & 0.8796 & 0.0146 & 0.8756 & 0.0148 & 0.8380 & 0.0170 & 0.8245 & 0.0191 \\
\hline$P$-value & \multicolumn{2}{|c|}{0.8312} & \multicolumn{2}{|c|}{0.7192} & \multicolumn{2}{|c|}{0.7177} & \multicolumn{2}{|c|}{0.2511} & \multicolumn{2}{|c|}{0.2898} & \multicolumn{2}{|c|}{0.1713} & \multicolumn{2}{|c|}{0.3508} \\
\hline
\end{tabular}

3) Release 2 - Reach survival

\begin{tabular}{|c|c|c|c|c|c|c|c|c|c|c|c|c|}
\hline & \multicolumn{2}{|c|}{ CR349 to CR325 } & \multicolumn{2}{|c|}{ CR325 to CR309 } & \multicolumn{2}{|c|}{ CR309 to CR275 } & \multicolumn{2}{|c|}{ CR275 to CR234 } & \multicolumn{2}{|c|}{ CR234 to CR161 } & \multicolumn{2}{|c|}{ CR161 to CR113 } \\
\hline & $\hat{S}$ & $\widehat{\mathrm{SE}}$ & $\hat{S}$ & $\widehat{\mathrm{SE}}$ & $\hat{S}$ & $\widehat{\mathrm{SE}}$ & $\hat{S}$ & $\widehat{\mathrm{SE}}$ & $\hat{S}$ & $\widehat{\mathrm{SE}}$ & $\hat{S}$ & $\widehat{\mathrm{SE}}$ \\
\hline Lot 1 & 0.9912 & 0.0062 & 0.9869 & 0.0077 & 0.9409 & 0.0159 & 0.9952 & 0.0048 & 0.9662 & 0.0127 & 0.9762 & 0.0127 \\
\hline Lot 2 & 0.9868 & 0.0066 & 0.9799 & 0.0081 & 0.9623 & 0.0111 & 0.9893 & 0.0061 & 0.9498 & 0.0132 & 1.0133 & 0.0066 \\
\hline Lot $3,4,5$ & 0.9913 & 0.0037 & 0.9939 & 0.0032 & 0.9531 & 0.0084 & 0.9961 & 0.0027 & 0.9688 & 0.0139 & 0.9316 & 0.0296 \\
\hline$P$-value & \multicolumn{2}{|c|}{0.8128} & \multicolumn{2}{|c|}{0.3376} & \multicolumn{2}{|c|}{0.4611} & \multicolumn{2}{|c|}{0.5483} & \multicolumn{2}{|c|}{0.5465} & \multicolumn{2}{|c|}{0.0096} \\
\hline
\end{tabular}


Table A.5. (contd)

4) Release 2-Cumulative survival

\begin{tabular}{|c|c|c|c|c|c|c|c|c|c|c|c|c|}
\hline & \multicolumn{2}{|c|}{ Release to CR325 } & \multicolumn{2}{|c|}{ Release to CR309 } & \multicolumn{2}{|c|}{ Release to CR275 } & \multicolumn{2}{|c|}{ Release to CR234 } & \multicolumn{2}{|c|}{ Release to CR161 } & \multicolumn{2}{|c|}{ Release to CR113 } \\
\hline & $\hat{S}$ & $\widehat{\mathrm{SE}}$ & $\hat{S}$ & $\widehat{\mathrm{SE}}$ & $\hat{S}$ & $\widehat{\mathrm{SE}}$ & $\hat{S}$ & $\widehat{\mathrm{SE}}$ & $\hat{S}$ & $\widehat{\mathrm{SE}}$ & $\hat{S}$ & $\widehat{\mathrm{SE}}$ \\
\hline Lot 1 & 0.9912 & 0.0062 & 0.9782 & 0.0098 & 0.9204 & 0.0180 & 0.9159 & 0.0185 & 0.8849 & 0.0213 & 0.8639 & 0.0236 \\
\hline Lot 2 & 0.9868 & 0.0066 & 0.9669 & 0.0103 & 0.9305 & 0.0146 & 0.9205 & 0.0156 & 0.8743 & 0.0191 & 0.8860 & 0.0201 \\
\hline Lot $3,4,5$ & 0.9913 & 0.0037 & 0.9852 & 0.0047 & 0.9390 & 0.0093 & 0.9353 & 0.0095 & 0.9061 & 0.0159 & 0.8441 & 0.0269 \\
\hline$P$-value & \multicolumn{2}{|c|}{0.8128} & \multicolumn{2}{|c|}{0.3195} & \multicolumn{2}{|c|}{0.6600} & \multicolumn{2}{|c|}{0.6329} & \multicolumn{2}{|c|}{0.4803} & \multicolumn{2}{|c|}{0.4571} \\
\hline
\end{tabular}

5) Release 3 - Reach survival

\begin{tabular}{|c|c|c|c|c|c|c|c|c|c|c|}
\hline & \multicolumn{2}{|c|}{ Release to CR309 } & \multicolumn{2}{|c|}{ CR309 to CR275 } & \multicolumn{2}{|c|}{ CR275 to CR234 } & \multicolumn{2}{|c|}{ CR234 to CR161 } & \multicolumn{2}{|c|}{ CR161 to CR113 } \\
\hline & $\hat{S}$ & $\widehat{\mathrm{SE}}$ & $\hat{S}$ & $\widehat{\mathrm{SE}}$ & $\hat{S}$ & $\widehat{\mathrm{SE}}$ & $\hat{S}$ & $\widehat{\mathrm{SE}}$ & $\hat{S}$ & $\widehat{\mathrm{SE}}$ \\
\hline Lot 1 & 0.9800 & 0.0114 & 0.9728 & 0.0134 & 0.9790 & 0.0120 & 0.9787 & 0.0122 & 0.9948 & 0.0112 \\
\hline Lot 2 & 0.9950 & 0.0050 & 0.9448 & 0.0162 & 0.9946 & 0.0054 & 0.9380 & 0.0180 & 0.9852 & 0.0149 \\
\hline$P$-value & \multicolumn{2}{|c|}{0.3806} & \multicolumn{2}{|c|}{0.2811} & \multicolumn{2}{|c|}{0.2815} & \multicolumn{2}{|c|}{0.1597} & \multicolumn{2}{|c|}{0.6857} \\
\hline
\end{tabular}

6) Release 3 - Cumulative survival

\begin{tabular}{|c|c|c|c|c|c|c|c|c|c|c|}
\hline & \multicolumn{2}{|c|}{ Release to CR309 } & \multicolumn{2}{|c|}{ Release to CR275 } & \multicolumn{2}{|c|}{ Release to CR234 } & \multicolumn{2}{|c|}{ Release to CR161 } & \multicolumn{2}{|c|}{ Release to CR 113} \\
\hline & $\hat{S}$ & $\widehat{\mathrm{SE}}$ & $\hat{S}$ & $\widehat{\mathrm{SE}}$ & $\hat{S}$ & $\widehat{\mathrm{SE}}$ & $\hat{S}$ & $\widehat{\mathrm{SE}}$ & $\hat{S}$ & $\widehat{\mathrm{SE}}$ \\
\hline Lot 1 & 0.9800 & 0.0114 & 0.9533 & 0.0172 & 0.9333 & 0.0204 & 0.9134 & 0.0230 & 0.9086 & 0.0250 \\
\hline Lot 2 & 0.9950 & 0.0050 & 0.9401 & 0.0168 & 0.9350 & 0.0174 & 0.8771 & 0.0235 & 0.8641 & 0.0261 \\
\hline Lot $3,4,5$ & 0.9831 & 0.0063 & 0.9318 & 0.0120 & 0.9265 & 0.0123 & 0.8812 & 0.0183 & 0.8941 & 0.0354 \\
\hline$P$-value & \multicolumn{2}{|c|}{0.3806} & \multicolumn{2}{|c|}{0.6137} & \multicolumn{2}{|c|}{0.9326} & \multicolumn{2}{|c|}{0.4326} & \multicolumn{2}{|c|}{0.5469} \\
\hline
\end{tabular}


Table A.5. (contd)

7) Release 4 - Reach survival

\begin{tabular}{|c|c|c|c|c|c|c|c|c|}
\hline & \multicolumn{2}{|c|}{ Release to CR275 } & \multicolumn{2}{|c|}{ CR275 to CR234 } & \multicolumn{2}{|c|}{ CR234 to CR161 } & \multicolumn{2}{|c|}{ CR161 to CR113 } \\
\hline & $\hat{S}$ & $\widehat{\mathrm{SE}}$ & $\hat{S}$ & $\widehat{\mathrm{SE}}$ & $\hat{S}$ & $\widehat{\mathrm{SE}}$ & $\hat{S}$ & $\widehat{\mathrm{SE}}$ \\
\hline Lot 1 & 0.9867 & 0.0094 & 0.9932 & 0.0067 & 0.9663 & 0.0150 & 0.9913 & 0.0106 \\
\hline Lot 2 & 0.9799 & 0.0115 & 0.9795 & 0.0117 & 0.9648 & 0.0155 & 1.0147 & 0.0060 \\
\hline Lot $3,4,5$ & 0.9926 & 0.0040 & 0.9954 & 0.0033 & 0.9655 & 0.0146 & 0.9260 & 0.0318 \\
\hline$P$-value & \multicolumn{2}{|c|}{0.5987} & \multicolumn{2}{|c|}{0.3169} & \multicolumn{2}{|c|}{0.9975} & \multicolumn{2}{|c|}{0.0043} \\
\hline
\end{tabular}

8) Release 4 - Cumulative survival

\begin{tabular}{|c|c|c|c|c|c|c|c|c|}
\hline & \multicolumn{2}{|c|}{ Release to CR275 } & \multicolumn{2}{|c|}{ Release to CR234 } & \multicolumn{2}{|c|}{ Release to CR161 } & \multicolumn{2}{|c|}{ Release to CR113 } \\
\hline & $\hat{S}$ & $\widehat{\mathrm{SE}}$ & $\hat{S}$ & $\widehat{\mathrm{SE}}$ & $\hat{S}$ & $\widehat{\mathrm{SE}}$ & $\hat{S}$ & $\widehat{\mathrm{SE}}$ \\
\hline Lot 1 & 0.9867 & 0.0094 & 0.9800 & 0.0114 & 0.9470 & 0.0184 & 0.9388 & 0.0207 \\
\hline Lot 2 & 0.9799 & 0.0115 & 0.9597 & 0.0161 & 0.9259 & 0.0215 & 0.9396 & 0.0225 \\
\hline Lot $3,4,5$ & 0.9926 & 0.0040 & 0.9880 & 0.0049 & 0.9539 & 0.0152 & 0.8833 & 0.0296 \\
\hline$P$-value & \multicolumn{2}{|c|}{0.5987} & \multicolumn{2}{|c|}{0.2137} & \multicolumn{2}{|c|}{0.5377} & \multicolumn{2}{|c|}{0.1777} \\
\hline
\end{tabular}

9) Release 5-Reach survival

\begin{tabular}{|c|c|c|c|c|c|c|}
\hline & \multicolumn{2}{|c|}{ Release to CR234 } & \multicolumn{2}{|c|}{ CR234 to CR161 } & \multicolumn{2}{|c|}{ CR161 to CR113 } \\
\hline & $\hat{S}$ & $\widehat{\mathrm{SE}}$ & $\hat{S}$ & $\widehat{\mathrm{SE}}$ & $\hat{S}$ & $\widehat{\mathrm{SE}}$ \\
\hline Lot 1 & 0.9733 & 0.0132 & 0.9381 & 0.0200 & 0.9890 & 0.0165 \\
\hline Lot 2 & 1.0000 & 0.0000 & 0.9656 & 0.0153 & 0.9896 & 0.0136 \\
\hline Lot $3,4,5$ & 0.9801 & 0.0062 & 0.9592 & 0.0154 & 0.9686 & 0.0362 \\
\hline$P$-value & \multicolumn{2}{|c|}{0.1775} & \multicolumn{2}{|c|}{0.4899} & \multicolumn{2}{|c|}{0.7849} \\
\hline
\end{tabular}


Table A.5. (contd)

10) Release 5 - Cumulative survival

\begin{tabular}{|c|c|c|c|c|c|c|}
\hline & \multicolumn{2}{|c|}{ Release to CR234 } & \multicolumn{2}{|c|}{ Release to CR161 } & \multicolumn{2}{|c|}{ Release to CR113 } \\
\hline & $\hat{S}$ & $\widehat{\mathrm{SE}}$ & $\hat{S}$ & $\widehat{\mathrm{SE}}$ & $\hat{S}$ & $\widehat{\mathrm{SE}}$ \\
\hline Lot 1 & 0.9733 & 0.0132 & 0.9131 & 0.0231 & 0.9031 & 0.0273 \\
\hline Lot 2 & 1.0000 & 0.0000 & 0.9656 & 0.0153 & 0.9556 & 0.0199 \\
\hline Lot $3,4,5$ & 0.9801 & 0.0062 & 0.9401 & 0.0162 & 0.9106 & 0.0335 \\
\hline$P$-value & \multicolumn{2}{|c|}{0.1775} & \multicolumn{2}{|c|}{0.1338} & \multicolumn{2}{|c|}{0.3440} \\
\hline
\end{tabular}

11) Release 6 - Reach survival

\begin{tabular}{|c|c|c|c|c|}
\hline & \multicolumn{2}{|c|}{ Release to CR161 } & \multicolumn{2}{|c|}{ CR161 to CR113 } \\
\hline & $\hat{S}$ & $\widehat{\mathrm{SE}}$ & $\hat{S}$ & $\widehat{\mathrm{SE}}$ \\
\hline Lot 1 & 0.9802 & 0.0140 & 0.9897 & 0.0155 \\
\hline Lot 2 & 0.9934 & 0.0066 & 1.0023 & 0.0079 \\
\hline Lot $3,4,5$ & 0.9951 & 0.0104 & 0.9472 & 0.0243 \\
\hline$P$-value & \multicolumn{2}{|c|}{0.5635} & \multicolumn{2}{|c|}{0.0608} \\
\hline
\end{tabular}

12) Release 6 - Cumulative survival

\begin{tabular}{|c|c|c|c|c|}
\hline & \multicolumn{2}{|c|}{ Release to CR161 } & \multicolumn{2}{|c|}{ Release to CR 113} \\
\hline & $\hat{S}$ & $\widehat{\mathrm{SE}}$ & $\hat{S}$ & $\widehat{\mathrm{SE}}$ \\
\hline Lot 1 & 0.9802 & 0.0140 & 0.9701 & 0.0204 \\
\hline Lot 2 & 0.9934 & 0.0066 & 0.9956 & 0.0103 \\
\hline Lot $3,4,5$ & 0.9951 & 0.0104 & 0.9425 & 0.0225 \\
\hline$P$-value & \multicolumn{2}{|c|}{0.5635} & \multicolumn{2}{|c|}{0.1277} \\
\hline
\end{tabular}


Table A.5. (contd)

13) Release 7 - Reach survival

\begin{tabular}{|c|c|c|}
\hline & \multicolumn{2}{|c|}{ Release to CR113 } \\
\hline & $\hat{S}$ & $\widehat{\mathrm{SE}}$ \\
\hline Lot 1 & 0.9874 & 0.0156 \\
\hline Lot 2 & 0.9790 & 0.0139 \\
\hline Lot $3,4,5$ & 0.9552 & 0.0229 \\
\hline$P$-value & \multicolumn{2}{|c|}{0.4180} \\
\hline
\end{tabular}

b. Steelhead smolts

14) Release 1 - Reach survival

\begin{tabular}{|c|c|c|c|c|c|c|c|c|c|c|c|c|c|c|}
\hline & \multicolumn{2}{|c|}{ Release to CR349 } & \multicolumn{2}{|c|}{ CR349 to CR325 } & \multicolumn{2}{|c|}{ CR325 to CR309 } & \multicolumn{2}{|c|}{ CR309 to CR275 } & \multicolumn{2}{|c|}{ CR275 to CR234 } & \multicolumn{2}{|c|}{ CR234 to CR161 } & \multicolumn{2}{|c|}{ CR161 to CR113 } \\
\hline & $\hat{S}$ & $\widehat{\mathrm{SE}}$ & $\hat{S}$ & $\widehat{\mathrm{SE}}$ & $\hat{S}$ & $\widehat{\mathrm{SE}}$ & $\hat{S}$ & $\widehat{\mathrm{SE}}$ & $\hat{S}$ & $\widehat{\mathrm{SE}}$ & $\hat{S}$ & $\widehat{\mathrm{SE}}$ & $\hat{S}$ & $\widehat{\mathrm{SE}}$ \\
\hline Lot 1 & 0.9571 & 0.0077 & 0.9623 & 0.0074 & 0.9907 & 0.0038 & 0.9637 & 0.0074 & 0.9771 & 0.0061 & 0.9691 & 0.0072 & 1.0002 & 0.0083 \\
\hline Lot 2 & 0.9318 & 0.0113 & 0.9761 & 0.0071 & 0.9957 & 0.0031 & 0.9756 & 0.0073 & 0.9725 & 0.0078 & 0.9427 & 0.0117 & 0.9965 & 0.0137 \\
\hline Lot $3,4,5$ & 0.9705 & 0.0045 & 0.9809 & 0.0038 & 0.9932 & 0.0023 & 0.9858 & 0.0036 & 0.9902 & 0.0031 & 0.9492 & 0.0083 & 0.9969 & 0.0258 \\
\hline$P$-value & \multicolumn{2}{|c|}{0.0037} & \multicolumn{2}{|c|}{0.0960} & \multicolumn{2}{|c|}{0.5329} & \multicolumn{2}{|c|}{0.0489} & \multicolumn{2}{|c|}{0.0945} & \multicolumn{2}{|c|}{0.1095} & \multicolumn{2}{|c|}{0.9867} \\
\hline
\end{tabular}

15) Release 1 - Cumulative survival

\begin{tabular}{|c|c|c|c|c|c|c|c|c|c|c|c|c|c|c|}
\hline & \multicolumn{2}{|c|}{ Release to CR349 } & \multicolumn{2}{|c|}{ Release to CR325 } & \multicolumn{2}{|c|}{ Release to CR309 } & \multicolumn{2}{|c|}{ Release to CR275 } & \multicolumn{2}{|c|}{ Release to CR234 } & \multicolumn{2}{|c|}{ Release to CR161 } & \multicolumn{2}{|c|}{ Release to CR113 } \\
\hline & $\hat{S}$ & $\widehat{\mathrm{SE}}$ & $\hat{S}$ & $\widehat{\mathrm{SE}}$ & $\hat{S}$ & $\widehat{\mathrm{SE}}$ & $\hat{S}$ & $\widehat{\mathrm{SE}}$ & $\hat{S}$ & $\widehat{\mathrm{SE}}$ & $\hat{S}$ & $\widehat{\mathrm{SE}}$ & $\hat{S}$ & $\widehat{\mathrm{SE}}$ \\
\hline Lot 1 & 0.9571 & 0.0077 & 0.9211 & 0.0102 & 0.9125 & 0.0107 & 0.8793 & 0.0123 & 0.8592 & 0.0132 & 0.8326 & 0.0142 & 0.8328 & 0.0158 \\
\hline Lot 2 & 0.9318 & 0.0113 & 0.9096 & 0.0129 & 0.9057 & 0.0131 & 0.8835 & 0.0144 & 0.8593 & 0.0156 & 0.8101 & 0.0178 & 0.8072 & 0.0207 \\
\hline Lot $3,4,5$ & 0.9705 & 0.0045 & 0.9520 & 0.0057 & 0.9455 & 0.0061 & 0.9321 & 0.0069 & 0.9229 & 0.0072 & 0.8760 & 0.0102 & 0.8734 & 0.0237 \\
\hline$P$-value & \multicolumn{2}{|c|}{0.0037} & \multicolumn{2}{|c|}{0.0085} & \multicolumn{2}{|c|}{0.0150} & \multicolumn{2}{|c|}{0.0017} & \multicolumn{2}{|c|}{0.0002} & \multicolumn{2}{|c|}{0.0045} & \multicolumn{2}{|c|}{0.0674} \\
\hline
\end{tabular}


Table A.5. (contd)

16) Release 2 - Reach survival

\begin{tabular}{|c|c|c|c|c|c|c|c|c|c|c|c|c|}
\hline & \multicolumn{2}{|c|}{ CR349 to CR325 } & \multicolumn{2}{|c|}{ CR325 to CR309 } & \multicolumn{2}{|c|}{ CR309 to CR275 } & \multicolumn{2}{|c|}{ CR275 to CR234 } & \multicolumn{2}{|c|}{ CR234 to CR161 } & \multicolumn{2}{|c|}{ CR161 to CR113 } \\
\hline & $\hat{S}$ & $\widehat{\mathrm{SE}}$ & $\hat{S}$ & $\widehat{\mathrm{SE}}$ & $\hat{S}$ & $\widehat{\mathrm{SE}}$ & $\hat{S}$ & $\widehat{\mathrm{SE}}$ & $\hat{S}$ & $\widehat{\mathrm{SE}}$ & $\hat{S}$ & $\widehat{\mathrm{SE}}$ \\
\hline Lot 1 & 1.0000 & 0.0000 & 0.9868 & 0.0075 & 0.9733 & 0.0107 & 0.9909 & 0.0064 & 0.9449 & 0.0155 & 1.0030 & 0.0135 \\
\hline Lot 2 & 0.9834 & 0.0073 & 0.9899 & 0.0058 & 0.9864 & 0.0068 & 0.9897 & 0.0059 & 0.9416 & 0.0140 & 0.9960 & 0.0136 \\
\hline Lot $3,4,5$ & 0.9992 & 0.0015 & 0.9813 & 0.0054 & 0.9735 & 0.0067 & 0.9879 & 0.0049 & 0.9425 & 0.0124 & 0.9594 & 0.0360 \\
\hline$P$-value & \multicolumn{2}{|c|}{0.0775} & \multicolumn{2}{|c|}{0.6208} & \multicolumn{2}{|c|}{0.4398} & \multicolumn{2}{|c|}{0.9344} & \multicolumn{2}{|c|}{0.9853} & \multicolumn{2}{|c|}{0.3713} \\
\hline
\end{tabular}

17) Release 2 - Cumulative survival

\begin{tabular}{|c|c|c|c|c|c|c|c|c|c|c|c|c|}
\hline & \multicolumn{2}{|c|}{ Release to CR325 } & \multicolumn{2}{|c|}{ Release to CR309 } & \multicolumn{2}{|c|}{ Release to CR275 } & \multicolumn{2}{|c|}{ Release to CR234 } & \multicolumn{2}{|c|}{ Release to CR161 } & \multicolumn{2}{|c|}{ Release to CR113 } \\
\hline & $\hat{S}$ & $\widehat{\mathrm{SE}}$ & $\hat{S}$ & $\widehat{\mathrm{SE}}$ & $\hat{S}$ & $\widehat{\mathrm{SE}}$ & $\hat{S}$ & $\widehat{\mathrm{SE}}$ & $\hat{S}$ & $\widehat{\mathrm{SE}}$ & $\hat{S}$ & $\widehat{\mathrm{SE}}$ \\
\hline Lot 1 & 1.0000 & 0.0000 & 0.9868 & 0.0075 & 0.9605 & 0.0129 & 0.9518 & 0.0142 & 0.8993 & 0.0200 & 0.9021 & 0.0234 \\
\hline Lot 2 & 0.9834 & 0.0073 & 0.9735 & 0.0092 & 0.9603 & 0.0112 & 0.9503 & 0.0125 & 0.8949 & 0.0177 & 0.8913 & 0.0213 \\
\hline$P$-value & \multicolumn{2}{|c|}{0.0775} & \multicolumn{2}{|c|}{0.4602} & \multicolumn{2}{|c|}{0.9084} & \multicolumn{2}{|c|}{0.8561} & \multicolumn{2}{|c|}{0.9118} & \multicolumn{2}{|c|}{0.3803} \\
\hline
\end{tabular}

18) Release 3 - Reach survival

\begin{tabular}{lccccccccccc}
\hline & \multicolumn{3}{c}{ Release to CR309 } & \multicolumn{2}{c}{ CR309 to CR275 } & \multicolumn{2}{c}{ CR275 to CR234 } & \multicolumn{2}{c}{ CR234 to CR161 } & CR161 to CR113 \\
\cline { 2 - 10 } & & $\hat{S}$ & $\widehat{\mathrm{SE}}$ & $\hat{S}$ & $\widehat{\mathrm{SE}}$ & $\hat{S}$ & $\widehat{\mathrm{SE}}$ & $\hat{S}$ & $\widehat{\mathrm{SE}}$ & $\hat{S}$ & $\widehat{\mathrm{SE}}$ \\
\hline Lot 1 & 0.9933 & 0.0066 & 0.9866 & 0.0094 & 0.9796 & 0.0117 & 0.9376 & 0.0202 & 1.0246 & 0.0164 \\
Lot 2 & 0.9898 & 0.0071 & 0.9282 & 0.0185 & 0.9669 & 0.0133 & 0.9675 & 0.0138 & 0.9913 & 0.0193 \\
Lot 3, 4, 5 & 0.9912 & 0.0044 & 0.9737 & 0.0081 & 0.9878 & 0.0061 & 0.9577 & 0.0144 & 1.0688 & 0.0563 \\
$P$-value & \multicolumn{2}{c}{0.9221} & & 0.0034 & & 0.3863 & & 0.4209 & & 0.3039 \\
\hline
\end{tabular}


Table A.5. (contd)

19) Release 3 - Cumulative survival

\begin{tabular}{lcccccccccc}
\hline & \multicolumn{3}{c}{ Release to CR309 } & \multicolumn{2}{c}{ Release to CR275 } & \multicolumn{2}{c}{ Release to CR234 } & \multicolumn{2}{c}{ Release to CR161 } & Release to CR113 \\
\cline { 2 - 10 } & $\hat{S}$ & $\widehat{\mathrm{SE}}$ & $\hat{S}$ & $\widehat{\mathrm{SE}}$ & $\hat{S}$ & $\widehat{\mathrm{SE}}$ & $\hat{S}$ & $\widehat{\mathrm{SE}}$ & $\hat{S}$ & $\widehat{\mathrm{SE}}$ \\
\hline Lot 1 & 0.9933 & 0.0066 & 0.9800 & 0.0114 & 0.9600 & 0.0160 & 0.9001 & 0.0245 & 0.9222 & 0.0291 \\
Lot 2 & 0.9898 & 0.0071 & 0.9188 & 0.0195 & 0.8883 & 0.0224 & 0.8595 & 0.0249 & 0.8520 & 0.0295 \\
Lot 3, 4, 5 & 0.9912 & 0.0044 & 0.9651 & 0.0091 & 0.9533 & 0.0099 & 0.9130 & 0.0167 & 0.9758 & 0.0522 \\
$P$-value & \multicolumn{2}{c}{0.9221} & \multicolumn{2}{c}{0.0058} & & 0.0042 & & 0.2107 & & 0.0739 \\
\hline
\end{tabular}

20) Release 4 - Reach survival

\begin{tabular}{|c|c|c|c|c|c|c|c|c|}
\hline & \multicolumn{2}{|c|}{ Release to CR275 } & \multicolumn{2}{|c|}{ CR275 to CR234 } & \multicolumn{2}{|c|}{ CR234 to CR161 } & \multicolumn{2}{|c|}{ CR161 to CR113 } \\
\hline & $\hat{S}$ & $\widehat{\mathrm{SE}}$ & $\hat{S}$ & $\widehat{\mathrm{SE}}$ & $\hat{S}$ & $\widehat{\mathrm{SE}}$ & $\hat{S}$ & $\widehat{\mathrm{SE}}$ \\
\hline Lot 1 & 0.9933 & 0.0066 & 0.9463 & 0.0185 & 0.9362 & 0.0206 & 1.0211 & 0.0192 \\
\hline Lot 2 & 0.9800 & 0.0114 & 0.9932 & 0.0068 & 0.9522 & 0.0177 & 0.9952 & 0.0142 \\
\hline$P$-value & \multicolumn{2}{|c|}{0.4905} & \multicolumn{2}{|c|}{0.0070} & \multicolumn{2}{|c|}{0.7848} & \multicolumn{2}{|c|}{0.0157} \\
\hline
\end{tabular}

21) Release 4 - Cumulative survival

\begin{tabular}{|c|c|c|c|c|c|c|c|c|}
\hline & \multicolumn{2}{|c|}{ Release to CR275 } & \multicolumn{2}{|c|}{ Release to CR234 } & \multicolumn{2}{|c|}{ Release to CR161 } & \multicolumn{2}{|c|}{ Release to CR113 } \\
\hline & $\hat{S}$ & $\widehat{\mathrm{SE}}$ & $\hat{S}$ & $\widehat{\mathrm{SE}}$ & $\hat{S}$ & $\widehat{\mathrm{SE}}$ & $\hat{S}$ & $\widehat{\mathrm{SE}}$ \\
\hline Lot 1 & 0.9933 & 0.0066 & 0.9400 & 0.0194 & 0.8800 & 0.0265 & 0.8986 & 0.0319 \\
\hline Lot 2 & 0.9800 & 0.0114 & 0.9733 & 0.0132 & 0.9268 & 0.0213 & 0.9224 & 0.0249 \\
\hline Lot $3,4,5$ & 0.9821 & 0.0064 & 0.9720 & 0.0074 & 0.9235 & 0.0154 & 0.8524 & 0.0338 \\
\hline$P$-value & \multicolumn{2}{|c|}{0.4905} & \multicolumn{2}{|c|}{0.1706} & \multicolumn{2}{|c|}{0.2305} & \multicolumn{2}{|c|}{0.2554} \\
\hline
\end{tabular}


Table A.5. (contd)

22) Release 5 - Reach survival

\begin{tabular}{|c|c|c|c|c|c|c|}
\hline & \multicolumn{2}{|c|}{ Release to CR234 } & \multicolumn{2}{|c|}{ CR234 to CR161 } & \multicolumn{2}{|c|}{ CR161 to CR113 } \\
\hline & $\hat{S}$ & $\widehat{\mathrm{SE}}$ & $\hat{S}$ & $\widehat{\mathrm{SE}}$ & $\hat{S}$ & $\widehat{\mathrm{SE}}$ \\
\hline Lot 1 & 0.9867 & 0.0094 & 0.9259 & 0.0216 & 1.0030 & 0.0124 \\
\hline Lot 2 & 0.9867 & 0.0094 & 0.9601 & 0.0162 & 0.9755 & 0.0187 \\
\hline Lot $3,4,5$ & 0.9840 & 0.0056 & 0.9436 & 0.0137 & 0.9586 & 0.0378 \\
\hline$P$-value & \multicolumn{2}{|c|}{0.9654} & \multicolumn{2}{|c|}{0.3840} & \multicolumn{2}{|c|}{0.4582} \\
\hline
\end{tabular}

23) Release 5 - Cumulative survival

\begin{tabular}{|c|c|c|c|c|c|c|}
\hline & \multicolumn{2}{|c|}{ Release to CR234 } & \multicolumn{2}{|c|}{ Release to CR161 } & \multicolumn{2}{|c|}{ Release to CR 113} \\
\hline & $\hat{S}$ & $\widehat{\mathrm{SE}}$ & $\hat{S}$ & $\widehat{\mathrm{SE}}$ & $\hat{S}$ & $\widehat{\mathrm{SE}}$ \\
\hline Lot 1 & 0.9867 & 0.0094 & 0.9135 & 0.0230 & 0.9163 & 0.0256 \\
\hline Lot 2 & 0.9867 & 0.0094 & 0.9473 & 0.0184 & 0.9241 & 0.0250 \\
\hline Lot $3,4,5$ & 0.9840 & 0.0056 & 0.9285 & 0.0145 & 0.8901 & 0.0358 \\
\hline$P$-value & \multicolumn{2}{|c|}{0.9654} & \multicolumn{2}{|c|}{0.4494} & \multicolumn{2}{|c|}{0.6900} \\
\hline
\end{tabular}

24) Release 6 - Reach survival

\begin{tabular}{|c|c|c|c|c|}
\hline & \multicolumn{2}{|c|}{ Release to CR161 } & \multicolumn{2}{|c|}{ CR161 to CR113 } \\
\hline & $\hat{S}$ & $\widehat{\mathrm{SE}}$ & $\hat{S}$ & $\widehat{\mathrm{SE}}$ \\
\hline Lot 1 & 0.9802 & 0.0142 & 0.9934 & 0.0163 \\
\hline Lot 2 & 0.9659 & 0.0151 & 0.9911 & 0.0136 \\
\hline Lot $3,4,5$ & 0.9705 & 0.0117 & 0.9449 & 0.0301 \\
\hline$P$-value & \multicolumn{2}{|c|}{0.7527} & \multicolumn{2}{|c|}{0.1916} \\
\hline
\end{tabular}


Table A.5. (contd)

25) Release 6 - Cumulative survival

\begin{tabular}{|c|c|c|c|c|}
\hline & \multicolumn{2}{|c|}{ Release to CR161 } & \multicolumn{2}{|c|}{ Release to CR113 } \\
\hline & $\hat{S}$ & $\widehat{\mathrm{SE}}$ & $\hat{S}$ & $\widehat{\mathrm{SE}}$ \\
\hline Lot 1 & 0.9802 & 0.0142 & 0.9738 & 0.0211 \\
\hline Lot 2 & 0.9659 & 0.0151 & 0.9573 & 0.0198 \\
\hline Lot $3,4,5$ & 0.9705 & 0.0117 & 0.9170 & 0.0288 \\
\hline$P$-value & \multicolumn{2}{|c|}{0.7527} & \multicolumn{2}{|c|}{0.2147} \\
\hline
\end{tabular}

26) Release 7 - Reach survival

\begin{tabular}{|c|c|c|}
\hline & \multicolumn{2}{|c|}{ Release to CR113 } \\
\hline & $\hat{S}$ & $\widehat{\mathrm{SE}}$ \\
\hline Lot 1 & 0.9714 & 0.0240 \\
\hline Lot 2 & 0.9835 & 0.0160 \\
\hline Lot $3,4,5$ & 0.9297 & 0.0282 \\
\hline$P$-value & \multicolumn{2}{|c|}{0.2303} \\
\hline
\end{tabular}




\section{A.3 Examination of Delayed Handling Effects}

The purpose of these tests was to assess whether downstream reach survivals were affected by how far upstream smolts were released. The results of these tests were used to determine which release groups were included in the constructs of a downstream virtual-release group. Data were pooled across taggers and tag lots in performing these analyses because previous tests of tag-lot and tagger effects were nonsignificant.

One of the 10 reach comparisons were significant at $\alpha=0.10$. In those 10 cases, the survival estimates typically differed by less than 0.01 , and reach survival for the uppermost release group was often higher than that of the downriver release groups (Table A.6). Comparison of cumulative survivals in reaches common to multiple release groups found 4 of 30 (i.e., 13.3\%) tests to be significant at $\alpha=0.10$ (Table A.7). In all cases, the upper release group $\left(R_{1}\right)$ had higher survival than a group released further downriver. These observations are not consistent with evidence of time-dependent tag effects.

In conclusion, no evidence was found that a delayed handling/tag effect may affect the survival studies. For this reason, all available upriver releases were used in the construction of virtual-release groups at the face of John Day, The Dalles, and Bonneville dams. 
Table A.6. Comparison of reach survivals between tag releases from different upstream locations for (a) yearling Chinook salmon and (b) steelhead during the 2011 JSATS survival study. Shaded reach survivals were not included in the $F$-tests of homogeneous survival because they represent new releases. Newly released fish and previously released fish were not compared within a reach.

a. Yearling Chinook salmon

\begin{tabular}{|c|c|c|c|c|c|c|c|c|c|c|c|c|c|c|c|}
\hline \multirow[b]{2}{*}{ Reach } & \multicolumn{2}{|c|}{ CR390 } & \multicolumn{2}{|c|}{ CR346 } & \multicolumn{2}{|c|}{ CR325 } & \multicolumn{2}{|c|}{ CR307 } & \multicolumn{2}{|c|}{ CR275 } & \multicolumn{2}{|c|}{ CR233 } & \multicolumn{2}{|c|}{ CR161 } & \multirow[b]{2}{*}{$P(F$-test $)$} \\
\hline & $\hat{S}$ & $\widehat{\mathrm{SE}}$ & $\hat{S}$ & $\widehat{\mathrm{SE}}$ & $\hat{S}$ & $\widehat{\mathrm{SE}}$ & $\hat{S}$ & $\widehat{\mathrm{SE}}$ & $\hat{S}$ & $\widehat{\mathrm{SE}}$ & $\hat{S}$ & $\widehat{\mathrm{SE}}$ & $\hat{S}$ & $\widehat{\mathrm{SE}}$ & \\
\hline Release to CR349 & 0.9810 & 0.0029 & & & & & & & & & & & & & \\
\hline CR349 to CR325 & 0.9620 & 0.0039 & 0.9923 & 0.0029 & & & & & & & & & & & \\
\hline CR325 to CR309 & 0.9924 & 0.0019 & 0.9892 & 0.0031 & 0.9874 & 0.0043 & & & & & & & & & 0.3788 \\
\hline CR309 to CR275 & 0.9636 & 0.0039 & 0.9538 & 0.0062 & 0.9525 & 0.0077 & 0.9915 & 0.0038 & & & & & & & 0.3760 \\
\hline CR275 to CR234 & 0.9954 & 0.0016 & 0.9947 & 0.0024 & 0.9919 & 0.0036 & 0.9924 & 0.0034 & 0.9851 & 0.0047 & & & & & 0.7845 \\
\hline CR234 to CR161 & 0.9551 & 0.0054 & 0.9518 & 0.0080 & 0.9464 & 0.0095 & 0.9541 & 0.0092 & 0.9451 & 0.0099 & 0.9863 & 0.0067 & & & 0.8916 \\
\hline CR161 to CR113 & 0.9577 & 0.0094 & 0.9515 & 0.0133 & 0.9799 & 0.0155 & 0.9467 & 0.0161 & 0.9571 & 0.0176 & 0.9586 & 0.0144 & 0.9479 & 0.0141 & 0.6943 \\
\hline
\end{tabular}

b. Steelhead

\begin{tabular}{|c|c|c|c|c|c|c|c|c|c|c|c|c|c|c|c|}
\hline \multirow[b]{2}{*}{ Reach } & \multicolumn{2}{|c|}{ CR390 } & \multicolumn{2}{|c|}{ CR346 } & \multicolumn{2}{|c|}{ CR325 } & \multicolumn{2}{|c|}{ CR307 } & \multicolumn{2}{|c|}{ CR275 } & \multicolumn{2}{|c|}{ CR233 } & \multicolumn{2}{|c|}{ CR161 } & \multirow[b]{2}{*}{$P(F$-test $)$} \\
\hline & $\hat{S}$ & $\widehat{\mathrm{SE}}$ & $\hat{S}$ & $\widehat{\mathrm{SE}}$ & $\hat{S}$ & $\widehat{\mathrm{SE}}$ & $\hat{S}$ & $\widehat{\mathrm{SE}}$ & $\hat{S}$ & $\widehat{\mathrm{SE}}$ & $\hat{S}$ & $\widehat{\mathrm{SE}}$ & $\hat{S}$ & $\widehat{\mathrm{SE}}$ & \\
\hline Release to CR349 & 0.9623 & 0.0039 & & & & & & & & & & & & & \\
\hline CR349 to CR325 & 0.9757 & 0.0032 & 0.9975 & 0.0020 & & & & & & & & & & & \\
\hline CR325 to CR309 & 0.9932 & 0.0017 & 0.9847 & 0.0036 & 0.9932 & 0.0033 & & & & & & & & & 0.0328 \\
\hline CR309 to CR275 & 0.9795 & 0.0031 & 0.9769 & 0.0046 & 0.9663 & 0.0068 & 0.9867 & 0.0047 & & & & & & & 0.1489 \\
\hline CR275 to CR234 & 0.9831 & 0.0029 & 0.9895 & 0.0033 & 0.9807 & 0.0054 & 0.9816 & 0.0052 & 0.9874 & 0.0043 & & & & & 0.4732 \\
\hline CR234 to CR161 & 0.9480 & 0.0052 & 0.9367 & 0.0080 & 0.9495 & 0.0092 & 0.9401 & 0.0097 & 0.9379 & 0.0096 & 0.9659 & 0.0082 & & & 0.7484 \\
\hline CR161 to CR113 & 0.9691 & 0.0107 & 0.9528 & 0.0151 & 0.9938 & 0.0208 & 0.9451 & 0.0189 & 0.9445 & 0.0178 & 0.9501 & 0.0175 & 0.9258 & 0.0167 & 0.2810 \\
\hline
\end{tabular}


Table A.7. Comparison of cumulative survivals between different upstream tag-release locations for (a) yearling Chinook salmon and (b) steelhead during the 2011 JSATS survival study. $P$-values associated with $F$-tests of homogeneous survival.

a. Yearling Chinook salmon

\begin{tabular}{|c|c|c|c|c|c|c|c|c|c|}
\hline \multirow[b]{2}{*}{ Reach } & \multicolumn{2}{|c|}{ CR390 } & \multicolumn{2}{|c|}{ CR346 } & \multirow[b]{2}{*}{$P(F$-test $)$} & & & & \\
\hline & $\hat{S}$ & $\widehat{\mathrm{SE}}$ & $\hat{S}$ & $\widehat{\mathrm{SE}}$ & & & & & \\
\hline CR325 to CR309 & 0.9924 & 0.001879 & 0.9955 & 0.0035 & 0.4352 & & & & \\
\hline CR325 to CR275 & 0.9565 & 0.004293 & 0.9542 & 0.010577 & 0.8403 & & & & \\
\hline CR325 to CR234 & 0.9524 & 0.004486 & 0.9515 & 0.010804 & 0.9387 & & & & \\
\hline CR325 to CR161 & 0.9097 & 0.006679 & 0.9178 & 0.020062 & 0.7017 & & & & \\
\hline \multirow[t]{2}{*}{ CR325 to CR113 } & 0.873 & 0.009901 & 0.8403 & 0.035585 & 0.3760 & & & & \\
\hline & \multicolumn{2}{|c|}{ CR390 } & \multicolumn{2}{|c|}{ CR346 } & \multicolumn{2}{|c|}{ CR325 } & & & \\
\hline Reach & $\hat{S}$ & $\widehat{\mathrm{SE}}$ & $\hat{S}$ & $\widehat{\mathrm{SE}}$ & $\hat{S}$ & $\widehat{\mathrm{SE}}$ & $P(F$-test $)$ & & \\
\hline CR309 to CR275 & 0.9636 & 0.003938 & 0.9538 & 0.00623 & 0.9525 & 0.007725 & 0.3794 & & \\
\hline CR309 to CR234 & 0.9591 & 0.00417 & 0.9487 & 0.006539 & 0.9447 & 0.00827 & 0.2754 & & \\
\hline CR309 to CR161 & 0.9173 & 0.006508 & 0.9035 & 0.009765 & 0.8932 & 0.01192 & 0.2085 & & \\
\hline \multirow[t]{2}{*}{ CR309 to CR113 } & 0.8778 & 0.009878 & 0.8603 & 0.013978 & 0.8763 & 0.017157 & 0.6184 & & \\
\hline & \multicolumn{2}{|c|}{ CR390 } & \multicolumn{2}{|c|}{ CR346 } & \multicolumn{2}{|c|}{ CR325 } & \multicolumn{2}{|c|}{ CR307 } & \\
\hline Reach & $\hat{S}$ & $\widehat{\mathrm{SE}}$ & $\hat{S}$ & $\widehat{\mathrm{SE}}$ & $\hat{S}$ & $\widehat{\mathrm{SE}}$ & $\hat{S}$ & $\widehat{\mathrm{SE}}$ & $P(F$-test $)$ \\
\hline CR275 to CR234 & 0.9953 & 0.00159 & 0.9947 & 0.002434 & 0.9919 & 0.003578 & 0.9924 & 0.003353 & 0.7922 \\
\hline CR275 to CR161 & 0.9484 & 0.005704 & 0.9459 & 0.008373 & 0.9400 & 0.010208 & 0.9453 & 0.009765 & 0.9199 \\
\hline CR275 to CR113 & 0.9175 & 0.009446 & 0.908 & 0.013089 & 0.9168 & 0.016292 & 0.9057 & 0.016121 & 0.9067 \\
\hline
\end{tabular}


Table A.7. (contd)

\begin{tabular}{|c|c|c|c|c|c|c|c|c|c|c|c|c|c|}
\hline \multirow[b]{2}{*}{ Reach } & \multicolumn{2}{|c|}{ CR390 } & \multicolumn{2}{|c|}{ CR346 } & \multicolumn{2}{|c|}{ CR325 } & \multicolumn{2}{|c|}{ CR307 } & \multicolumn{2}{|c|}{ CR275 } & \multirow[b]{2}{*}{$P(F$-test $)$} & & \\
\hline & $\hat{S}$ & $\widehat{\mathrm{SE}}$ & $\hat{S}$ & $\widehat{\mathrm{SE}}$ & $\hat{S}$ & $\widehat{\mathrm{SE}}$ & $\hat{S}$ & $\widehat{\mathrm{SE}}$ & $\hat{S}$ & $\widehat{\mathrm{SE}}$ & & & \\
\hline CR234 to CR161 & 0.9552 & 0.005388 & 0.9519 & 0.007953 & 0.9465 & 0.009451 & 0.9542 & 0.009151 & 0.9452 & 0.009856 & 0.8898 & & \\
\hline \multirow[t]{2}{*}{ CR234 to CR113 } & 0.9148 & 0.009493 & 0.9057 & 0.013356 & 0.9275 & 0.016155 & 0.9033 & 0.016241 & 0.9047 & 0.017662 & 0.7595 & & \\
\hline & \multicolumn{2}{|c|}{ CR390 } & \multicolumn{2}{|c|}{ CR346 } & \multicolumn{2}{|c|}{ CR325 } & \multicolumn{2}{|c|}{ CR307 } & \multicolumn{2}{|c|}{ CR275 } & \multicolumn{2}{|c|}{ CR233 } & \\
\hline Reach & $\hat{S}$ & $\widehat{\mathrm{SE}}$ & $\hat{S}$ & $\widehat{\mathrm{SE}}$ & $\hat{S}$ & $\widehat{\mathrm{SE}}$ & $\hat{S}$ & $\widehat{\mathrm{SE}}$ & $\hat{S}$ & $\widehat{\mathrm{SE}}$ & $\hat{S}$ & $\widehat{\mathrm{SE}}$ & $P(F$-test $)$ \\
\hline CR161 to CR113 & 0.9508 & 0.009279 & 0.9467 & 0.01329 & 0.9683 & 0.014953 & 0.9425 & 0.016114 & 0.9475 & 0.017317 & 0.951 & 0.014248 & 0.8584 \\
\hline
\end{tabular}

b. Steelhead

\begin{tabular}{|c|c|c|c|c|c|c|c|}
\hline \multirow[b]{2}{*}{ Reach } & \multicolumn{2}{|c|}{ CR390 } & \multicolumn{2}{|c|}{ CR346 } & \multirow[b]{2}{*}{$P(F$-test $)$} & & \\
\hline & $\hat{S}$ & $\widehat{\mathrm{SE}}$ & $\hat{S}$ & $\widehat{\mathrm{SE}}$ & & & \\
\hline CR325 to CR309 & 0.9932 & 0.001732 & 0.9847 & 0.003614 & 0.0339 & & \\
\hline CR325 to CR275 & 0.9732 & 0.003501 & 0.9623 & 0.00573 & 0.1045 & & \\
\hline CR325 to CR234 & 0.9566 & 0.004246 & 0.9521 & 0.006327 & 0.5548 & & \\
\hline CR325 to CR161 & 0.9075 & 0.006436 & 0.8938 & 0.009622 & 0.2366 & & \\
\hline \multirow[t]{2}{*}{ CR325 to CR113 } & 0.8798 & 0.011103 & 0.8527 & 0.015729 & 0.1593 & & \\
\hline & \multicolumn{2}{|c|}{ CR390 } & \multicolumn{2}{|c|}{ CR346 } & \multicolumn{2}{|c|}{ CR325 } & \\
\hline Reach & $\hat{S}$ & $\widehat{\mathrm{SE}}$ & $\hat{S}$ & $\widehat{\mathrm{SE}}$ & $\hat{S}$ & $\widehat{\mathrm{SE}}$ & $P(F$-test $)$ \\
\hline CR309 to CR275 & 0.9795 & 0.003114 & 0.9770 & 0.004568 & 0.9663 & 0.006767 & 0.1449 \\
\hline CR309 to CR234 & 0.9628 & 0.003942 & 0.9667 & 0.005313 & 0.9476 & 0.007999 & 0.0587 \\
\hline CR309 to CR161 & 0.9137 & 0.006254 & 0.9055 & 0.009175 & 0.8998 & 0.011579 & 0.5660 \\
\hline CR309 to CR113 & 0.8869 & 0.011095 & 0.8628 & 0.015653 & 0.8932 & 0.021076 & 0.3864 \\
\hline
\end{tabular}


Table A.7. (contd)

\begin{tabular}{|c|c|c|c|c|c|c|c|c|c|c|c|c|c|}
\hline \multirow[b]{2}{*}{ Reach } & \multicolumn{2}{|c|}{ CR390 } & \multicolumn{2}{|c|}{ CR346 } & \multicolumn{2}{|c|}{ CR325 } & \multicolumn{2}{|c|}{ CR307 } & \multirow[b]{2}{*}{$P(F$-test $)$} & & & & \\
\hline & $\hat{S}$ & $\widehat{\mathrm{SE}}$ & $\hat{S}$ & $\widehat{\mathrm{SE}}$ & $\hat{S}$ & $\widehat{\mathrm{SE}}$ & $\hat{S}$ & $\widehat{\mathrm{SE}}$ & & & & & \\
\hline CR275 to CR234 & 0.9832 & 0.002878 & 0.9895 & 0.003287 & 0.9807 & 0.005444 & 0.9816 & 0.005216 & 0.4769 & & & & \\
\hline CR275 to CR161 & 0.9346 & 0.005959 & 0.9251 & 0.008922 & 0.9334 & 0.010451 & 0.9199 & 0.011227 & 0.6431 & & & & \\
\hline \multirow[t]{2}{*}{ CR275 to CR113 } & 0.9049 & 0.010877 & 0.8887 & 0.015463 & 0.9408 & 0.020741 & 0.8824 & 0.019403 & 0.0699 & & & & \\
\hline & \multicolumn{2}{|c|}{ CR390 } & \multicolumn{2}{|c|}{ CR346 } & \multicolumn{2}{|c|}{ CR325 } & \multicolumn{2}{|c|}{ CR307 } & \multicolumn{2}{|c|}{ CR275 } & & & \\
\hline Reach & $\hat{S}$ & $\widehat{\mathrm{SE}}$ & $\hat{S}$ & $\widehat{\mathrm{SE}}$ & $\hat{S}$ & $\widehat{\mathrm{SE}}$ & $\hat{S}$ & $\widehat{\mathrm{SE}}$ & $\hat{S}$ & $\widehat{\mathrm{SE}}$ & $P(F$-test $)$ & & \\
\hline CR234 to CR161 & 0.9481 & 0.005237 & 0.9368 & 0.007967 & 0.9496 & 0.00921 & 0.9402 & 0.009665 & 0.938 & 0.009601 & 0.7478 & & \\
\hline \multirow[t]{2}{*}{ CR234 to CR113 } & 0.9192 & 0.010907 & 0.8925 & 0.015407 & 0.9437 & 0.020814 & 0.8886 & 0.019067 & 0.8859 & 0.018182 & 0.0788 & & \\
\hline & \multicolumn{2}{|c|}{ CR390 } & \multicolumn{2}{|c|}{ CR346 } & \multicolumn{2}{|c|}{ CR325 } & \multicolumn{2}{|c|}{ CR307 } & \multicolumn{2}{|c|}{ CR275 } & \multicolumn{2}{|c|}{ CR233 } & \\
\hline Reach & $\hat{S}$ & $\widehat{\mathrm{SE}}$ & $\hat{S}$ & $\widehat{\mathrm{SE}}$ & $\hat{S}$ & $\widehat{\mathrm{SE}}$ & $\hat{S}$ & $\widehat{\mathrm{SE}}$ & $\hat{S}$ & $\widehat{\mathrm{SE}}$ & $\hat{S}$ & $\widehat{\mathrm{SE}}$ & $P(F$-test $)$ \\
\hline CR161 to CR113 & 0.9651 & 0.01067 & 0.9459 & 0.014803 & 0.9828 & 0.020228 & 0.9385 & 0.018589 & 0.94 & 0.017674 & 0.9403 & 0.017119 & 0.3321 \\
\hline
\end{tabular}




\section{Appendix B}

\section{Capture Histories Used in Estimating Dam}

Passage Survival 


\section{Appendix B}

\section{Capture Histories Used in Estimating Dam Passage Survival}

Table B.1. Capture histories at sites at rkm 161, 113, and 86 (Figure 2.1) for release group $V_{1}$ (see Figure 2.1) for yearling Chinook salmon used in estimating dam passage survival and boatrestricted zone (BRZ)-to-BRZ survival. A " 1 " denotes detection, " 0 " denotes nondetection, and "2" denotes detection and censoring due to removal.

\begin{tabular}{|c|c|c|c|c|}
\hline \multirow[b]{2}{*}{$\begin{array}{l}\text { Capture } \\
\text { History }\end{array}$} & \multicolumn{2}{|c|}{$V_{1}$ (Season-Wide) } & \multicolumn{2}{|c|}{$V_{1}$ (Early Season) } \\
\hline & $\begin{array}{l}\text { Dam Passage } \\
\text { Survival }\end{array}$ & $\begin{array}{c}\text { BRZ-to-BRZ } \\
\text { Survival }\end{array}$ & $\begin{array}{c}\text { Dam Passage } \\
\text { Survival }\end{array}$ & $\begin{array}{c}\text { BRZ-to-BRZ } \\
\text { Survival }\end{array}$ \\
\hline 111 & 2,393 & 2,382 & 1,689 & 1,691 \\
\hline 0111 & 324 & 323 & 83 & 84 \\
\hline 101 & 757 & 751 & 399 & 402 \\
\hline 001 & 128 & 127 & 16 & 16 \\
\hline 120 & 0 & 0 & 0 & 0 \\
\hline 020 & 0 & 0 & 0 & 0 \\
\hline 110 & 880 & 864 & 132 & 134 \\
\hline 010 & 236 & 231 & 11 & 11 \\
\hline 200 & 0 & 0 & 0 & 0 \\
\hline 100 & 503 & 494 & 44 & 44 \\
\hline 000 & 321 & 357 & 112 & 110 \\
\hline Total & 5,542 & 5,529 & 2,486 & 2,492 \\
\hline
\end{tabular}

Table B.2. Capture histories at sites at rkm 113 and 86 (Figure 2.1) for release groups $R_{2}$, and $R_{3}$ for yearling Chinook salmon used in estimating dam passage survival. A " 1 " denotes detection, " 0 " denotes nondetection, and " 2 " denotes detection and censoring due to removal.

\begin{tabular}{crrrrr}
\hline & \multicolumn{2}{c}{ Season-Wide Dam Passage Survival } & & \multicolumn{2}{c}{ Early Season Dam Passage Survival } \\
\cline { 2 - 3 } \cline { 5 - 6 } Capture History & $R_{2}$ & $R_{3}$ & & $R_{2}$ & $R_{3}$ \\
\hline 1 & 424 & 127 & 131 & 264 & 61 \\
01 & 0 & 0 & & 0 & 59 \\
20 & 155 & 152 & & 17 & 0 \\
10 & 92 & 90 & & 8 & 12 \\
00 & $\mathbf{7 9 8}$ & $\mathbf{7 9 4}$ & $\mathbf{3 5 0}$ & $\mathbf{3 4 0}$ \\
\hline Total & & &
\end{tabular}


Table B.3. Capture histories at sites at rkm 161, 113, and 86 (Figure 2.1) for release group $V_{1}$ for steelhead used in estimating dam passage survival and BRZ-to-BRZ survival. A "1" denotes detection, " 0 " denotes nondetection, and " 2 " denotes detection and censoring due to removal.

\begin{tabular}{|c|c|c|c|c|}
\hline \multirow[b]{2}{*}{$\begin{array}{l}\text { Capture } \\
\text { History }\end{array}$} & \multicolumn{2}{|c|}{$V_{1}$ (Season-Wide) } & \multicolumn{2}{|c|}{$V_{1}$ (Early Season) } \\
\hline & $\begin{array}{c}\text { Dam Passage } \\
\text { Survival }\end{array}$ & $\begin{array}{c}\text { BRZ-to-BRZ } \\
\text { Survival }\end{array}$ & $\begin{array}{c}\text { Dam Passage } \\
\text { Survival }\end{array}$ & $\begin{array}{c}\text { BRZ-to-BRZ } \\
\text { Survival }\end{array}$ \\
\hline 111 & 2,242 & 2,241 & 1,603 & 1,607 \\
\hline 011 & 139 & 138 & 31 & 31 \\
\hline 101 & 742 & 738 & 385 & 384 \\
\hline 001 & 60 & 59 & 11 & 11 \\
\hline 120 & 0 & 0 & 0 & 0 \\
\hline 020 & 0 & 0 & 0 & 0 \\
\hline 110 & 1,294 & 1,280 & 281 & 282 \\
\hline 010 & 191 & 185 & 10 & 9 \\
\hline 200 & 0 & 0 & 0 & 0 \\
\hline 100 & 644 & 639 & 66 & 66 \\
\hline 000 & 351 & 382 & 123 & 124 \\
\hline Total & 5,663 & 5,662 & 2,510 & 2,514 \\
\hline
\end{tabular}

Table B.4. Capture histories at sites at rkm 113 and 86 (Figure 2.1) for release groups $R_{2}$, and $R_{3}$ for steelhead used in estimating dam passage survival. A "1" denotes detection, " 0 " denotes nondetection, and " 2 " denotes detection and censoring due to removal.

\begin{tabular}{|c|c|c|c|c|}
\hline \multirow[b]{2}{*}{ Capture History } & \multicolumn{2}{|c|}{ Season-wide Dam Passage Survival } & \multicolumn{2}{|c|}{ Early Season Dam Passage Survival } \\
\hline & $R_{2}$ & $R_{3}$ & $R_{2}$ & $R_{3}$ \\
\hline 11 & 353 & 360 & 246 & 248 \\
\hline 01 & 114 & 97 & 53 & 56 \\
\hline 20 & 0 & 0 & 0 & 0 \\
\hline 10 & 195 & 218 & 25 & 33 \\
\hline 00 & 130 & 119 & 19 & 13 \\
\hline Total & 792 & 794 & 343 & 350 \\
\hline
\end{tabular}




\section{Distribution}

No. of

Copies

OFFSITE

3 Brad Eppard

USACE Portland District

P.O. Box 2946

Portland, OR 97204

Mike Langeslay (PDF)

USACE Portland District

P.O. Box 2946

Portland, OR 97204

3 University of Washington Columbia Basin Research

Puget Sound Plaza

$13254^{\text {th }}$ Avenue, Suite 1820

Seattle, WA 98101

ATTN: AG Seaburg

John Skalski

RL Townsend
No. of

Copies

\section{ONSITE}

2 Pacific Northwest National Laboratory

GE Johnson (PDF) BPO

GR Ploskey* NBON

S Schlahta (PDF) K6-83

MA Weiland (PDF) NBON

*NBON copies sent to:

Gene Ploskey

390 Evergreen Drive

P.O. Box 241

North Bonneville, WA 98639 


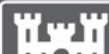

1101

US Army Corps

of Engineers

Prepared for the U.S. Army Corps of Engineers, Portland District, under a Government Order with the U.S. Department of Energy Contract DE-AC05-76RL01830

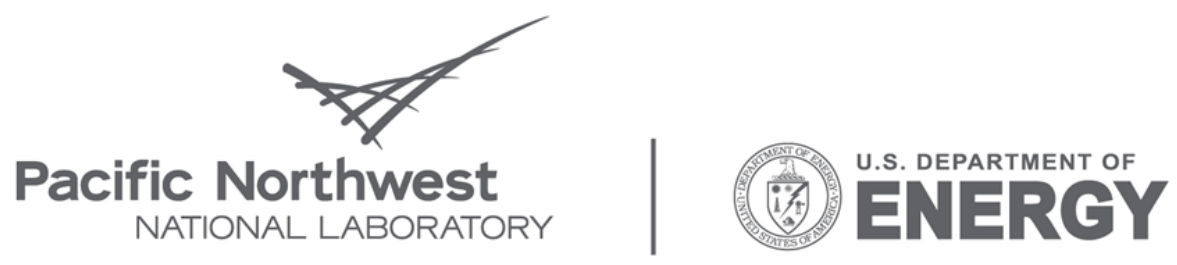

Proudly Operated by Battelle Since 1965

902 Battelle Boulevard

P.O. Box 999

Richland, WA 99352

1-888-375-PNNL (7665)

www.pnl.gov 